\title{
Modifying HMA Stone Aggregates Prone to Stripping With Lime- Based Additives under Controlled Curing Conditions
}

\author{
Submitted by \\ Arash Khoshghalb, B.Sc. \\ Sharif University of Technology \\ Tehran, Iran \\ A thesis submitted to the \\ Faculty of Graduate Studies and Research \\ in partial fulfillment of the requirements for the degree of \\ Master of Applied Science in Engineering \\ Department of Civil and Environmental Engineering \\ Carleton University \\ Ottawa, Ontario, Canada
}

The Master of Applied Science in Civil Engineering is a joint program with the University of Ottawa, administered by the Ottawa-Carleton Institute for Civil Engineering

(C) Arash Khoshghalb, 2006 


$\begin{array}{ll}\begin{array}{l}\text { Library and } \\ \text { Archives Canada }\end{array} & \begin{array}{l}\text { Bibliothèque et } \\ \text { Archives Canada }\end{array} \\ \begin{array}{l}\text { Published Heritage } \\ \text { Branch }\end{array} & \begin{array}{l}\text { Direction du } \\ \text { Patrimoine de l'édition }\end{array} \\ \begin{array}{l}\text { 395 Wellington Street } \\ \text { Ottawa ON K1A ON4 }\end{array} & \begin{array}{l}\text { 395, rue Wellington } \\ \text { Ottawa ON K1A ON4 } \\ \text { Canada }\end{array}\end{array}$

Your file Votre référence ISBN: 978-0-494-18320-5 Our file Notre référence ISBN: 978-0-494-18320-5

NOTICE:

The author has granted a nonexclusive license allowing Library and Archives Canada to reproduce, publish, archive, preserve, conserve, communicate to the public by telecommunication or on the Internet, loan, distribute and sell theses worldwide, for commercial or noncommercial purposes, in microform, paper, electronic and/or any other formats.

The author retains copyright ownership and moral rights in this thesis. Neither the thesis nor substantial extracts from it may be printed or otherwise reproduced without the author's permission.
AVIS:

L'auteur a accordé une licence non exclusive permettant à la Bibliothèque et Archives Canada de reproduire, publier, archiver, sauvegarder, conserver, transmettre au public par télécommunication ou par l'Internet, prêter, distribuer et vendre des thèses partout dans le monde, à des fins commerciales ou autres, sur support microforme, papier, électronique et/ou autres formats.

L'auteur conserve la propriété du droit d'auteur et des droits moraux qui protège cette thèse. $\mathrm{Ni}$ la thèse ni des extraits substantiels de celle-ci ne doivent être imprimés ou autrement reproduits sans son autorisation.
In compliance with the Canadian

Privacy Act some supporting forms may have been removed from this thesis.

While these forms may be included in the document page count, their removal does not represent any loss of content from the thesis.
Conformément à la loi canadienne sur la protection de la vie privée, quelques formulaires secondaires ont été enlevés de cette thèse.

Bien que ces formulaires aient inclus dans la pagination, il n'y aura aucun contenu manquant.

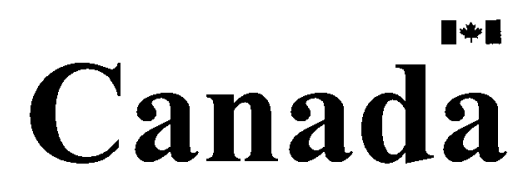




\section{Abstract}

"Stripping" has been known as one of the foremost problems associated with Hot Mix Asphalt pavements since the beginning of asphalt pavement practices. "Stripping" is a physiochemical phenomenon and defined as moisture damage to HMA due to separation of asphalt cement molecules from the surface of stone aggregates.

Among different theories explaining the stripping mechanism, this study mainly relies on the concept of surface free charges in the aggregate-asphalt-water interface. According to this rationale, extent of aggregates surface charges determines their degree of propensity to stripping. Application of lime-based additives is a conventional treatment for improving the problematic aggregates.

This study discusses an experimental approach to identify any significant correlation among percentage of siliceous minerals in aggregates, their zeta potential characteristics and stripping propensity. Also a procedure will be presented for studying the effect of temperature and pressure on the healing behaviour of lime in reaction with rock aggregates. 


\section{Acknowledgements}

I would like to express my sincere thanks first to my direct supervisor Prof. Abd El Halim whose continuous support and valuable suggestions as final words during the course of this research enabled me to accomplish this thesis. Valuable contribution of Dr. Y. Niazi from Mashad University (Mashad-Iran) in initiating this research work is greatly acknowledged. I also would like to appreciate the generous support of City of Ottawa, Fawler Construction, and Bitumar Inc. for supplying the materials used in this research work. Supports of laboratories of the Department of Earth Science of Carleton University, University of Ottawa GeoScience Department, and especially National Research Council Canada - Institute for Research in Construction (NRC-IRC) for providing the required equipment and laboratory facility for this research are greatly appreciated.

Above all I would like to thank my dearest wife Yulia for all her love, patience, and dedications during our very first year of marriage, without which the completion of this work would not have been possible. 


\section{Table of Content}

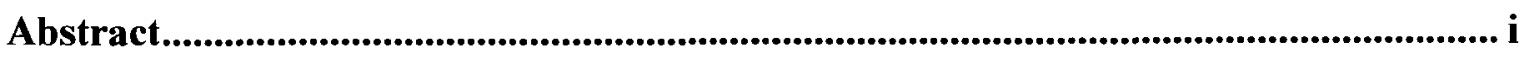

Acknowledgements ........................................................................................................... ii

Table of Contents ........................................................................................................ iii

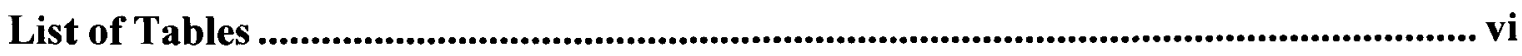

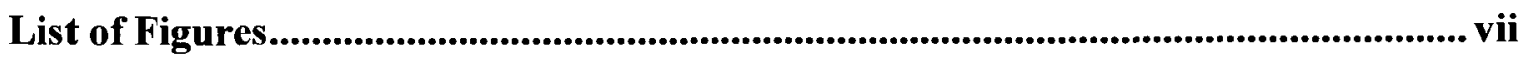

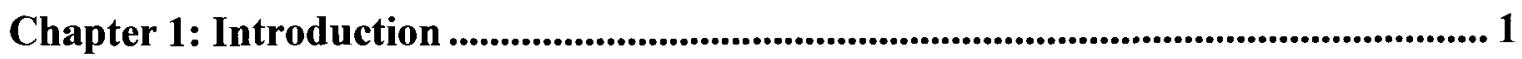

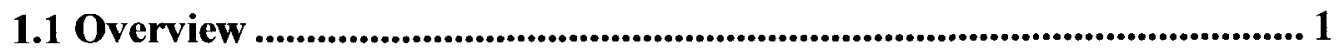

1.2 Problem Definition ........................................................................... 4

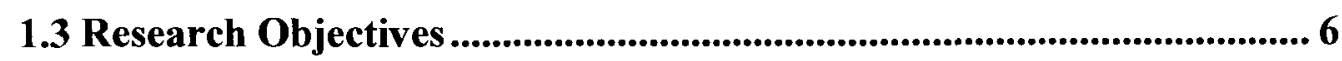

1.4 Scope of the Thesis ..................................................................................... 7

Chapter 2: Literature Review .................................................................................... 10

2.1 Background................................................................................. 10

2.2 Different Failure Mechanisms ...................................................... 11

2.3 Role of Surface Energy ............................................................................. 16

2.4 Role of Water (in bitumen and aggregates) ....................................... 24

2.5 Role of Acidic - Basic nature of HMA Raw Materials ......................... 25

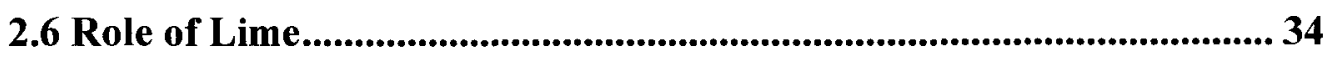

2.7 Role of Surface (Zeta) Potential ........................................................ 48

2.8 Role of Anti-Stripping Agents.............................................................55

2.9 Evaluation and Prediction of Stripping ...............................................60 


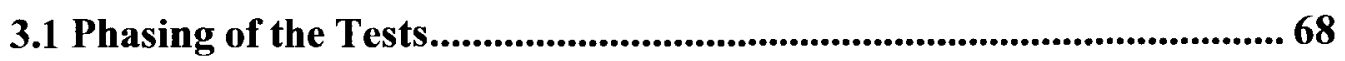

3.2 PHASE (I): Material Selection and Characterization ......................... 69

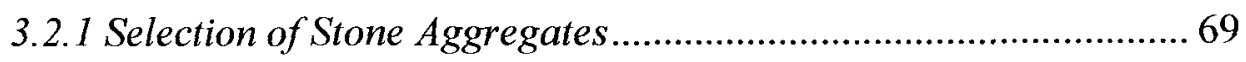

3.2.2 Selection of Lime Products ................................................. 72

3.2.3 Selection of Asphalt Bitumen ................................................ 72

3.2.4 X-Ray Fluorescence (or Whole Rock Analysis) ........................ 73

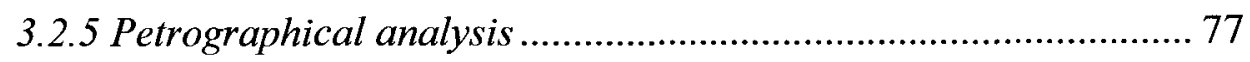

3.2.6. Mix Design and Test Settings............................................... 82

3.2.7. Boiling Water Test on Raw Materials................................... 83

3.2.8 Static Immersion Test on Raw Materials ................................ 87

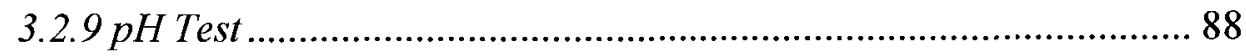

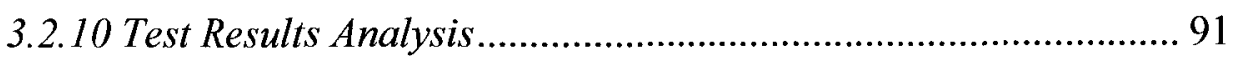

3.3 PHASE (II) Examining Lime Treated Materials ................................. 94

3.3.1 Lime Treatment Scenarios and Mix Design............................... 94

3.3.2 Boiling Water Test ........................................................... 95

3.3.3 Static Immersion Test ......................................................... 98

3.3.4 Zeta potential Measurements ............................................... 99

3.3.5 Test Results Analysis ....................................................... 105

3.4 PHASE (III) Examining Cured Lime Treated Materials................... 109

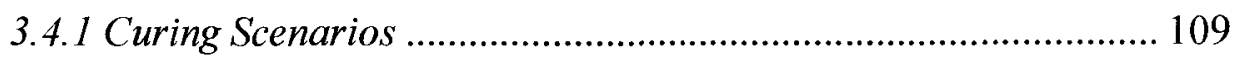

3.4.2 Results of Water Boiling Test for Cured Limed Materials ......... 111

3.4.3 Static Immersion Test ..................................................... 112 
3.4.4 Zeta Potential Measurements (on cured lime treated aggregate

powder) 113

3.4.5 Test Results Analysis...... 116

Chapter 4. Conclusion, Recommendations and Application

4.1Conclusion. 119

4.2 Recommendations For Future Research 122

4.3 Application in the Asphalt Industry 123

REFERENCES

APPENDIX A: Samples of Zeta Potential Reading Datasheet(s)

132

APPENDIX B: Test Results of Sampled Aggregates

136 


\section{List of Tables}

Table 2-1: Contribution of Gibbs free energy of aggregate-bitumen in the established adhesion bonds in the mix per unit amount of aggregates- unit: ergs .20

Table 2-2: Concentration of acid functionality in a moisture-sensitive and satisfactory pavement

Table 2-3: Comparison of stripping tests and their popularity in states DOTs before and after SHRP 62

Table 2-4: Summary of qualitative test methods to evaluate stripping for loose mix of HMA .65

Table 3-1: $\quad$ The Physical characteristics of the Agg.\#1, Agg.\#2 \& Agg.\#3 .........................71

Table 3-2: $\quad$ The Individual Aggregate Percentage Passing Gradations for Agg.\#1, Agg.\#2 \& Agg.\#3 is Illustrated Based on U.S. Sieve \& Opening Size .71

Table 3-3: Test results of "whole rock analysis" or "X-ray Fluorescence Spectroscopy " (XRF) $75 \& 76$

Table 3-4: Average of weighted means and standard errors of zeta potential readings for untreated and lime treated powdered aggregates .102

Table 3-5: Zeta potential readings for different curing settings performed on hydrated lime treated samples of aggregate (3). 


\section{List of Figures}

Figure 2-1: Effect of the contributing bonds of aggregates on their total surface free energies (based on contact angles) 17

Figure 2-2: Effect of contributing bonds of asphalt bitumen(s) on their total surface free energies (based on the receding contact angles)

Figure 2-3: Presence of polar hydrophilic minerals and polar impurities in asphalt

binder

Figure 2-4: Emphasis on the healing effect of lime as a common links among its diverse applications in the construction industry .37

Figure 2-5: Display of a quartz particle surrounded by CSH under the electron micrograph

Figure 2-6: $\quad$ surficial silanol groups present a negative surface potential

Figure 2-7: Chemical Functional groups present in asphalt molecules

Figure 2-8: Electro-positive or Electro-negative characteristics of mineral aggregates according to their silica and alkaline contents

Figure 2-9: $\quad$ Surface structure of siliceous and calcareous aggregates in the proximity of water molecules .53

Figure 2-10: The orientation of asphalt anionic and cationic functionalities toward calcareous (limestone) and siliceous (granite) aggregates.........................54

Figure 3-1: The procedural diagram of the staging and hierarchy of the Tests .68

Figure 3-2: $\quad$ Sieve analysis plot on a normal scaled graph for gradations of aggregates no. $1,2 \& 3$. .72

Figure 3-3: Devices used in the preparation of samples for the whole rock analysis and petrographical analysis .74 
Figure 3-4: The details of observations made in examination of the thin sections of aggregate (1) under optical microscope

Figure 3-5: The details of observations made in examination of the thin sections of aggregate (2) under optical microscope

Figure 3-6: The details of observations made in examination of the thin sections of aggregate (3) under optical microscope 81

Figure 3-7: The effect of different asphalt contents on the percentage coating retained on the asphalt asphalt-aggregate mixture .83

Figure 3-8: The effect of boiling duration on the percent coating retained on asphaltaggregate mixtures .86

Figure 3-9: Results of the static immersion test on all three types of aggregates .88

Figure 3-10: The $\mathrm{pH}$ meter instrument .89

Figure 3-11: Record of $\mathrm{pH}$ meter for powdered aggregates in three minutes interval readings .90

Figure 3-12: The effect of different percentage of lime-based additives on the percentage coating retained on aggregate (1) in the boiling water test .96

Figure 3-13: The effect of adding hydrated lime and quick lime on the percentage coating retained on aggregates (1), (2) and (3) in the boiling water test

Figure 3-14: Graphical comparison of treated and untreated samples in static immersion test.

Figure 3-15: Zetaplus zeta potential analyzer (Brookhaven Model) .100

Figure 3-16: The effect of hydrated lime and quick lime on Zeta potential of pulverized aggregates 103

Figure 3-17: The effect of different dosages of hydrated lime on Zeta potential of powdered aggregate (3). .104

Figure 3-18: Steam autoclave with variable temperature and pressure settings .110 
Figure 3-19: The effect of temperature and pressure on the percent coating retained on aggregate (3) treated by hydrated lime in different temperature

Figure 3-20: The effect of curing in different pressure and temperature settings on percent coating retained in the static immersion test for Aggregate (3) treated with hydrated lime.

Figure 3-21: Comparison of the effectiveness of different curing settings on Zeta potential values for hydrated lime treated samples of aggregate (3). 114

Figure 3-22: Effect of adding hydrated lime in different temperature, and pressure settings in Zeta potential of hydrated-lime treated aggregate (3).. 115 


\section{Chapter 1: Introduction}

\subsection{Overview}

The problem of "Stripping of Asphalt Concrete Pavements" has a history almost as old as the asphalt pavement industry in North America. According to Hubbard (1938), stripping of asphalt pavements was first recognized as a problem in the early years of asphalt development. After World War II, road transportation networks experienced an explosion of development in most North American territories. Most of these infrastructures were designed for an effective service life between twenty-five and thirty-five years. Historical data from rehabilitation and re-construction projects launched in the early 1950 s showed that a surprising portion of the newly paved roads were deteriorated ahead of time. This was because of a type of moisture damage later described as stripping. In late 1970, a large portion of primary and secondary highways in the southeastern and western jurisdictions in the United States were reported to be prematurely damaged due to stripping in the United States (Little and Epps 2001). At this time, road agencies had limited options for restoring their deteriorated flexible pavements. Most of those failed pavements were to be substantially rehabilitated and/or reconstructed through the spending of millions of dollars. Such implications required asphalt industry and road agencies to fund and initiate numerous research projects in order to confront and control the stripping problem in the process of design, procurement and during construction of new roads and highways projects. 
The "Stripping" phenomenon has been long known as the premature failure of asphalt pavements due to the effect of moisture damage. Stripping is a physicochemical phenomenon that initiates premature failure mechanisms such as rutting, alligator cracking, bleeding, pavement wear, shoving, and specially raveling (Little and Epps 2001). Kandhal and Rickards (2001) has also designated "presence of white or gray spots (as a sign of upward evacuation of fines through layers)", "flushing" and finally "creation of potholes" as the most typical symptoms of stripping in pavement saturated layers. Since there is little that can be done to save a moisture-damaged pavement when it is under service traffic, prediction and timely treatment of stripping-prone materials are critical to quality HMA and long-lasting flexible pavements.

There have been abundant research reports, descriptions and theories developed to identify and explain the mechanisms and characteristics of this type of moisture damage since 1950s. The onset of severe moisture damage within the first two years of the construction of asphalt pavements in the United States was officially recorded as a major problem associated with asphalt pavements in late 1970s (Kandhal and Rickards 2001). Based on a nation-wide survey launched by Federal Highway Administration of United state Department of Transportation (FHWA DOT) in 1987 to investigate the asphalt pavement rutting distress and stripping, about twenty three percent of the regions under FHWA's jurisdiction have experienced the stripping problem (Kiggundu and Roberts 1988). Since then numerous research studies were launched to address the problem and avoid further loss of capital costs due to deterioration of pavements as a result of stripping. However, after over thirty-five years of extensive research and investigation of the concepts and cause of the stripping phenomenon this complex problem has not yet 
been completely addressed. Also lots of experimental test procedures have been devised to predict and quantify stripping propensity of Hot Mix Asphalt (HMA) since early 1980s. Among many other research efforts made to explain stripping of asphalt pavements, Taylor and Khosla presented a comprehensive collection of issues and concluded key findings regarding stripping in a state-of-the-art report in 1983. They updated most of the published research practices regarding asphalt pavement stripping since 1954. However, a lot more have been researched on this subject since then putting forward new criteria and techniques to hypothesize state-of-the-practice and state-of-theknowledge aspects of stripping. Yet there seems to be a lack of fresh state-of-the-art review to conclusively compare these new and old findings, conclude the best practices, revise the controlling guidelines and provide the optimum feedback for the industry. Concerns such as:

Why anti-stripping agents have unexpected effects on different bituminous and aggregate materials in such a surprising way?,

- How they influence the final products properties during the life span of the pavement? and How different treatment techniques respond under different environmental and service conditions?,

- What is the most reliable, optimum, and conclusive procedure to forecast and control stripping when utilizing new quarry materials,

The above statements are still voiced questions being heard in the asphalt industry demanding further research to be performed on this critical topic.

The material presented in this thesis addresses the stripping problems associated with stone aggregates, focusing on the effect of lime on the silica components of 
minerals. An experimental approach is designed in this study to substantiate the influence of surface charge of stone aggregates on their stripping susceptibility. This study also addresses how lime can effectively modify the surface of minerals and change the stripping propensity of susceptible materials in HMA. This thesis also opens an argument regarding the cause of controlling curing conditions of temperature and pressure on the performance of lime in treatment process. This criterion is a fresh approach and has the potential to change the mechanism of adding lime to the HMA in the asphalt industry in order to get the optimum stripping resistance result.

\subsection{Problem Definition}

There have been several mechanisms developed by many researchers to explain the complex process of stripping. These theories are addressed and explained in the literature review of section 2.2 of this thesis. However, it is generally agreed by the majority of researchers that no individual mechanism is completely responsible for the phenomenon of stripping and a combination of causes are involved in this complex process. The importance of contributing mechanisms to the stripping phenomenon has been rather subjective and widely diverse among researchers. Chemical and mineral composition of materials is one of those contributing factors that their role is not yet fully understood in the stripping of HMA (Roberts et al. 1996). The focus of this thesis is mainly on finding a relationship between mineralogy of stone aggregates, their surface charge, and their affinity to stripping. A few researchers have partially addressed the existence of such a connection in their research (Taylor and Khosla 1983, Yoon and Tarrer 1988 and Hefer 
ad Little 2005) while there has been no documented research that has synthesized and deeply examined the aspects of this relationship.

On the other hand, lime-based additives have been long used, as a traditional treatment of asphalt mixes with affinity to stripping. It has been also a common practice in Ontario to use lime in addition to other anti-stripping agents in almost all projects regardless of the physiochemical characteristics of source materials, which does not seem to be a sound procedure. Developing more effective treatment procedures for the problematic HMA has been a matter of ongoing research. Several brands of chemical anti-stripping agents have been produced and claimed to be most effective on stripper asphalt mixtures, yet unexpected results have been reported after their application on different sources of materials. Also the long term effects of chemical anti-stripping agents are the other matter of concern expressed by researchers. This thesis attempts to explain the healing effect of lime, establish criteria for quality application of lime on the stripper aggregates, and demonstrate how the quality of treatment is affected by controlling the curing conditions. This would be an original approach to enhance the effectiveness of application of lime-based additives on HMA.

The following issues are known to be the points of interest in this thesis:

- Explain the role of quartz components $\left(\mathrm{SiO}_{2} \%\right)$, surface charge and $\mathrm{pH}$ in the minerals susceptibility to stripping,

- Determine WHY \& HOW lime affects aggregates resistance to stripping and WHEN is it needed,

- WHAT are the optimum ranges of controlling curing conditions (pressure \& temperature) 


\subsection{Research Objectives}

The goal of this thesis is to advance the understanding of the stripping phenomenon with respect to the aggregate characteristics and also to improve the current curing techniques. In order to achieve this goal an experimental framework has been designed, and pursued to obtain certain objectives. The preliminary objectives of this thesis are as follows:

- Task 1: Assessment of vulnerability of stone aggregates based on their mineralogy and petrographical characteristics:

- Subtask 1: Assessment and examination of sampled aggregates based on their different mineral composition, surface characteristics, and petrographical nature

- Subtask 2: Establishing relation between $\mathrm{SiO}_{2} \%, \mathrm{pH}$ and surface charge of aggregate samples

- Subtask 3: Establishing relation between surface charge and stripping affinity of aggregate samples

- Task 2: Evaluating the application of lime in regards to the following aspects:

- Subtask 1: Summarizing the preceding research works on the application of lime for treatment of siliceous soil, minerals and materials

- Subtask 2: Determination of the optimum percentage of lime-based additive(s) to be added to the different sources of samples and measuring incurred change(s) in their affinity to stripping

o Subtask 3: Examining the effect of curing conditions (i.e. temperature and pressure) on the healing performance of lime on susceptible raw 
aggregates, and optimizing the process of introducing lime-based additives to HMA aggregates under new controlling conditions.

This thesis mainly concerns with the above-said objectives, however, it does not provide details about the criteria of all practical techniques to resist stripping of HMA. Yet after evaluation of experimental results it intends to develop rationales and procedural guideline for promoting the conventional methods that improve resistance to stripping of raw stone aggregates before introducing the asphalt cement to the hot mix.

\subsection{Scope of the Thesis}

Structure of the thesis corresponds with the following arrangements:

I- $\quad$ The first chapter outlines the introductory needs for this research work and describes the problem statement. It provides preliminary grounds to be covered through deeper discussions and literature support in the following chapters.

II- The second chapter summarizes the previously developed hypothesis and the relevant test procedures used to quantify and predict the stripping phenomenon, focusing on the role of aggregate characteristics. This section justifies the provisions for claims and findings of this laboratory-based research exercise. In other words, this section disputes "what to look at among the abundant approaches to respond the stripping phenomenon ...". Prevailing selected rationales together with the author's justifications are put forward in this chapter to validate a fresh premise in regards to the effects of aggregate 
characteristics and role of lime-based additives in the stripping propensity of HMA.

III- $\quad$ The third chapter practically integrates the selective rationales established in the previous chapters, and describes the experimental design procedure pursued in this research plan. Elements addressed in the design process include, but are not limited, to the following potential issues: sampling, characterization, and preparation of materials, devising the test procedures in sequential stages, setting and controlling the variable components in the test modules, and also input/output data processing. This chapter is the implementation and demonstration of the thesis assertion and validates the hypothesis as expressed in chapter II.

IV- Chapter four goes deeper in terms of interpretation of the output data in line with the intended research objectives. This is the conclusion of experimental findings that can lead to the establishment of the criteria for selection and improvement of materials. In this section author ensures that objectives of this study are well achieved and the specified problems are duly responded. Accuracy of results, aptness (or -in case- inappropriateness) of the assumptions, controlling conditions and other involved factors will be further discussed and interpreted in this section of thesis.

V- Section five discusses the possibility and practical requirements of potential applications of this research study in an industrial settings. It also prepares the guidelines for future research in order to investigate and generalize the initial findings of this original study. At this closing section, the author denotes how 
the industry can benefit the applications of the present study and future proposal if a provincial research project can be financed in this regard. 


\section{Chapter 2: Literature Review}

\subsection{Background}

Stripping is a serious distress to flexible asphalt pavements that is regarded as the loss of chemical and physical bonds among the elements of the HMA. This physicochemical phenomenon is a complex process that disintegrates the structural quality of layers and critically affects the serviceability of pavement in the presence of moisture (Roberts et al. 1996, Little and Jones IV 2003, and Hefer and Little 2005). Ever since the asphalt community recognized stripping as a major detriment, there have been abundant research studies conducted to investigate the different aspects of this phenomenon. Some of these studies were designed to provide newer descriptions and theories in explanation of the concept of the stripping phenomenon. Some studies targeted the initial causes leading to, and factors affecting the stripping of stone aggregates. Still some other researchers touched on the area of prediction techniques, and pre-construction controlling tests in order to timely address the eminent problem. Also there have been studies that dealt with a variety of techniques developed to modify the stripping-prone materials (including the aggregates and asphalt binders) and control their application in order to minimize the risk of stripping. Collection of a full-scale history of all previous research literature in this thesis is not practically possible nor beneficial to the purpose of this study which is supposed to address a very specific area of concern in regards to the stripping problem. This thesis provides a brief review of the relevant concepts, theories, and tests that play role in stripping of stone aggregates from the bituminous binder. However, it rather concentrates on the areas related to the later subject of modifying the surface of stripping- 
prone aggregates with lime-based anti-stripping additives. The theory of surface charge would be explained to the performance of such additives on aggregates. The main objective in this literature review, has been to develop background knowledge and find common conceptual grounds among already available sources. These background information will then be used to relate and apply these conceptual grounds to support and justify the interpretations, and conclusion of obtained results in future chapters. Since the original proposal is substantiated through an experimental approach in this research work, a part of the literature review is also devoted to review the applicable tests for evaluation of stripping propensity of aggregates, HMA, or pavements.

\subsection{Different Failure Mechanisms}

Since the recognition of the stripping phenomenon as a potential moisture damage to asphalt pavements, a few mechanisms have been developed that led to a better understand of this process. Proposing new ideas to explain how the stripping process actually takes place and progresses the moisture damage in the pavement has been always appreciated in the industry. It has been commonly believed that when the technical aspects of stripping process are well understood, more suitable and effective methodologies can be devised to predict and control this moisture damage. One of the most precise collections of stripping mechanisms was given in a review by Taylor and Khosla in 1983 as follows: Detachment, Displacement, Spontaneous Emulsification, Pore Pressure, and Hydraulic Scouring. These mechanisms were also the most often cited classification by later researchers (Kiggundu and Roberts 1988, Mohamed 1991, Little and Jones IV 2003, and etc.). However, new mechanisms were developed by other researchers to include modern 
concepts and complete the previous models. Some of the foremost mechanisms of stripping are listed and explained as follows:

\subsubsection{Detachment}

The detachment mechanism is the most leading and convincing mechanism commonly referred to as the primary cause of stripping. The detachment course, by definition is the separation of asphalt film from the aggregate surface by layer(s) of water. However, a significant distinction is considered between the detachment mechanism and raveling, which is a different sort of segregation of aggregates from pavement because of environmental effects (Jimenez 1974 and Mohamed 1991). Physiochemical aspects of detachment are explained based on the thermodynamic theory of interfacial energy which considers the effect of affinity to creation of polar bonds in aggregates interface. This theory shows that the physical features of the phenomenon are related to the mechanical interlock theory (Kiggundu and Roberts 1988, Little and Jones IV 2003 and Taylor and Khosla 1983), while its chemical characteristics of asphalt bitumen are related to the change in surface free energy. According to Cheng et al. (2002) variable surface energy of different aggregates and asphalt sources is related to their different chemical components and strength of different ionic and/or covalent bonds, which again justifies the effect of surface chemistry in the mechanism of detachment (Little and Jones IV 2003). Based on the theory of minimum surface energy, water and aggregate surface molecules are of opposite polar nature, possess greater surface potential energies as apposed to aggregate-bitumen molecules, and can potentially contribute to establish strong ionic bonds. As a result of this process, the wettability of aggregates by water medium (wettability means the capability of being made wet, or ability to make a liquid 
spread easily across the surface of a solid by reducing surface tension - Microsoft Corporation Encarta Reference Library (C) 2004) becomes greater than of by bitumen heavy hydrocarbon molecules. Aggregate-bitumen bonds are then weakened and replaced by aggregate-water bonds. This system leads to the "complete loss of adhesion" in the aggregate-bitumen interface, and is typically known as detachment. This mechanism is widely accepted among researchers who developed the theoretical grounds of the stripping phenomenon (Taylor and Khosla 1983).

\subsubsection{Displacement}

One of the other stripping mechanisms is regarded to as displacement of bitumen film by water film because of the break in asphalt film (Taylor and Khosla 1983 and Little and Jones IV 2003). Stripping of asphalt concrete due to displacement is primarily caused by an incomplete coating of aggregates or by secondary fracture of bitumen films at the sharper edges of aggregates surface (Fromm 1974, Taylor and Khosla 1983, and Tarrer and Wagh 1991). Similar to the detachment mechanism, displacement can also be explained based on the thermodynamic theory of adhesion. According to this theory, due to the intrusion of contact water in the triplicate interface, accumulation of negative charges in the aggregate and asphalt surfaces promotes the creation of dipole bonds in the water-aggregate interface. In order to reach a stabilized energy level more water is invited into the interface and asphalt films will be physically removed from the aggregate surface (Taylor and Khosla 1983, Tarrer and Wagh 1991, Little and Jones IV 2003).

\subsubsection{Spontaneous Emulsification}

The main idea of explaining stripping phenomenon based on spontaneous emulsification was mainly developed by Fromm (1974) and subsequently confirmed and applied by 
many others (Taylor and Khosla 1983, Tarrer and Wagh 1991, Little and Jones IV 2003). Spontaneous emulsification is described as the inverse suspension of water particles in bitumen solvent (Little and Jones IV 2003). Fromm (1974) postulated that water as a discontinuous phase can be combined with asphalt as the continuous phase even in the aggregate-bitumen surface and result in loss of adhesion and stripping. He also concluded that in hot weather, water molecules evaporate and leave the asphalt emulsion, and as a result the asphalt binder retains its original condition and viscosity. This is the reason why some pavements with history of stripping show healing behavior and recover the moisture damages in hot weather. Nature of asphalt and presence of additives affect the rate of spontaneous emulsification (Fromm 1974, , and Little and Jones IV 2003).

\subsubsection{Pore Pressure}

Pore pressure occurs in the microcracks and pores of the lower underlying layers. Based on the studies of Taylor and Khosla (1983), in mixes with high percentages of air voids, water might penetrate into this porous mix and circulate through interconnected voids. They hypothesized that upon the release of service traffic, openings close and the penetrated moisture entraps inside the voids. Continued traffic adds to the pore pressure and the bitumen films strip from aggregate surface in proximity of voids. Little and Jones IV (2003) related the role of pore pressure in wet conditions to development of microcracks. This is the main cause of loss of adhesion and cohesion bonds in the mix and binder respectively. Kandhal and Rickards (2001) studied the difference in the moisture damage caused to two similar HMA wearing courses, one overlaid with OGFC (Open Graded Friction Course) and one without OGFC. They observed that permeability and vulnerability to stripping of surface layer without OGFC drops dramatically. They 
also justified that since the surface also dries rapidly due to release of traffic (e.g. tire kneading, dust and oil, and traffic heat). This causes firstly void percent reduce in the mix, and secondly embedded water vapours tear the hot film and escape from the voids. This process results in a general reduction in vapour pressure in the pavement as apposed to the wearing course with OGFC overlay, that promotes vapour pressure in the wearing course layer. The other important issue is that the mechanism of pore pressure might be the potential reason for premature stripping, and the damage can be accelerated and promoted if the stripping prone materials are used in HMA (Kandhal and Rickards 2001).

\subsubsection{Hydraulic Scouring}

Hydraulic scouring can explain the stripping phenomenon when it is the cause of damage in surface layers (Taylor and Khosla 1988, Little and Jones IV 2003). Fromm (1974) suggested that the possible reasoning behind scouring can be physical retract of moisture in the HMA. Little and Jones IV (2003) discussed that osmosis promotes the process of hydraulic scoring since salt solutions penetrate in aggregate voids and invite more water to balance the concentration of salts in the interface environment. Taylor and Khosla (1984) related the hydraulic scouring to the cyclic pressure-suction of surface water in the

front and back of tires of vehicles respectively. They debated that this compression and suction results in the stripping of asphalt film from aggregates. As it can be seen there are a variety of opinions on the cause and effect of hydraulic scouring in connection with the stripping phenomenon.

In addition to the above mechanisms there are other systems that are proposed to explain the stripping process such as $\mathrm{pH}$ instability, and the Mechanical Interlock theory. Not all of them are applied directly, and hence they were skipped in this thesis . 


\subsection{Role of Surface Energy}

Surface energy is one of the key concepts that is directly related to the detachment mechanism of stripping. Cheng et al. (2002) in a comprehensive study at Texas A\&M University defined, measured and compared the surface free energy of different sources of asphalt and aggregates based on the concept of contact angles. According to Cheng et al. (2002) surface energy of a solid or liquid is "the energy required to create a new element area of surface under a vacuum", which in case of HMA surface free energy is regarded to as the summation of cohesive and adhesion bonds in the aggregate-bitumen system. Cheng et al. (2002) also calculated the surface energy of an asphalt bitumen sample (HCR) before and after six months aging and concluded that aging has a great effect on reduction of surface free energy of asphalt bitumen. Their test results showed that stripping is more likely to develop because aging of asphalt dramatically reduced both cohesion and adhesion bonds of asphalt binder. Figures 2-1 and 2-2 demonstrate the trend of surface energy change among different sources of asphalt bitumen and aggregates respectively. 


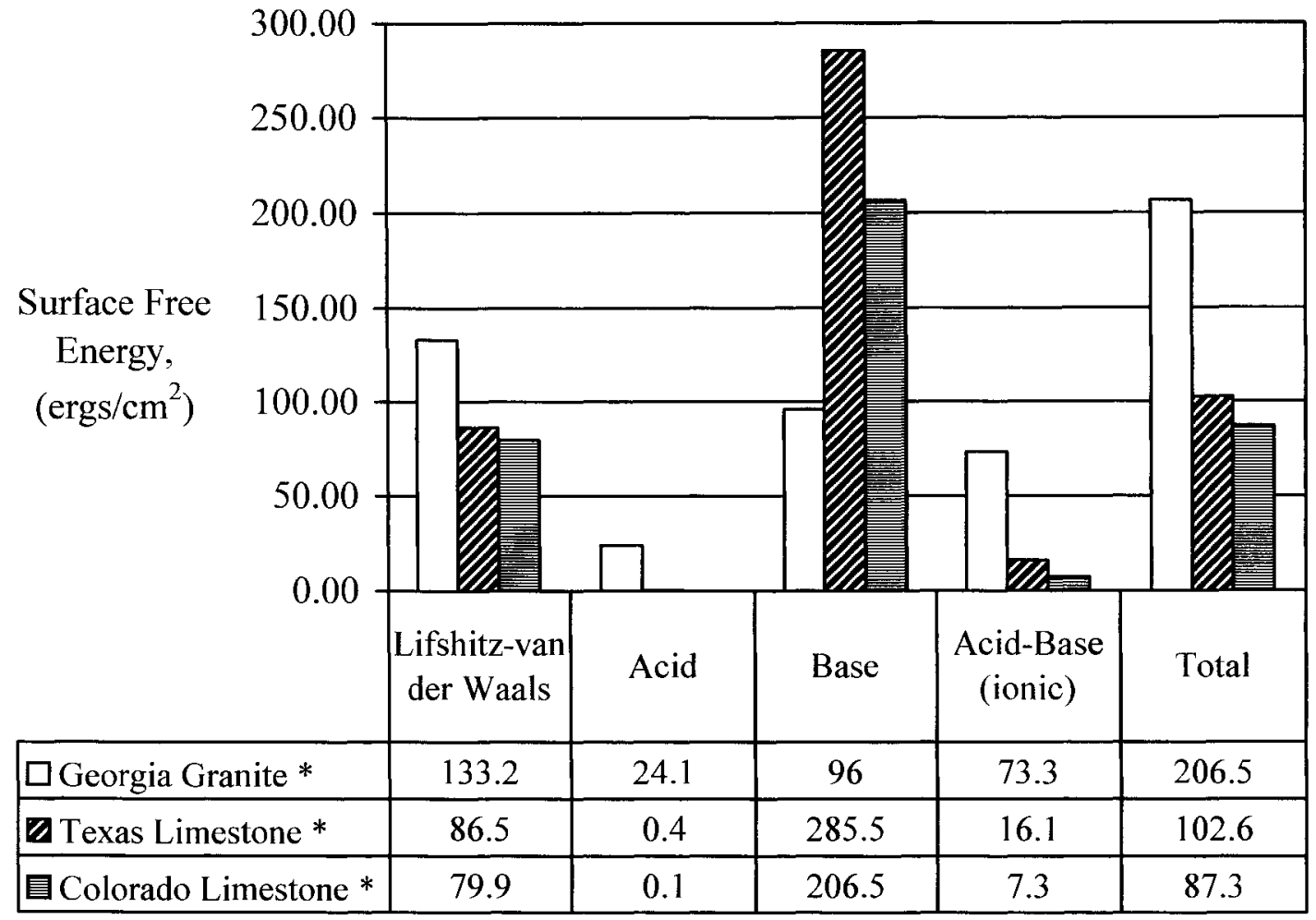

Contributing bond components of aggregates .

* Georgia Granite, Colorado Limestone and Texas Limestone selected from different sources are known to have high acidity, medium alkality, and high alkality nature respectively.

Figure 2-1: Effect of the contributing bonds of aggregates on their total surface free energies (based on contact angles) (After Cheng et al. (2003) 


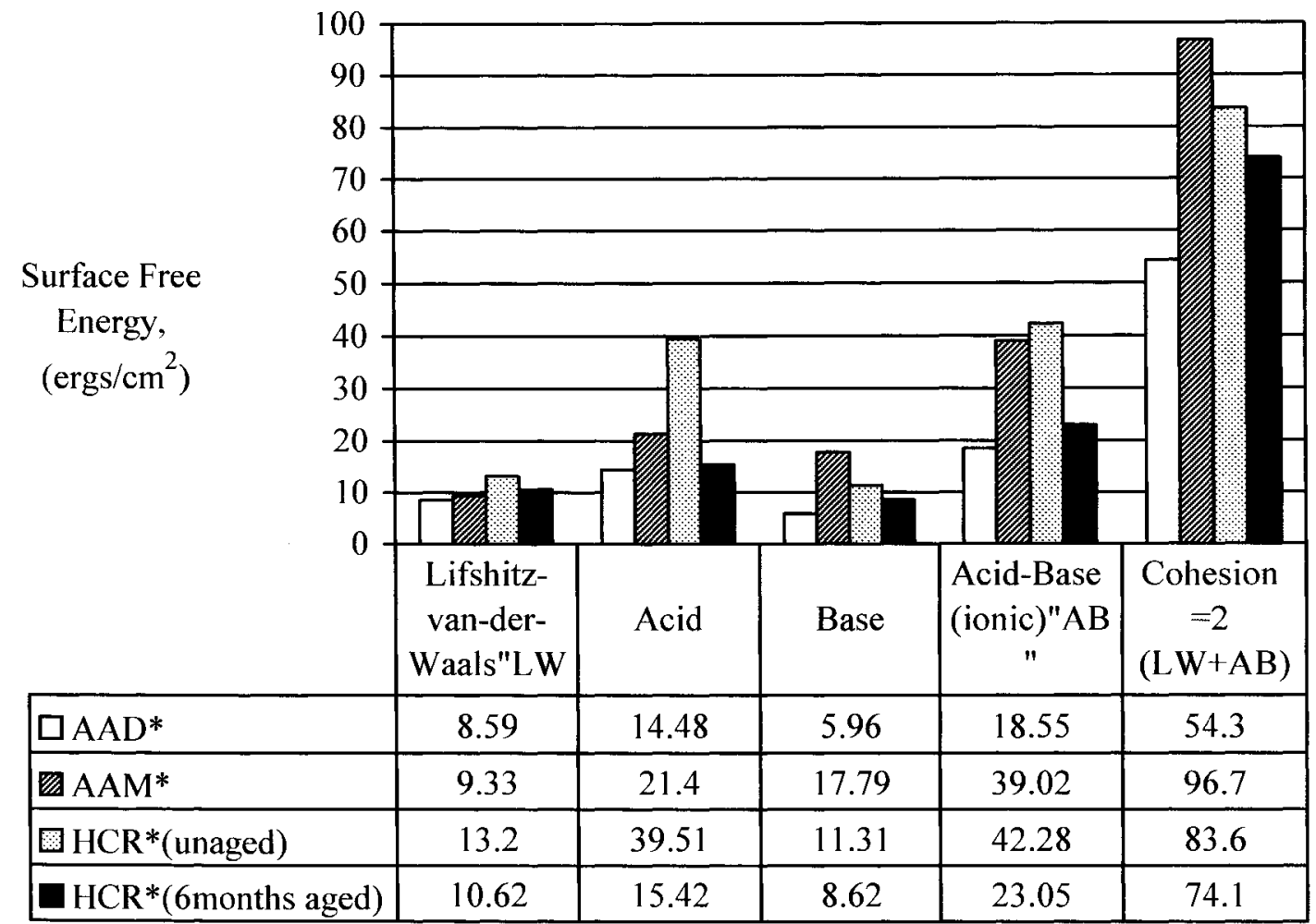

Surface Energy Components

* AAD and AAM are SHRP core Asphalts, and HCR is a blend of base Asphalt with \#20 rubber.

Figure 2.2: Effect of contributing bonds of asphalt bitumen(s) on their total surface

free energies (based on the receding contact Angles) (After Cheng et al. 2003) 
According to Cheng et al. (2003), both aggregates and asphalt cements possess positive and/or negative surface free energies, which represent the basic and acidic nature of materials respectively. The existence of these variable acid-basic natures among the tested materials resulted in the creation of adhesion bonds with different magnitudes in the mixture of aggregates and asphalt bitumen in presence of water. Cheng et al. (2003) measured the free energy of asphalt-aggregate components in presence of water and obtained the total established adhesion bonds using the formula (1) as follows:.

$$
\begin{aligned}
\Delta \mathrm{G}_{132}^{\mathrm{a}}= & \left(\Gamma_{13}+\Gamma_{23}-\Gamma_{12}\right)(\mathrm{SSA}) \\
= & 2 \Gamma_{3}^{\mathrm{LW}}+2\left(\Gamma_{1}^{\mathrm{LW}} \Gamma_{2}^{\mathrm{LW}}\right)^{0.5}-2\left(\Gamma_{1}^{\mathrm{LW}} \Gamma^{\mathrm{LW}}{ }_{3}\right)^{0.5}-2\left(\Gamma_{2}^{\mathrm{LW}} \Gamma_{3}^{\mathrm{LW}}\right)^{0.5}+ \\
& +4\left(\Gamma_{3}^{+} \Gamma_{3}^{-}\right)^{0.5}-2\left(\Gamma_{3}^{+}\right)^{0.5}\left[\left(\Gamma_{1}^{-}\right)^{0.5}+\left(\Gamma_{2}\right)^{0.5}\right]- \\
& -2\left(\Gamma_{3}^{-}\right)^{0.5}\left[\left(\Gamma_{1}^{+}\right)^{0.5}+\left(\Gamma_{2}^{+}\right)^{0.5}\right]+2\left(\Gamma_{1}^{+} \Gamma_{2}\right)^{0.5}+2\left(\Gamma_{2}^{+} \Gamma_{1}\right)^{0.5}
\end{aligned}
$$

Where:

$\Delta \mathrm{G}_{132}^{\mathrm{a}}(\mathrm{ergs} / \mathrm{gm})$ is the magnitude of established adhesion bond between asphalt

(being material "l") and aggregates (being material "2") in presence of water medium (being material "3"),

$\Gamma^{\mathrm{LW}}{ }_{\mathrm{x}}\left(\mathrm{ergs} / \mathrm{cm}^{2}\right)$ is the "Lifshtiz-van der Waals" component of the surface free energy of material " $\mathrm{x}$ " ( $\mathrm{x}$ being1, 2, or 3 representing asphalt, water, or aggregates, respectively)

$\Gamma^{-/+} \times\left(\mathrm{ergs} / \mathrm{cm}^{2}\right)$ is the "polar" or "acid-basic" component of the surface free energy of material " $\mathrm{x}$ " ( $\mathrm{x}$ beingl, 2 , or 3 representing asphalt, water, or aggregates, respectively)

SSA $\left(\mathrm{cm}^{2} / \mathrm{gr}\right)$ specific surface area of aggregates. 
Table 2-1 illustrates the strength of adhesion bonds made between different aggregates and bitumen sources that had shown different acid-basic characteristics. Higher free energy represents greater adhesion bonds between aggregate and the wetting agent in presence of the third competing wetting agent.

Table 2-1 Contribution of Gibbs free energy of aggregate-bitumen in the established adhesion bonds in the mix per unit amount of aggregates- unit: ergs/gm (partly- referenced from Cheng et al. 2003).

\begin{tabular}{|l|c|c|c|}
\hline \multicolumn{1}{|c|}{$\begin{array}{c}\text { Aggregates } \\
\text { Bitumen } \\
\text { (/water })\end{array}$} & $\begin{array}{c}\text { Georgia } \\
\text { Granite } \\
(\mathrm{SSA}=0.10 \\
\left.\mathrm{cm}^{2} / \mathrm{gr}\right)\end{array}$ & $\begin{array}{c}\text { Texas } \\
\text { Limestone } \\
(\mathrm{SSA}=0.44 \\
\left.\mathrm{cm}^{2} / \mathrm{gr}\right)\end{array}$ & $\begin{array}{c}\text { Colorado } \\
\text { Limestone } \\
(\mathrm{SSA}=0.31 \\
\left.\mathrm{cm}^{2} / \mathrm{gr}\right)\end{array}$ \\
\hline $\mathrm{AAD}$ & $1.58 \mathrm{E}+05$ & $6.14 \mathrm{E}+05$ & $3.75 \mathrm{E}+05$ \\
\hline $\mathrm{AAM}$ & $2.06 \mathrm{E}+05$ & $8.89 \mathrm{E}+05$ & $5.36 \mathrm{E}+05$ \\
\hline $\mathrm{HCR}$ unaged & $2.19 \mathrm{E}+05$ & $8.19 \mathrm{E}+05$ & $4.97 \mathrm{E}+05$ \\
\hline $\begin{array}{l}\mathrm{HCR}-6 \text { months } \\
\text { aged }\end{array}$ & $1.78 \mathrm{E}+05$ & $7.14 \mathrm{E}+05$ & $4.35 \mathrm{E}+05$ \\
\hline $\mathrm{H}_{2} \mathrm{O}^{*}$ & $2.56 \mathrm{E}+05$ & $11.59 \mathrm{E}+05$ & $7.17 \mathrm{E}+05$ \\
\hline
\end{tabular}

* $\mathrm{H}_{2} \mathrm{O}$ considered to be he primary wetting agent in presence of bitumen; and Gibbs free energy of aggregate-water interface in presence of bitumen was calculated by the author based on the available data in Cheng et al. (2003) study.

According to the measurements of surface free energies (Table 2-1, Figure 2-1, and Figure 2-2), the following significant results are postulated that are helpful in explanation of role of surface free energy in the process of stripping: 
1- Surface free energy of aggregates is higher than that of asphalt bitumen (Cheng et al. 2003). This means in the selection of materials, chemical (acid-basic nature) characteristics and especially mineralogy of aggregates governs the selection criteria as apposed to chemical characteristics of the asphalt bitumen. However the role of asphalt chemistry and its compatibility with the aggregate chemistry should not be neglected.

2- The greater the polarity of acid-base components present in asphalt bitumen, the higher surface free energy of asphalt bitumen(s), and as a result, the stronger cohesion bonds (see Figure 2-2). Cohesion bonds of asphalt binder, as well as the adhesion bonds, contribute to maintain the integrity and stripping resistance of HMA system (Kanitpong and Bahia 2003, Cheng et al. 2003). It has been postulated that in the selection of materials, the asphalt type(s) with higher free energy tend to be stickier and more resistant to stripping in the mix. However, since the stripping is directly related to the adhesion and partly influenced by cohesion, the stripping is potentially affected by the magnitude of adhesion bond energy. It is also evident from Figure 2-2 that cohesion of the three samples of asphalts is more governed by ionic components instead of covalent bonds caused by hydrocarbons of asphalt binder.

3- The opposite (acid/base) polarity exists in the individual asphalt bitumen (magnitude of "AB" in Figure 2-2) results in stronger adhesion bonds between that bitumen and aggregates in the presence of water medium. In other words, the stripping resistance characteristic of the mixture will be enhanced if the asphalt contains more acid-base residuals. Depending on how these acid-base components 
can match the acid-base components of the platform aggregates the adhesion can be improved.

4- Figure 2-2 also reveals that the magnitude of acidic components is higher than that of the basic components in all three tested asphalt bitumen(s), which is generally the case for most of commercial asphalt bitumen(s). This simply means all three bitumen(s) exhibit acidic natures. Although basic components also contribute to make adhesion bonds, the role of acidic components is greater.

5- Considering the acid and base polarity of aggregates as shown in Figure 2-1, Granite happens to be of acidic nature while both Texas and Colorado Limestone(s) are considered to represent basic nature. This result corresponds to the general behavior of these aggregates as expected from the mineralogy of these stones. Based on the findings of part 1, 4, and 5, it is logically expected that Texas Limestone, Colorado Limestone and Georgia Granite establish respectively strongest to weakest adhesion bonds with all three asphalt Bitumen(s). All calculated Gibbs free energies of aggregate-asphalt mixes as depicted in Table 2-1 illustrate that adhesion bonds established for Texas limestone, Colorado Limestone, and Granite are in order of the highest to lowest respectively, which supports the original expectation. Hence, the tested samples of limestone are expected to exhibit higher resistance to stripping in presence of water for in comparison with Granite

6- Granite is generally more acidic in comparison with both Texas and Colorado Limestone. However, since the basic components of the Georgia granite are more 
than its acidic components, it establishes stronger adhesion bonds with acidic Asphalt binders and exhibits more resistant to stripping. According to Figure 2-2, acidity of HCR, AAM, and AAD is from higher to lower order. Table 2-1 also supports the correctness of the above interpretation by representing the highest to lowest Gibbs energy of adhesion to Granite for HCR, AAM, and AAD respectively. The same conclusion is supported for Texas and Colorado Limestone.

7- Figures 2-1 and 2-2 demonstrate the fact that oxidation aging of asphalt reduces the magnitude of polarity in asphalt acidic-basic residuals, which is a sign of reduction of adhesion and cohesion characteristics of asphalt bitumen. Table 2-1 also supports the idea since the adhesion bonds established for aged asphalt binders are without exception weaker than those of un-aged asphalts. Accordingly it is understood that aged pavements could be more vulnerable to moisture damage, however the technical reason for the reduction in polarity of asphalt residuals needs further research (Cheng et al. 2003).

8- Cheng et al. (2003) also postulated that all three aggregates might have the chance to show hydrophilic character and strip in presence of water (with different affinity), because free energies of water-aggregate bonds are clearly greater than of those for bitumen-aggregate bonds (Table 2-1). Other studies have also revealed the appropriateness of this idea (Nguyen et al. 2005). This means there is no limestone that will never strip (Cheng et al. 2003) or there is no granite that always strips. Limestone(s) also may develop stripping as good as granites but 
under different conditions (e.g. in saturated environment) and with further delay (Kandhal and Rickards 2001).

The above findings and interpretations demonstrate why considering the acid-basic nature of both asphalt bitumen and aggregates is crucial in selection of materials and as a result in improving the stripping resistance of asphalt pavement. In fact the higher acidic nature of asphalt bitumen and the higher basic nature of aggregate surface, the higher interaction between opposite surface energies, the stronger adhesion bonds and as a result, the less vulnerability of HMA to stripping and vice versa for basic asphalt in mix with acidic aggregates. However, at the current level of knowledge, specific differentiation between the portion of contribution of acidic and basic component in the "global bond energy" or "summation effect of ionic residuals" is not precisely measurable and is rather theorized based on speculation (Little and Jones IV 2003).

\subsection{Role of Water (in bitumen and aggregates)}

Water is a significant contributor in the process of stripping so that it has become a common belief that "stripping of asphalt pavements will not occur in absence of water or moisture (Kandhal and Rickards 2001, Cheng et al. 2003). Intrusion of water inside the HMA weakens the bonds of materials and yields disintegration of the mixture. There is evidence showing that infiltrated water can soften the asphalt binder, reduce the stiffness of the asphalt, and finally loosen both cohesion and adhesion bonds of HMA (Kanitpong and Bahia 2003; discussion).

Nguyen et al. discussed that the mono-layer of water between asphalt bitumen and siliceous aggregate interface is about $0.3 \mathrm{~nm}$. According to Nguyen et al. (2005) the main 
factor responsible for the loss of adhesion that in turn leads to moisture damage is not the mono-layer but the multi layered water molecules. However, at longer periods of contact with a humid environment the bonds of HMA ingredients may become weakened. What happens in super humid conditions is that bitumen layers, multi-layered water groups (containing ions), and aggregates can slide on each other's surface respectively and this leads to a sort of segregation of asphalt and aggregate, and eventually disintegrates the HMA structure.

Multi-layered water molecules represent a saturated interface site and signify the formation of thick water films sandwiched by crystal shells of $\mathrm{SiO} 2$ (as covered the silica-rich aggregate surface) on one side and polar sites of asphalt cement on the other side. According to Nguyen et al. (2005) an increase in the environment temperature significantly augments the vulnerability of adhesion bonds in the asphalt/aggregates interface. This can be related to an increase in the degree of freedom of heavy molecules of bitumen (which loosens the bonds) as a result of increase in the their kinetic energy.

\subsection{Role of Acidic - Basic nature of HMA Raw Materials (aggregates, asphalt, and water medium)}

The issue of acidic or basic characteristics of materials in the asphalt- bitumen- aggregate interface has been known as a significant factor that initially affects the propensity of asphalt mixes to stripping. Acidity or basicity of ingredients can be viewed form three

prospects in the stripping process: hydrophilic versus hydrophobic aggregates, content of carboxylic acids in the asphalt bitumen, and the $\mathrm{pH}$ of infiltrated water. Each of these three aspects are discussed as follows: 


\subsubsection{Hydrophilic versus hydrophobic aggregates}

Hydrophilicity and hydrophobicity are the chemical characteristics of mineral aggregates that exhibit their affinity for easily mixing and adsorbing with water. In the competition of mixing with water against bituminous asphalt, if aggregates show more tendencies for receiving water they are called hydrophilic or water-loving materials. On the contrary, if the aggregates show stable affinity for keeping the bonds with bitumen molecules and do not replace the bitumen molecules with water polar molecules they are called hydrophobic or of water-hating nature.

In essence hydrophilicity and hydrophobicity of materials are directly related to the acidic or basic nature of their mineral components. According to previous studies (Nguyen et al. 2005, Taylor and Khosla 1983) presence of siliceous and calcareous minerals are responsible for the acidity and basicity of the materials respectively. According to Roberts et al. (1996) in addition to $\mathrm{SiO} 2$ and $\mathrm{CaO}$, the presence of other alkaline earth oxides also known as oxides of earth metals as well as aluminum, and iron can also enhance the basicity level of aggregates. Aggregates mostly contain a mixture of both the above-mentioned siliceous and calcareous minerals and may develop a spectrum of acidity to bacisity characteristics accordingly. The greater the percentage of alkalinebased minerals as opposed to silica rich components, the more basic and strippingresistance characteristics would be normally expected for the materials and vice versa for the acidic and stripping-prone characteristics.

Water-loving or water-hating behavior of materials can be also affected by other factors involved in the stripping. However, it is commonly evidenced through the 
previous studies that quartz, granite and other silica-rich stone materials are hydrophilic in nature and highly prone to stripping, while limestone, dolomite, and those minerals with high concentrations of calcium and magnesium are of hydrophobic type and tend to resist moisture damage.

The other area of interest that is actually a significant part of this thesis is the potential connection between the surface electric charge and the acidity-basicity of aggregate materials. Although some sporadic studies in the past (e.g. Roberts et al. 1996, Nguyen et al. 2005, and Taylor and Khosla 1983) have partially implied such connectivity, there is still lack of a clear image regarding the concept of surface electric charge of aggregates and its relation with the propensity of materials to stripping. It has been speculated through the above study that aggregates containing calcareous and earth oxides minerals accumulate cationic sites on their peripheral surface. On the other hand, silica rich materials typically tend to develop anionic platforms, which build up surface negative charges. Accordingly the more negative charge accumulated on the aggregates surface, the more affinity to absorption of polar water molecules will be considered for that aggregate.

As far as it relates to stripping, this is only the composition of the external surface of aggregates that really maters in terms of having or an affinity for water. It is accordingly understood that if newly crushed aggregates, as so called plant-crush-run type, are weathered for a 2 to 3 weeks period of time before being used in HMA their stripping resistance will be enhanced. This is a conventional application being exercised in the asphalt pavement industry to diminish the chance of pre-mature moisture damage. The technical reason behind this practice is that weathering provides a time window for 
the exposed cationic crystals of aggregate surface for oxidation in presence of Oxygen molecules. The metal oxides will develop a relatively protective shield when surrounded by water multi-layer molecules and avoid the anionic component to have the chance of being easily mixed and absorbed by water instead of asphalt molecules.

\subsubsection{Content of carboxylic acids in the asphalt bitumen}

There are a variety of organic factors and heavy hydrocarbons that affect the susceptibility of HMA to the loss of aggregate-bitumen bonds. Amongst different chemical functionalities present in asphalt molecules, carboxylic acid is a $\mathrm{COOH}$ structured group that its high concentration in the asphalt-aggregate interface has been investigated by Peterson (1986). His research shows that the carboxylic acid functions are responsible for the stripping of granite aggregates. Nguyen et al. (2005) has also reiterated that carboxylic acids establish more stable bonds with materials of basic nature rather than acidic rocks in the presence of water (e.g. better cohesion with limestone versus granite). In essence, carboxylic acids are both present naturally in the asphalt binder base as free acid groups and also can be formed as a result of atmospheric oxidation of asphalt molecules, which leads to aging of asphalt mass around aggregates. Cheng et al. (2002) compared wettability of three different types of asphalt bitumen after and before aging. According to their test results, asphalt bitumen sources with higher concentration of acid-base components have lower potential for establishing Lifshitz-van der Walls bonds- that calls for higher wettability of aggregates. They also indicated that aging (e.g. six months aging) has a significant affect on reduction of surface free energy of asphalts. Peterson (1986) considered the problem associated with carboxylic-acid salts by measuring their concentration in two HMA's with different susceptibility to stripping. 
The aggregates used in both HMA's were from the same source of granite, while the carboxylic acid salts of their asphalt binders were different. Obtained results, as given in Table 2-2, illustrate that concentration of total carboxylic acid contents in the susceptible HMA is almost 5 to 6 times of the stripping resistant HMA. Their test results interestingly show that susceptibility to stripping is a result of interaction of granite surface minerals with the created carboxylic acid salts and not the free acid molecules. Hence, quantifying the concentration of carboxylic acid salts in the mix can be an approach to determine the susceptibility of pavement to moisture damage as a general criteria.

Table 2-2 Concentration of carboxylic acid functionality in moisture-sensitive and satisfactory pavements (after Peterson 1986)

\begin{tabular}{|l|c|c|c|}
\hline \multirow{2}{*}{ Asphalt Source } & \multicolumn{3}{|c|}{ Carboxylic Acids (mol L') } \\
\cline { 2 - 4 } & Free & Salts & Total \\
\hline $\begin{array}{l}\text { Moisture Sensitive } \\
\text { Pavement }\end{array}$ & 0.013 & 0.082 & 0.095 \\
\hline $\begin{array}{l}\text { Satisfactory } \\
\text { Pavement }\end{array}$ & 0.017 & None & 0.017 \\
\hline
\end{tabular}

\subsection{3 pH of infiltrated water}

$\mathrm{pH}$ of intruded water into the HMA can be affected by two factors of acidity-basicity of aggregates, and initial acidity-basicity of water. The $\mathrm{pH}$ of waterbed that is the penetrated water reached to the HMA structure, dictates initial $\mathrm{pH}$ of infiltrated water. Regardless of the source and factors affecting the $\mathrm{pH}$ of penetrated water into the HMA, it is generally 
understood that $\mathrm{pH}$ of water plays a significant role in the stripping of HMA. This has been acknowledged by comparing the affect of changing the $\mathrm{pH}$ of boiling water and susceptibility of HMA's through application of Boiling Water tests (Yoon and Tarrer 1988, and Kennedy et al. 1984, ASTM D665). The $\mathrm{pH}$ of infiltrated water can also be affected by hydrophilic impurities present in the asphalt bitumen. Applying experimental data from polymer studies, Nguyen et al. (2005) speculated that hydrophilic and watersoluble impurities in asphalt could develop polar sites in the asphalt matrix of HMA. If these hydrophilic regions and polar sites randomly take place in overlapping positions, the surrounding water molecules can emulsify the polar mineral particles of asphalt base and then reach deep down to the aggregate-bitumen interface. In a persistent supply of water molecules, a capillary waterway would be built up to invite more water molecules associated with other polar ions. Change in the $\mathrm{pH}$ of the infiltrated water is likely to occur in the emulsification process as explained above which is known to be one of the stripping various mechanisms (Taylor and Khosla 1983). Such process can significantly explain one of the reasons why some aggregates with a good history of stripping resistance- can still become vulnerable to stripping when mixed with new sources of asphalt bitumen and even show unexpected stripping-resistance behaviors in response to anti-stripping agents. 


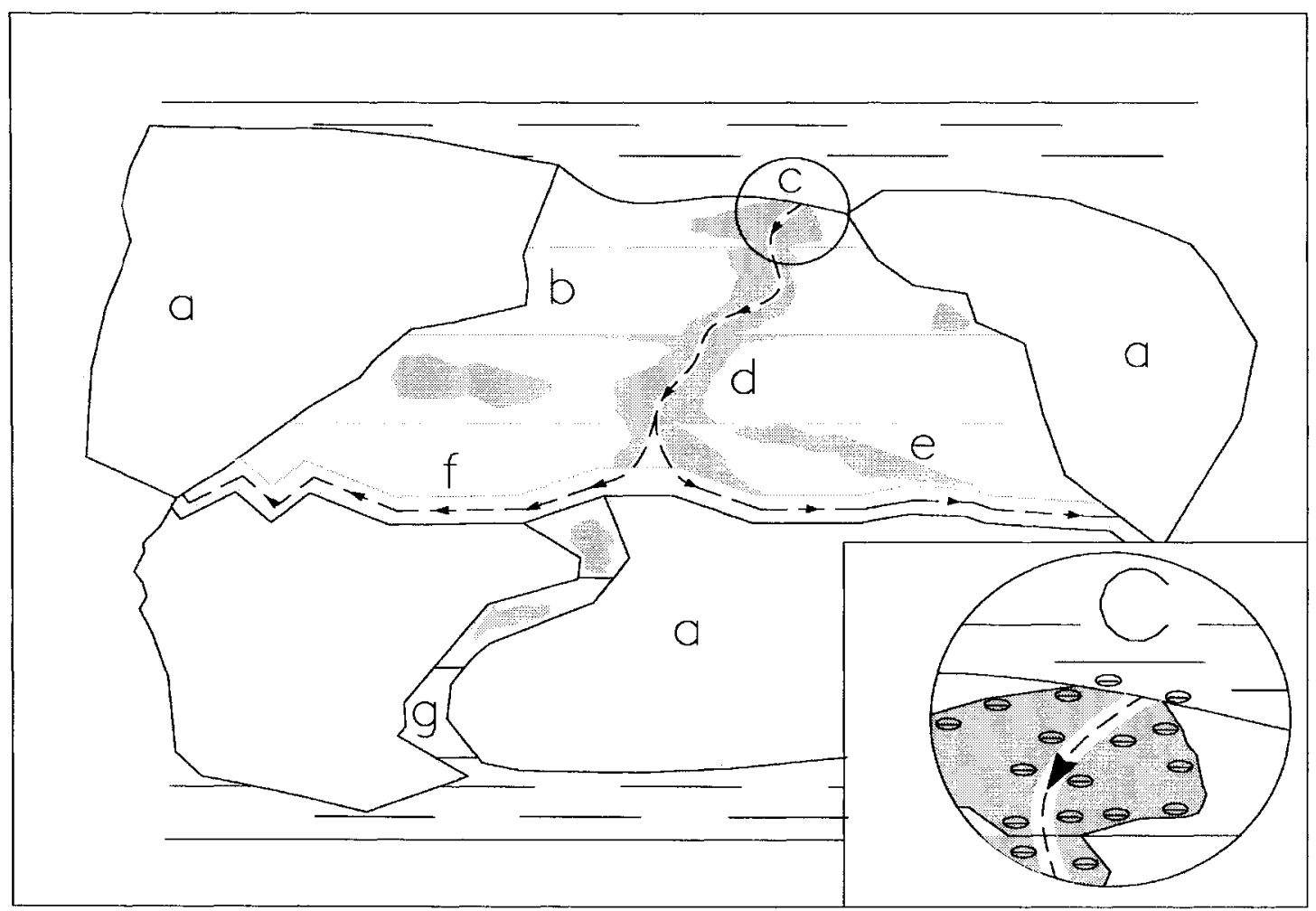

Figure 2-3- Presence of polar hydrophilic minerals and polar impurities in asphalt binder: (a) aggregates, (b) asphalt bitumen multi-layers, (c) bitumenwater contact interface, (d) overlapping impurities and polar sites, (e) isolated (not overlapping) impurities, (f) developing water double-layer between asphalt and aggregate, $(\mathrm{g})$ intact asphalt single layer.

Figure 2-3 depicts how presence of hydrophilic minerals and impurities in asphalt binder promotes stripping. Overlapping impurities and polar sites contribute to the creation of a circuitous waterway and infiltration of the water-bitumen emulsion (Nguyen et al. 2005) Yoon and Tarrer (1988), based on a series of boiling water tests, also showed that effectiveness of amine-based anti-stripping agents on aggregates is diminished when $\mathrm{pH}$ of the water medium is increased. The reasoning behind this observation was that 
adsorptive bonds between amine-type additives and aggregate surfaces are weakened allowing easily separation of asphalt films from aggregate surface. Yoon and Tarrer (1988) pointed out that hydrated lime does not follow the above rule, for which the resistance to stripping is independent of the $\mathrm{pH}$ of the contacting water. Little and Jones IV (2003) hypothesized that normally $\mathrm{pHs}$ as high as 10 will not extract amines from the aggregate, and pHs greater than 10 are very unusual in asphalt mixes nor they have any effect on performance of hydrated lime.

It is known from previous research that aggregates tend to increase the $\mathrm{pH}$ of their contacting water regardless of being calcareous or siliceous (Yoon and Tarrer 1988). In case of calcareous aggregates, the explanation of the phenomenon is more straightforward and can be explained by formula (2) and (3) in which buildup of $\mathrm{OH}^{-}$ (high $\mathrm{pH}$ ) in the aqueous interface of a typical calcareous aggregate is depicted (Hefer and Little 2005):

$$
\begin{aligned}
& \mathrm{Agg}-\mathrm{CaOH}+\mathrm{H}_{2} \mathrm{CO}_{3} \rightarrow\left(\mathrm{Agg}-\mathrm{Ca}-\mathrm{CO}_{3} \mathrm{H}\right)+\mathrm{H}_{2} \mathrm{O} \\
& \mathrm{Agg}-\mathrm{Ca}-\mathrm{CO}_{3} \mathrm{H} \rightarrow \mathrm{Agg}-\mathrm{Ca}^{3}+\mathrm{HCO}^{-}
\end{aligned}
$$

For siliceous aggregates there are other mechanisms that primarily increase the protons in the interface, while ultimately yield an increase in $\mathrm{pH}$. Reactions 4-1, 4-2 and 4-3 indicate how siliceous aggregate normally tends to show hydrophilic (acidic nature), and reduce the $\mathrm{pH}$ accordingly (Hefer and Little 2005). 
Reactions (4-1) through (5) show that the presence of sodium change the interface and add to the concentration of negative hydroxyl groups. The hypothesis is based on the postulation made by Yoon and Tarrer (1983) that related the increase in $\mathrm{pH}$ of siliceous aggregates to their sodium content as a so-called silicate lattice. However, Hefer and Little (2005) indicated that other earth alkaline oxides such as potassium, calcium, and magnesium can also react similarly to increase the $\mathrm{pH}$ of the interface. They explained the increase in $\mathrm{OH}^{-}$of the interface of silica-rich materials is according to formula (5) as follows:

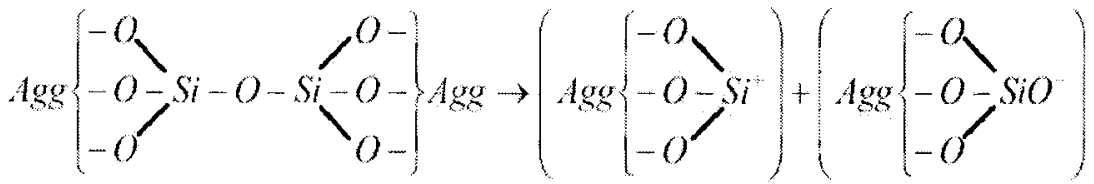

$$
\begin{aligned}
& \left(A g g\left(\begin{array}{l}
-\mathrm{O} \\
-\mathrm{O}-\mathrm{Si}^{\prime} \\
-\mathrm{O}
\end{array}\right)+\left(\operatorname{Agg}\left\{\begin{array}{l}
-\mathrm{O} \\
-\mathrm{O}-\mathrm{SiO} \\
-\mathrm{O}
\end{array}\right)+\mathrm{H}_{2} \mathrm{O}\right.\right. \\
& \rightarrow\left(A g g\left\{\begin{array}{l}
-O \\
-O-S i-O H \\
-O
\end{array}\right)+A g g\left\{\begin{array}{l}
-O \\
-O-S i-O H \\
-O
\end{array}\right)\right.
\end{aligned}
$$

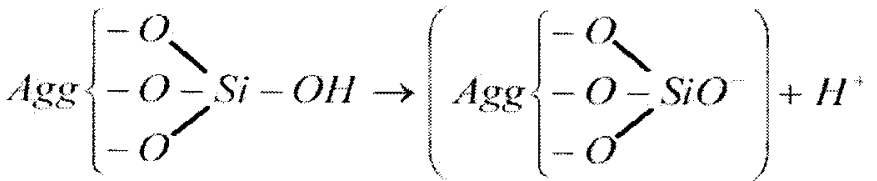

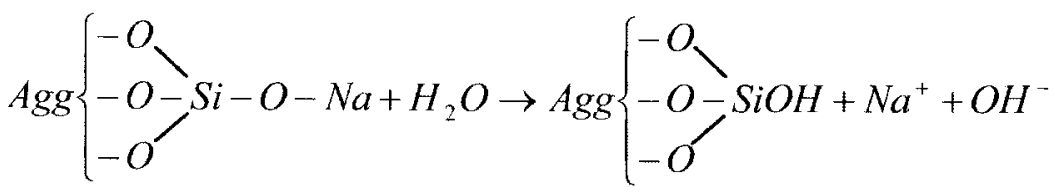




\subsection{Role of Lime}

\subsubsection{Historical background}

Hydrated lime or $\mathrm{Ca}(\mathrm{OH})_{2}$ is known as a fine, strong and basic inorganic powder with multifunctional industrial and environmental applications. It has been used since 1910 first as asphalt stiffener and its application in the industry has been extended to 1970 s when the stripping problem arose in the US (Epps et al. 2003). Application of lime-based additives in HMA has been one of the most important techniques to enhance the stripping resistance of pavements in North America since the 1970s. Since 1990 projects in the United States have been adding $1 \%$ to $1.5 \%$ (percentage weight of aggregates) lime to the HMA, (yet stripping were reported in some cases) so that in 1992 almost all states were applying lime regardless of materials to solve the problem. (Based on unpublished discussion in a breakout session (No.3) hosted by D'Angelo, J., Cook, M., Popescu, L. (February 2003) "Design and Specifications of lime." Summary report- Moisture Sensitivity of Asphalt Pavements: A national seminar, San Diego, California.). According to a state-wide telephone survey in 1998 application of lime became a popular treatment to prevent moisture damage, however, only fifteen states reported the use of lime-based additives in their mix design by that time (Little and Epps 2001).

As it seems decision on using lime-based or chemical anti-stripping agents to prevent stripping is rather subjective and experience-based in State highway projects and vary from one State to another. However anti-stripping additives are easy to use, there is a general agreement that hydrated lime exhibits more significant and reliable 
improvements on a variety of materials as apposed to liquid anti-stripping additives e.g. polymers and amine based chemicals (Lee and Al-Jarallah 1986, Stroup-Gardiner and Epps 1987 and Little and Epps 2001). Collins (1988) also compared the relative behavior of lime and liquid anti-stripping additives applied on Georgia aggregates and observed that the effective rate of improvements in stripping resistance (\% retained) as well as flow, stability, tensile strength were evidently higher when hydrated lime has been applied instead of liquid anti-stripping agents. The other comparative research done by Curtis (1991), between lime and amine anti-stripping agents showed that the lime is generally a more successful and consistent agent than other chemical liquids. All these studies and findings demonstrate the effectiveness and reliability of hydrated lime on enhancing the resistance of mix and materials to water damage, which calls for more research on improving the current methods of application of lime-based additives in HMA.

\subsubsection{Form(s) of Application}

The most common application of lime-based additives as an anti-stripping agent is the form of hydrated lime. Hydrated lime is obtained as a result of combination of quick lime and water. It is usually used in a slurry form (1:4 ratio) with a rate of $1 \%$ to $2 \%$ weight of aggregates. It is applied to dry or damped aggregates, however in some practices it has been observed that lime additive has been added to the asphalt binder at the mix time, in which case it plays the role of a mineral filler. Stocking lime-added materials for about a week to a few months is a practice called "marinating" and is used to increase the effectiveness of the reaction of lime on materials. This exercise is not yet sufficiently researched to have a reliable effect on the healing process of lime and is rather subject to 
the site conditions. Some road agencies in the United States also applied hydrated lime, or quick lime with or without marination and some used lime together with chemical antistripping additives to get better results. The Ministry of Transportation of Ontario also require that highway projects apply hydrated lime to the aggregates coming from the most of quarries located in and/or near the city of Ottawa (alongside Rideau River). However, in a majority of cases in addition to the hydrated lime to the aggregates, a commercial liquid anti-stripping also is added to the asphalt binders (e.g. Redicote 82-S premixed in plant) as a general practice.

\subsubsection{General Healing Effects of Lime}

There have been abundant studies regarding application of lime and/or lime-based additives to soil (as stabilizer), to HMA stone aggregates (as anti-stripping modifier, and filler), in sand-lime building blocks (to enhance compressive characteristics), and to ground or water for change in $\mathrm{pH}$ (as alkaline stabilizer agent). However these research themes outline diverse areas of application of lime in applied science and technology, this thesis makes use of and concentrates on their shared keystone that is:

"Lime products excessively react with siliceous ingredients of minerals (e.g. Quartz or $\mathrm{SiO}_{2}$ ) and treat their stripping susceptibility by mitigating their negatively charged surfaces."

This study aims to establish a link among the diverse applications of lime in real industrial practices and use the shared premise of reaction of lime with siliceous and alkali components of minerals i.e. $\mathrm{SiO} 2 \%$ and $(\mathrm{MgO} \%+\mathrm{CaO} \%)$. Figure 2-4 depicts this schematic approach. 


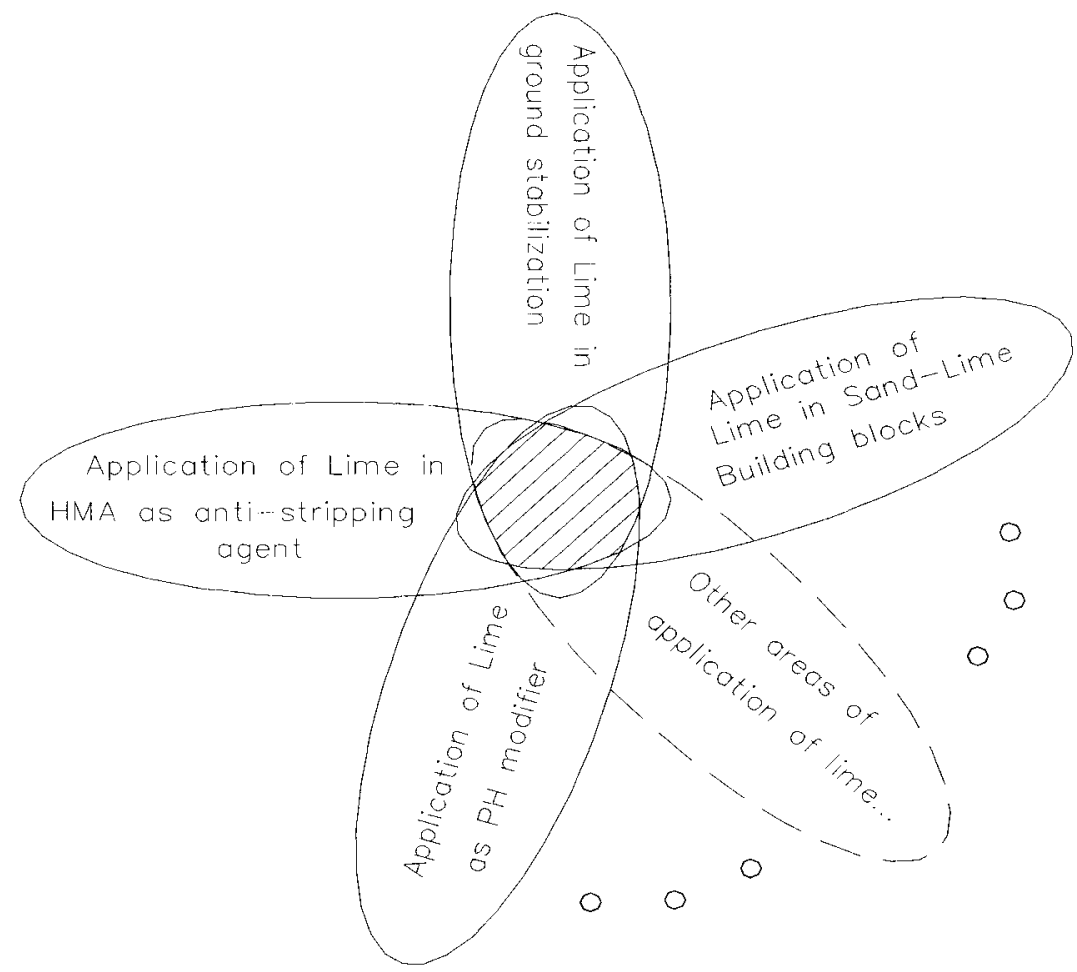

Figure 2-4. Emphasis on the healing effect of lime as a common link among its diverse applications in the construction industry.

Sporadic research has addressed the above-said healing phenomenon through surface chemistry and thermodynamic principles. However, the precise mechanisms and factors affecting the role of lime in reaction with siliceous minerals of aggregates are still multi-faceted issues that require more research. Waterproofing effects and long-term side effects of commercial anti-stripping agents on asphalt pavement have received a diverse range of satisfaction. 
Despite the few studies (Stroup-Gardiner and Epps 1987, Little et al. 1995, Tarer 1996, and Little and Epps 2001), it appears that research on the effects of hydrated lime on easing surface potential of aggregates, restructuring aggregate surface, and the role of controlling factors involved in pozzolanic and ionic reactions of lime with Silica components has, thus far, received little attention. One of the areas of interest in this thesis is to emphasize on this concept.

\subsubsection{Improving Effects of Lime on Asphalt Binder}

Multifunctional benefits of lime in HMA are generally related to its two effective functions: application of lime as filler, and as anti-stripping additive. When hydrated lime is applied as mineral filler, the mechanical quality of binder is improved and therefore, fracture resistance of HMA is enhanced. Little and Epps (2001) through a comprehensive literature review of the previous research works, concluded the following findings about the filler performance of hydrate lime:

1- Hydrated lime through a physicochemical process enhances the stiffness and viscosity (and therefore increase the high-temperature stability) of asphalt binder; this effect is probably related to the high surface activity and flaky shape of hydrated lime particles (Buttlar et al. 1999),

2- Addition of hydrated lime can reduce the age hardening of asphalt bitumen (Petersen et al. 1987, and Curtis 1990),

3- Hydrated lime enhances the mix resistance to low temperature fracture, without dissipation of energy of binder due to relaxation (Cheng et al. 2002, Shah 2003),

4- Plasticity of fine aggregates in the mix can be reduced by hydrated lime, 
5- Granite surface is considerably smoother and has less porosity than limestone (which promotes susceptibility to stripping),

6- Lime significantly increases resistance to stripping (Cheng et al. 2002, Shah 2003).

Kim et al. (2003) studied the healing effects of application of hydrated lime directly to the asphalt binder and concluded that hydrated lime enhances the fatigue and fracture resistance of the HMA by pinning the initial (cohesive and adhesive) microcracks. He inferred that an interactive physicochemical effect between filler and binder, which is related to the fine quality and surface characteristics of the filler, is responsible for the crack pinning mechanism of hydrated lime in mix with asphalt binder. However, Little and Epps (2001) speculated that the level of impact of hydrated lime on absorbing the fracture energy depends on the quality of the asphalt binder. In other words, distribution of polar sites in the mastic determines whether lime fines can either interactively absorb those polar sites (also known as ionization of lime surface in contact with carboxylic acid groups) or work as inert filler in the HMA structure and reduce the unfilled voids (Tunnicliff 1997, and Little and Epps 2001). The first improves the mixture strength against microckracks, while the latter enhances the resistance to high temperature permanent deformation properties of the pavement.

One approach to the above subject is that hydrated lime can improve the general quality of mixture (including lowering the percentage of air voids), and hence, a higher level of resistance to moisture damage is expected. This is called as the synergistic effect of lime on the mix total quality. On the other hand, past studies have shown that, although air voids strongly affect the strength characteristics of mixture they have been found to 39 
have limited effects on the resistance to stripping of materials (Stroup-Gardiner and Epps 1987).

Based on studies done by Plancher et al. (1970) at Western Research Institute, reaction of hydrated lime with carboxylic acids and 2-quinolene in asphalt bitumen results in formation of stabilized salts that are not easily displaced by water molecules. Those reactions were considered to promote development of strong bonds between asphalt nitrogen-based groups and aggregate surface that resist moisture damage (Epps et al. 2003). Little and Epps (2001) also discussed that after the reaction of hydrated lime with asphalt bitumen and formation of calcium salts (that are not solvable in water), there would be no (or less) free acid group available from bitumen side to be adsorbed in water and lose the bond with siliceous aggregates.

\subsubsection{Mechanisms of Effects of Hydrated Lime on (Siliceous) Aggregates}

Among all beneficial characteristics of lime as reiterated in the above, this thesis concentrates mostly on those characteristics of lime, which promote stripping resistance of siliceous stone aggregates in HMA. Nguyen et al. (2005) denoted that siliceous surfaces, if properly modified with basic agents, are potential candidates to set up strong bonds with the hydrophilic asphalts, which can suspend the water displacement process. Stroup-Gardiner and Epps (1987) as well as many other researchers showed that hydrated lime seems to be the most effective anti-stripping agent especially when applied to siliceous materials. They reiterated the mechanisms of effectiveness of hydrated lime as follows:

- Hydrated lime boosts up the calcium-silicate bonds in aggregates, 
- It interacts with acidic functionalities in asphalt bitumen, and improves the quality of asphalt,

- Calcium ions existed in hydrated lime enter an ion exchange with the silica particles of clay coatings on the aggregates surface.

Healing effects of lime on asphalt bitumen were discussed earlier in sections 2-6-1 through 2-6-4. The other two issues i.e. reaction of lime with silica (quartz or $\mathrm{SiO}_{2}$ ) and pozzolanic reaction of lime with clay minerals will be further discussed and used to establish premises for this thesis. According to Epps et al. (2003), covering aggregates surface with hydrated lime or a "hydrated lime wash" can alter the surface energy of aggregates. This is related to the pozzolanic effect of hydrated lime that defuses the deleterious clay minerals masking the aggregates surface.

It is traditionally known that materials containing lime (Calicuom oxide, $\mathrm{CaO}$ ) such as ash gain strength and harden in presence of water. Such materials are so called pozzolans and pozzolanic reaction is responsible for the cementitious nature of such materials. The main contributing components in the pozolanic reactions are $\mathrm{CaO}, \mathrm{SiO} 2$, and $\mathrm{H} 2 \mathrm{O}$. The calcium oxide through the hydration process transforms to calcium hydroxide. Hydrated lime as a by-product then react with $\mathrm{SiO} 2$ components and result in Calcium-Silicate-Hydrate which contributes to the strength, durability, impermeability and other enhanced characteristics of the amorphous product. In this thesis, the concept of pozzolanic reaction of lime on siliceous materials is originally adopted from two applications of lime-based products in the construction industry, "Soil Lime Stabilization" and "Autoclaved Calcium Silicate Building products". These two applications and their connection with the principles of this thesis are briefly discussed as 
follows:

"Lime Stabilization" is described as the application of hydrated lime directly into soil in order to improve its strength, or load bearing capacity to support infrastructure. In this process hydrated lime (mostly) in slurry-form is blended with soil to modify the containing clay and its associate deleterious particles. The problem with clay particles in soil is that these fine materials have high plastic indexes, and are very water susceptible. Clay is regarded as a material that should be carefully controlled in soil used in embankment and subgrade fills in road construction. This is because clay fine aggregates rapidly swell upon receipt of water and adversely affect the strength characteristics of the compacted soil. Lime is added to the soil and reacts with the clay minerals including silica $\left(\mathrm{SiO}_{2}\right)$ and aluminum oxide. By the addition of hydrated lime to the soil, quartz and metal oxide compositions in clay are attacked by calcium $\left(\mathrm{Ca}^{++}\right)$cations in the presence of water, and new materials known as "hydrated cement pastes" are produced on the surface of the conglomerated clay minerals. These new products are also known as CSH (calcium silicate hydrates), and $\mathrm{CAH}$ (calcium aluminate hydrates). During the defuse process of clay minerals, their molecular structure substantially changes and as a result, their physicochemical characteristics including compressive strength, resistance to swelling, and impermeability are significantly improved. The rate of improvement vary from 2 to 10 times more depending on the suitability of treatment and presence of adequate pozzoloanic elements for the pozzolanic reaction (previous research on soil stabilization). It also takes place in two stages, one short term phase, that lasts about $5 \sim 10$ hours and a longer term improvement that gives the soil its ultimate compressive strength that prolongs to weeks and even months. 
It is postulated that a similar process occurs when hydrated lime $\left(\mathrm{CaO}+\mathrm{H}_{2} \mathrm{O}\right)$ is introduced to the silica-rich aggregates resulting in formation of the surficial CSH.

Formulas $6,7,8,9$, and 10 illustrate the basic chemical reactions of the above said pozzolanic process.

$$
\begin{aligned}
& \left.\mathrm{CaCO}_{3} \text { (limestenc) } \text { [heated in } 500 \sim 600 \mathrm{C}\right] \rightarrow \mathrm{CaO}_{\text {(Ouich Lime) }}+\mathrm{CO}_{2} \\
& \mathrm{CaO} \text { (ouick Lime) } \\
& +\mathrm{H}_{2} \mathrm{O} \rightarrow \mathrm{Ca}(\mathrm{OH})_{2} \text { (flydtated L ine) }
\end{aligned}
$$

(Calcinations Process)

(Slaking Process)

(Hydration)

$\mathrm{Ca}(\mathrm{OH})_{2}$ arydrated $\left.\mathrm{lime}\right) \rightarrow \mathrm{Ca}^{++}+2(\mathrm{OH})$

$\mathrm{Ca}+2(\mathrm{OH})^{-}+\mathrm{SiO}_{2}$ (silica or (Quarz $) \rightarrow \mathrm{C}-\mathrm{S}-\mathrm{H}$ (silica Gid)

$\mathrm{Ca}^{+4}+2(\mathrm{OH})^{-}+\mathrm{Al}_{2} \mathrm{O}_{3}$ (Alumila) $\rightarrow \mathrm{C}-\mathrm{A}-\mathrm{HI}$ (Alumina Gel)

(Pozzolanic cementation)

Obviously, the concentration of hydrated product depends on the predominance of siliceous or aluminous materials in the soil. C-S-H (tobermorite or silica gel), which is formed in a pozzolanic reaction, is a high-calcium cementing agent and is responsible for the strength of Portland cement concrete. There is a common agreement that reactions 6 , 7 and 8 are accelerated and enhanced under higher temperature and humid (steam) conditions. Boynton (1980) indicated that the rate of hydration (slaking) of lime might double for each $10^{\circ} \mathrm{C}$ increase in the temperature of water, reaching its pick value when steam is applied. This is why addition of extra water slows down the hydration system neutralizing the heat effect. 
Another typical application of lime is in the autoclaved calcium silicate products such as calcium-silicate bricks, or sand-lime bricks that exhibit enhanced compressive strength. The general recipe for the production of such materials is curing Slicia (Quartz), and lime in the presence of water (saturated steam) and pressure. Formation of the final cementing product (brick or block) occurs under a few hours hydrothermal curing process (upto $12 \mathrm{hrs}$, curing under $190^{\circ} \mathrm{C}$ ). Autoclaving provides for the pressure-temperature required in the curing process. $\mathrm{SiO}_{2}$ and $\mathrm{CaO}$ (that later converts to $\mathrm{Ca}(\mathrm{OH})_{2}$ ) transform to different forms of CSH phases (i.e. CSH I, CSH II, and CSH gel ) depending on the curing conditions and duration (Dietz and Bohnemann 2000). Crystallinity and composition of these three CSH vary significantly. Of these three CSH types CSH (gel), which is a poorly crystalline phase, can be synthesized in lower temperature (observed even in ordinary temperature $25^{\circ} \mathrm{C}$ ).

Dietz and Bohnemann (2000) discuss that $\mathrm{SiO}_{2}$ particles enter into the process of chemical reaction in two form, first dissolution of the $\mathrm{SiO}_{2}$ in the aqueous phase $(\mathrm{H} 3 \mathrm{SiO} 4)^{-}$or $(\mathrm{H} 2 \mathrm{SiO} 4)^{2-}$ complexes, and second as a central core for flocculation and conglomeration of lime-rich $\mathrm{CSH}$ masking the surface of $\mathrm{SiO}_{2}$ source. It is postulated by Dietz and Bohnemann (2000) that crystallization process, if any, takes place at the interface between solid surrounding particle of $\mathrm{SiO}_{2}$ and the aqueous $\mathrm{CSH}$ gel phase. During the longer period of pozzolanic reactions the CSH nuclei system grows developing new shells, and adding to its waterproofing and compressive strength characteristics. 
Figure 2-5 exhibits such a flocculation process through which aqueous CSH (gel) masks (waterproofs) the $\mathrm{SiO} 2$ particle and enhances its compressive strength.

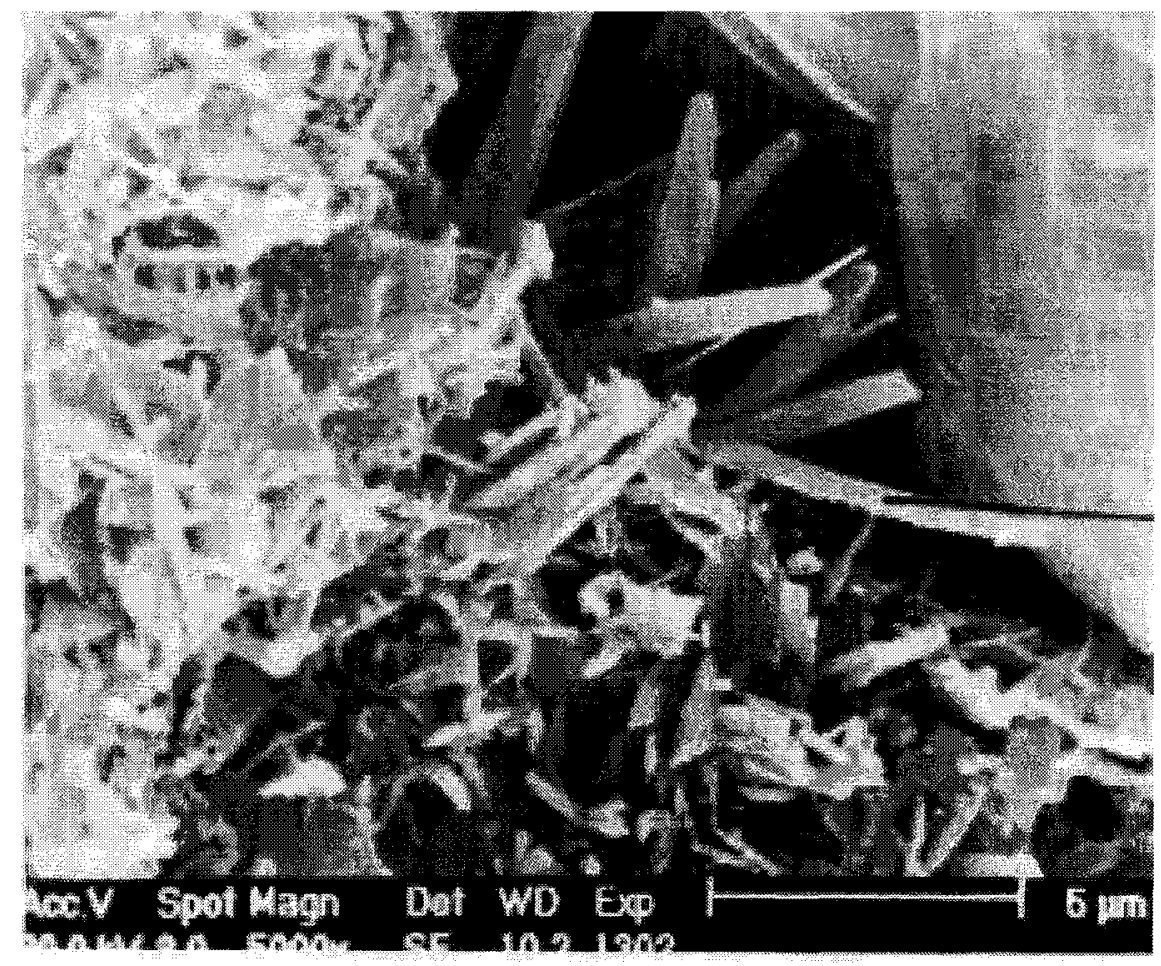

Figure 2-5: Display of a quartz particle surrounded by CSH under the electron micrograph. (after Dietz and Bohnemann 2000).

Viallis-Terris H. et al. (2001) investigated the zeta-potential characteristic of CSH in the presence of alkaline hydrates using solid-state nuclear magnetic resonance (NMR). According to their findings $\mathrm{CSH}$ is described as a nanoporous material consisting of aggregates of nanocrystalline particle materials of a high specific area $(200-300 \mathrm{~m} 2 / \mathrm{g})$. Viallis-Terris H. et al. (2001) also observed that pure CSH has a layered molecular 
structure, so that each layer includes three sheets of a "pseudo-octahedral" calcium plane that is sandwiched between two tetrahedral silicate chains.

2.6.6 Surface charge of silanol (an explanation for surface charge of siliceous aggregates)

Hydroxyl groups $(\mathrm{OH})$ connected to the silicon atoms in silica gel are known as silanol (or silanol groups). Silanol groups exhibit strong surface charge in presence of water molecules. This is because when these silanol groups shorten by loosing their hydrogen bond they are partially ionized forming a layer of polar solvent on the surface (ViallisTerris H. et al. 2001). This process is hypothesized to be responsible for the strong polar character (negatively charged) of siliceous aggregates in presence of water. In fact, this is the most important reason why siliceous aggregates (being negatively charged through silanol groups of silica gel) in presence of water repulse carboxylic groups of acidic asphalt bitumen and attracts positively charged hydrogen molecules of $\mathrm{H}_{2} \mathrm{O}$ instead.

Figure 2-6 depicts such a polar interaction among silanol, $\mathrm{H}_{2} \mathrm{O}$, and carboxylic groups. 


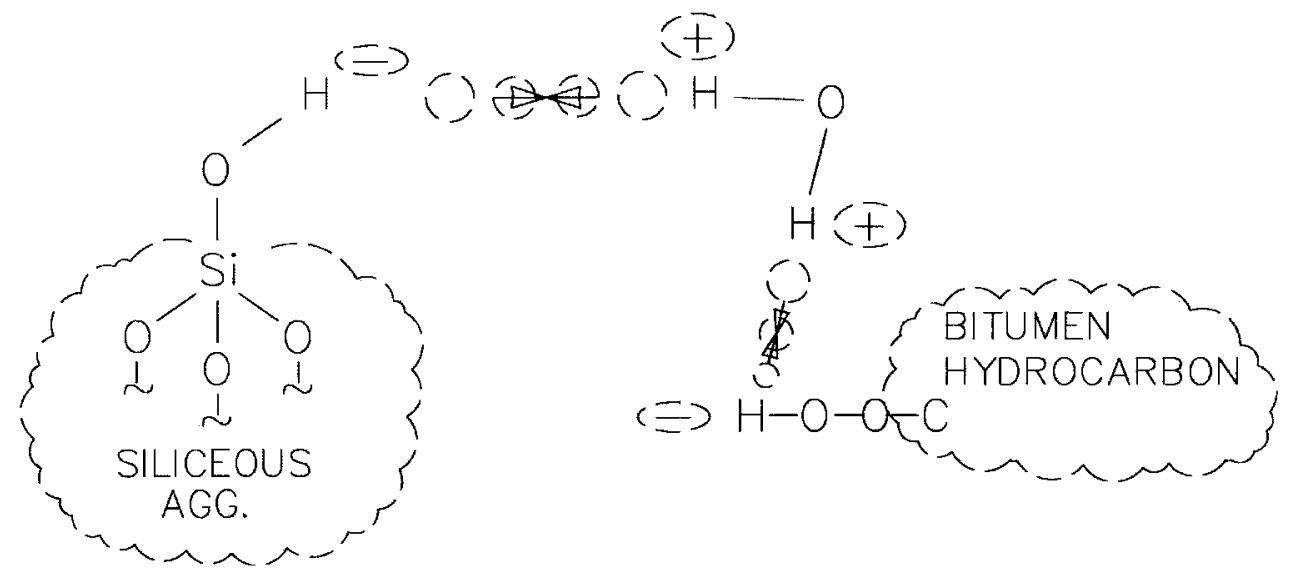

Figure 2-6 Contribution of the negative surface potential of surficial silanol groups in the strong polar orientation of quartz molecules in water.

It is hypothesized that at the onset of $\mathrm{CSH}$ phase i.e. dissolution of the $\mathrm{Ca}(\mathrm{OH})_{2}$ and $\mathrm{SiO}_{2}$ in the aqueous phase, due to exchange of $\mathrm{Ca}^{++}$cations, hydrated lime is more deionized and consumed by silanol groups. This gradually alters the interface from limerich to lime-poor aqueous phase. Dietz and Bohnemann (2000) observed that the solubility of $\mathrm{Ca}(\mathrm{OH})_{2}$ (hydrated lime) is much more than that of $\mathrm{SiO}_{2}$ (Silica) at low temperature (around 40C) while at higher temperatures (over 100C) the solubility rates are inversed for both components. It is widely accepted that the cationic exchange rate depends on the availability (concentration and activity) of hydrated calcium in the initial aqueous phase. Viallis-Terris H. et al. (2001) discuss that during the development of CSH phase, $\mathrm{Ca}^{++}$cations, if available, act as "potential-determining" ions on CSH surface 47 
(instead of silanols) and change the surface charge of CSH to positive potential. According to this hypothesis and considering the earlier observation made by (Dietz and Bohnemann 2000), if temperature is increased during the initial reactions of $\mathrm{CSH}$, a significant reduction in the surface potential of the resulted product is expected.

\subsection{Role of Surface (Zeta) potential}

One of the major objectives of this thesis is to study the role of surface potential in the Aggregate-Asphalt-Water interface. This thesis concentrates on the existence of a relationship between zeta potential of stone aggregates and their susceptibility to moisture damage. This section provides underlying principles to establish such an assertion.

The functional groups attached to the hydrocarbon chains of asphalt binders are the important factors that determine the compatibility of that type of asphalt with siliceous or calcareous aggregates. These highly polar and active functional groups may naturally occur in the asphalt matrix or be a result of atmospheric oxidation of asphalt molecules or -as so called- age hardening (Petersen 1986).

Figure 2-7 exhibits the classification of these functional groups in asphalt molecules. 


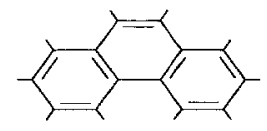

Polynuclear aromatic(1)<smiles></smiles>

Pyrrolic(1)<smiles>C=C1C(=CC)C(=O)OC(=O)C1=CC</smiles>

Anhydride(2)

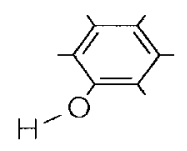

Phenolic(1)

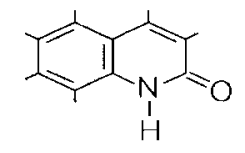

2-Quinolone type(1)

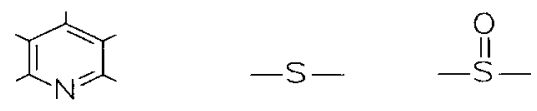

Pyridinic(1) Sulfide(1) Sulfoxide(2)
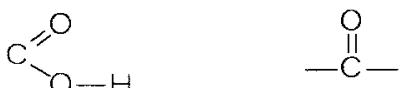

Carboxylic $\operatorname{acid}(1,2)$

Ketone (2)
(1) Naturally occuring

(2) Formed on atmospheric oxidative aging

\section{Figure 2-7 Chemical Functional groups present in asphalt}

molecules (Petersen 1986).

Yoon and Tarrer (1986) discuss that among functional groups present in asphalt molecules, those responsible for making bond and being adsorbed on the aggregate surface are mainly consist of the acid components of the asphalt binder. Mertens and Borgfeldt (1965) observed that the magnitude of particles charge on cationic asphalt droplets (e.g. $\mathrm{R}_{-\mathrm{NH}_{3}}{ }^{+}$functional groups) is twice that of anionic asphalt particles. In other words if cationic acids impart adhesion bonds with aggregates with opposite polarity (in this case being negatively charged such as granite), the bond will be 
primarily stronger than anionic asphalts with positive calcareous materials. However, this initial bond is postulated to be weakened and unstable in the presence of water molecules, promoting stripping susceptibility. The more direct problem of stripping occurs when the anionic bitumen are applied to siliceous aggregates also of a negative nature. The result is repulsion of the two particles or detachment of bitumen droplets from aggregate particles. One of the typical examples of anionic functional groups is the carboxylic acid group (R-COOH), which can be easily hydrolyzed to carboxylic anion (R-COO), and a proton $\left(\mathrm{H}^{+}\right)$. Little and Epps (2001) discuss that hydroxyl groups present in asphalt bitumen can form strong bonds - from their hydrogen side- with hydroxyl groups of siliceous materials (i.e. silanol groups), but this bond is not stable in presence of water. This is because hydrogen bonds or other dipole-dipole attractive bonds are highly water susceptible and vulnerable to detachment (Yoon and Tarrer 1986). Protons are responsible for the acidic nature of the mastic and the carboxylic anions governs the negative polarity of the binder. Yoon and Tarrer also postulated that an increase in $\mathrm{pH}$ of contact water significantly encourages the process of detachment of hydrogen bonds and break of established links between the asphalt salt components and aggregate negative surface. On the other hand, change in electrochemistry of the asphalt-water-aggregate interface also strongly depends on the aggregate minerals and their surface potential. Mertens and Borgfeldt (1965), based on past studies, used a very distinctive approach in their classification of aggregates and stressed the role of potential charge in their propensity to stripping. 
They postulated the mechanism of fracturing and ionization of siliceous and calcareous aggregates in presence of water is according to two simple but substantial reactions as

$\mathrm{Agg}=\mathrm{SiOH} \rightarrow \mathrm{Agg}=\mathrm{SiO}^{-}+\mathrm{H}$

$\mathrm{Agg}-\mathrm{Ca}-\mathrm{CO}_{3} \mathrm{H} \rightarrow \mathrm{Agg}-\mathrm{Ca}+\mathrm{HCO}^{-}$

follows:

Reactions (11) and (12) as indicated in the above are responsible for making the aggregate-water interface acidic and basic respectively.

Roberts et al. (1996) also confirmed the above mechanism and discussed that aggregates depending on their mineral composition impart variable ranges of $\mathrm{pH}$ on their surface being either negatively charged and showing acidic nature, or positively charged and showing basic character. Surfaces of those aggregates that are known to be hydrophilic such as sandstone, quartzite, (especially) granite, and usually silica-rich materials become negatively charged in the presence of water and promote stripping, while the surface of most calcareous materials- especially dolomite and limestone- become positively charged and resist stripping. However some aggregates contain elements of both kinds and contain, therefore, a mixed polar character such as trap rock, basalts, and porphyries (Roberts et al. 1996).

Mertens and Borgfeldt (1965) based on the available classifications of aggregates specifically related the negative and positive charge of siliceous and calcareous aggregates to the contents of Silica (SiO2\%), metal oxides (such as aluminum, iron and alkaline earth oxides) respectively. 
Figure 2-8 exhibits a diagram depicting the spectrum of $\mathrm{SiO} 2 \%$ and alkaline earth oxides contents of aggregates, and their relative surface charge characteristics.

According to this diagram, for instance, an aggregate containing $15 \%$ Silica, $20 \%$ $\mathrm{MgO}$, and $28 \% \mathrm{CaO}$, is expected to exhibit a mild electropositive surface potential and is

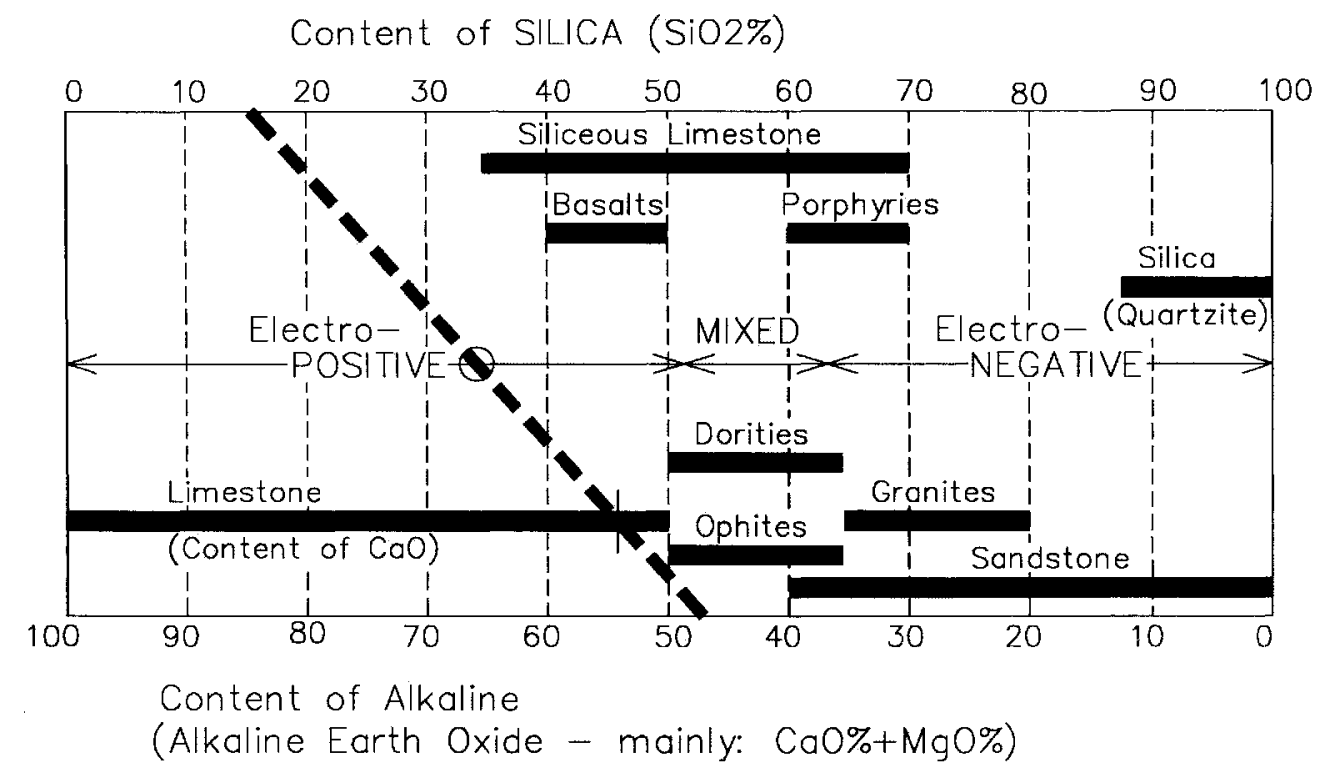

Figure 2-8 Electro-positive or Electro-negative characteristics of mineral aggregates according to their silica and alkaline contents (Mertens and Borgfeldt 1965).

categorized either as a minor limestone, basalt, or siliceous limestone (probably with high percentage of impurities; purity varies depending on its $\mathrm{CaO} \%$ ) depending on its mineralogy and petrographical composition. 
Figure 2-9 and formulas (13) and (14) also show the pattern of distribution of surface charge according to the different molecular structure of calcareous and siliceous materials.

Calcareous Aggregates:

$\mathrm{CaCO}_{3}+\mathrm{H}_{2} \mathrm{O} \leftrightarrow \mathrm{Ca}^{2}+2 \mathrm{OH}$

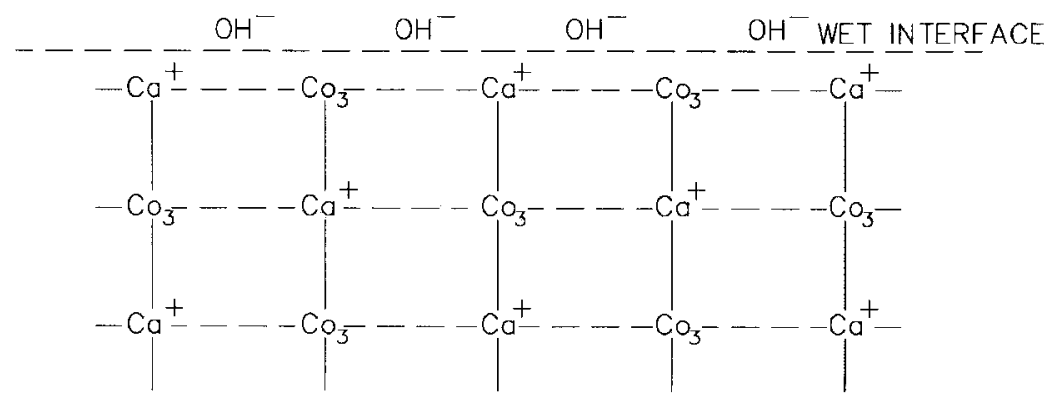

Siliceous Aggregates:

$\left(\mathrm{SiO}_{2}\right)_{n}+\mathrm{nH}_{2} \mathrm{O} \leftrightarrow \mathrm{nH}+\mathrm{SiO}_{3} \mathrm{H}^{-}$

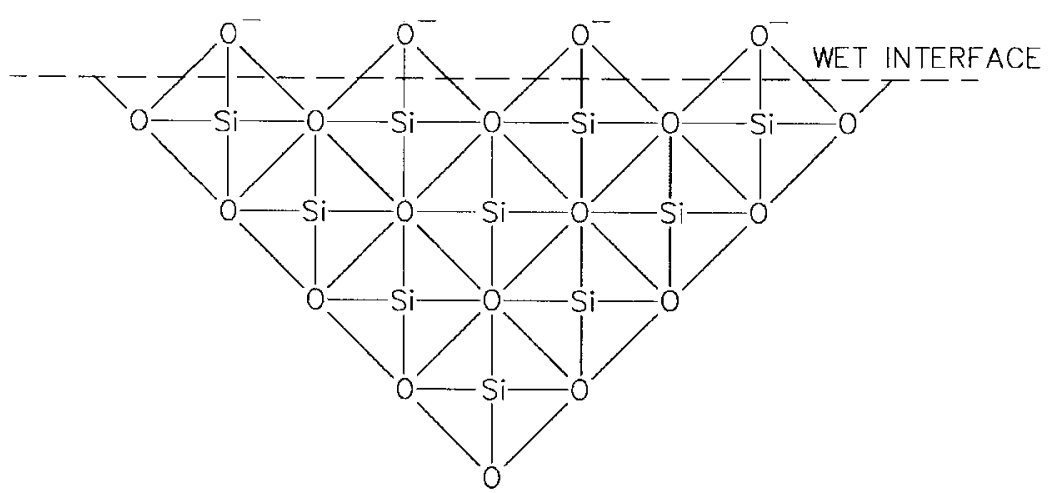

Figure 2-9 Surface structure of siliceous and calcareous aggregates in the proximity of water molecules (Schilling and Schreuders 1988). 
Figure 2-10 illustrates how compatible aggregates and bitumen types with opposite surface charge promote good adhesion bond against stripping
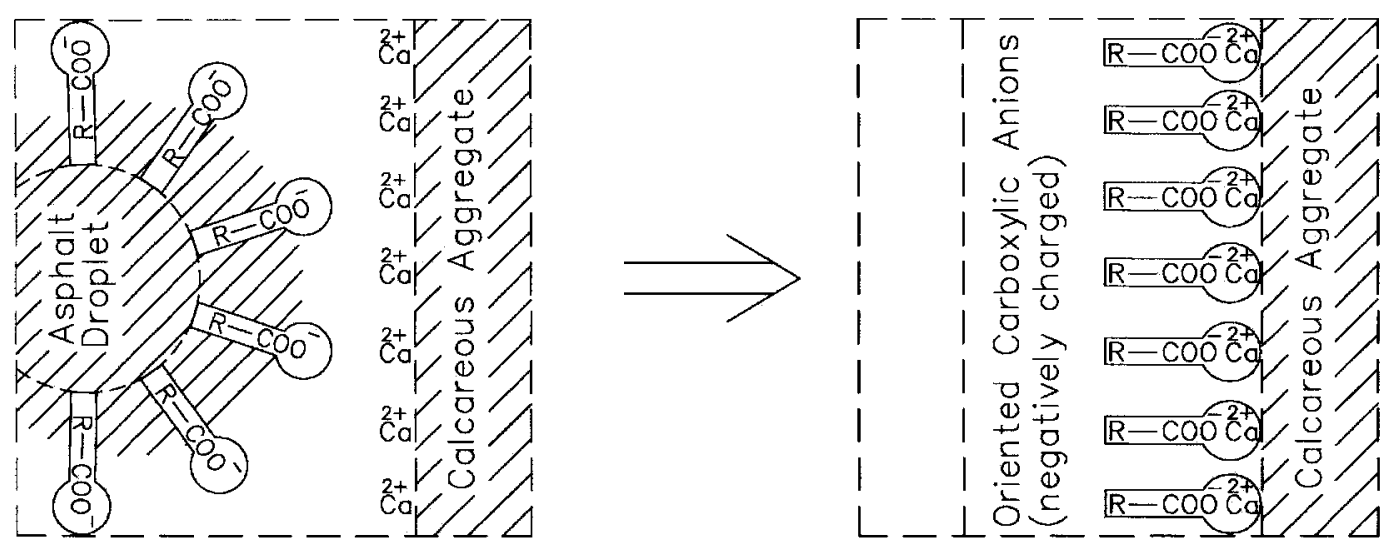

(Anionic Asphalt and Calcareous aggregate)
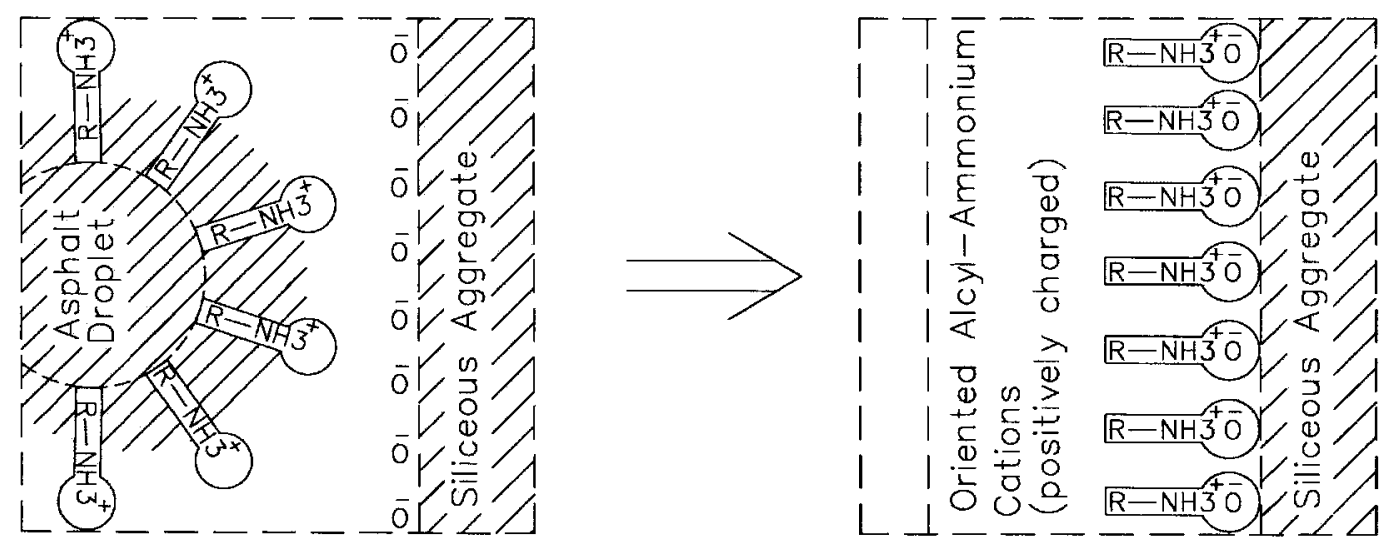

(Cationic Asphalt and Siliceous aggregate)

Figure 2-10 The orientation of asphalt anionic and cationic functionalities toward calcareous (limestone) and siliceous (granite) aggregates (Mertens and Borgfeldt 1965). 
The incompatibility of siliceous aggregates upon asphalts containing carboxylic acids due to the same negative polarity is seemingly a potential reason for repulsion of hydrolyzed carboxylic acid groups (or affinity to stripping). However, there is another speculation to justify this issue, reiterated by other researchers. Based on previous fundamental studies regarding the asphalt functionalities, it is postulated that carboxylic acids with high concentration in the aggregate-asphalt interface potentially adsorb at the aggregate surface, however upon intrusion of water into the interface, hydrogen bonds are weakened and carboxylic anions are easily displaced by water molecules (Peterson 1986 and Nguyen et al. 2005).

\subsection{Role of Anti-Stripping Agents}

Application of chemical anti-stripping agents in order to increase the stripping-resistant characteristics of asphalt pavements has been a common practice during the past fifteen years throughout North American research agencies and Road Construction industries. Kanitpong and Bahia (2003) studied the improvement of stripping resistance of HMA as a result of the application of polymer and anti-stripping additives. According to their study chemical additives improve vulnerable mixtures through strengthening both the adhesion and cohesion bonds of HMA elements, however the main beneficial effect of anti-stripping was reported to be related to improvement of adhesion rather than cohesion bonds. Healing effects of alkaline amine-based anti-stripping on hydrophilic aggregates has also been stressed by Yoon and Tarrer (1986), Curtis (1990), Tarrer and Wagh (1991), Tunnicliff (1997), Little and Jones IV (2003), and many others. It is commonly accepted by these researchers that long chain amine-based anti-stripping agents - as so 
called "hydroxyl-alkali-amines" (Curtis 1990)- have a dramatic effect on improving the adhesion bonds between silica-rich aggregates and asphalt binders. Little and Jones IV (2003) indicated that these fatty-amines are long because of their heavy hydrocarbon groups and when ionized in presence of water molecules they become positively charged from their amine cationic group $\left(\mathrm{R}^{-} \mathrm{NH}_{3}{ }^{+}\right)$. Tarrer and Wagh (1991) hypothesized that both amine groups and hydrocarbon chains contribute to improve the adhesion, and that the length of chain and number of amine groups in the agent composition control the level of improvement. They speculated that fatty amines act as a link between hydrophilic aggregates from one side, and hydrophobic (non-polar) asphalt molecules from the other side. In fact, $\mathrm{R}^{-\mathrm{NH}_{3}}$ group(s) being positive in nature (compete with water molecules and) establish strong dipole bonds with negatively charged aggregates, while heavy hydrocarbons tend to establish covalent bonds with other heavy hydrocarbons of bitumen asphalt promoting the adhesion bond between aggregates and asphalt.

Some chemical anti-stripping additives are directly applied to asphalt bitumen and some are applied to raw aggregates. Those chemical anti-stripping agents that are readily mixed with bitumen are mostly known as surfactants and basically used to increase the wettability of the stone aggregates (Tunnicliff 1997) through reducing the surface tension of the asphalt binder (Mostafa 2005). On the other hand those chemical anti-stripping additives that are applied to the raw materials are used to modify the hydrophilic characteristics of vulnerable materials against moisture damage (Mostafa 2005) and provide additional dipole bonds between asphalt matrix and aggregate surface minerals. Another concept that is used to explain the effect of anti-stripping on stone aggregates is that anti-stripping can mask and waterproof the surface of aggregates. Perry and Curtis 
(1993) studied the effects of three organosilane treatments a hydroarbon (i.e. $\mathrm{RCH}_{3} \mathrm{R}$ ), thiol (i.e. $\mathrm{SH}$ ), an amino group (i.e. $\mathrm{NH}_{2} \mathrm{R}$ ) on a few sources of aggregates. They concluded that application of such silanes on aggregates, in many cases, decreased the sensitivity and affinity of aggregates to water and as a result reinforced the bitumenaggregate adhesion bonds against moisture. However, according to their obtained data this conclusion has not been applicable to limestone aggregates, which are known to be initially of less polar nature and less competitive for moisture adsorption than the other examined aggregates. This again is an indicator of the selective behavior of anti-stripping additives on aggregates, so that there is no guarantee whether or not a certain antistripping agent should work on limestone if prone to stripping conditions.

The asphalt research community has long argued the effectiveness and long-term effects of amine-based chemical additives on HMA and quality of asphalt pavements since its initial development. However, one of the controversial problems associated with the liquid amine-based antistripping agents is their effect on reduction of viscosity of asphalt bitumen. This effect can significantly change the expected characteristics of HMA, for instance reducing the stability of the mix, reducing the grade and viscosity of asphalt bitumen, decreasing the air void contents of the HMA, and so on. Taylor and Khosla (1983) indicated that as well as reducing the viscosity of binder some commercial anti-stripping agents show low heat stability, promote binder emulsification (despite enhancing initial adhesion bonds), develop unstable shear surfaces in asphalt matrix that result in disintegration of binder, and unbalance the concentration of cationic groups in asphalt binder. Any such changes in characteristics of asphalt and HMA can then be followed with further deterioration and disintegration of asphalt pavement layers under 
traffic service and severe environmental conditions and lead to premature moisture damage. Tunnicliff (1997) carried out laboratory pre-construction tests (tensile strengthASTM D4867, and water boiling test - ASTM D3625) in order to determine the effects of nine commercial anti-stripping agents on stripping propensity of different HMA's. He determined the air voids of field cores using ASTM D3203 as a supplementary test to the tensile test (ASTM D4867). Based on the test results of his experiments amine-based liquid anti-stripping agents could have caused reduction in air voids of HMA. Decrease in air voids reported to be caused as a potential result of reduction in the asphalt viscosity. However, according to their obtained results (Tunnicliff 1997) of nine commercial antistripping additives only one happened to reduce the Asphalt Cement grade to a lower margin.

Expecting a successful performance from chemical anti-stripping agents also depends on the concentration of the chemical additives that make the prediction of their performance even more complex. Nguyen et al. (2005) has debated that controlled application of amine-based anti-stripping furnishes the surface of siliceous aggregates with a basic waterproofing layer that can establish bonds with asphalt acidic groups $(\mathrm{COOH})$. Curtis (1990) and Nguyen et al. (2005) has also indicated that misapplication (overdose) of anti-stripping can, however, promote the stripping process by over saturating the aggregates surface and result in de-bonding. The explanation for this drawback is that amine-based anti-stripping agents are capable of easily absorbing the penetrated moisture from the asphalt-aggregates interface and in order to balance the concentration of humidity, the caused osmotic pressure invites more water molecules into the interface environment and promotes stripping. 
Regardless of the importance of the above concerns, the influence of different chemical anti-stripping additives on the asphalt cement and HMA's long-term characteristics is rather a subjective performance that changes from one asphalt-bitumen source to another one. The initial cause of stripping is also another key factor that should be well considered when recommending the anti-stripping additives to address the problem. For instance anti-stripping additive(s) could not probably be of any help to a vulnerable pavement that is being deteriorated because of severe cyclic water pore pressure in saturated ambient conditions or as a result of substandard underlying asphalt binder, or even poor side drainage. Based on findings of (Kandhal and Rickards 2001) in such cases modifying the moisture resistant characteristics of the materials may only postpone the onset of failure and would not save the pavement.

In general, based on sporadic studies and empirical data, behavior of amine-based anti-stripping additives and/or their degree of effectiveness are not theoretically predictable, and depend on other multivariate ambient conditions. Furthermore, application of chemical anti-stripping additives also adds to the construction costs of highways (Mohamed 1991). Cost of using anti-stripping additives in HMA vary dramatically from one project to another project. Epps et al. (2003) estimated the cost of using a typical chemical anti-stripping in the asphalt pavement that adds about $\$ 0.50$ to \$0.81 US per ton HMA. This is while Lee and Al-Jarallah (1986) reported the use of a type of liquid anti-stripping agent in a highway project in Saudi Arabia added up to about \$13 US per ton HMA, which is surprisingly high.

The utilization of chemical anti-stripping additives is one of the possible recommendations to improve a vulnerable pavement against stripping. However, since 
the mechanism of how these stripping additives strengthen the adhesive and/or cohesive bonds is not yet fully hypothesized, there is the lack of a unified voice in terms of definite superiority of one additive against other chemicals or lime-based additives. A research-based guideline for their effective application is not currently available in the real practice and the subject, therefore requires further research.

\subsection{Evaluation and Prediction of Stripping}

Timely recognition of moisture susceptible materials and vulnerable HMA has been a serious concern for the asphalt community and road agencies since 1930 (Taylor and Khosla 1983 and Parker and Wilson 1986). The obtained knowledge about the mechanisms of stripping resulted in devising a variety of test procedures to date. These tests meant to serve three concepts (Taylor and Khosla 1930): (i) determine the resistance / susceptibility of a given mix to stripping, (ii) evaluate the effect of using different materials in the resistance to stripping of mix, or (iii) compare the effectiveness of different anti-stripping additives.

These tests are performed either on loose or compacted asphalt mixes. Despite the diversity of the developed tests there is still no single test that can objectively and consistently represent the real site condition and with 100 percent certainty approve or reject mix (or material) samples (Taylor and Khosla 1983, Kiggundu and Roberts 1988, Parker and Gharaybeh 1988, and others). The main reason for this wide acceptance is multiplicity of variables is simply the mechanism of stripping itself, which is affected by several variables. Characteristics of aggregates, asphalts, drainage conditions, 
compaction, variability of antistripping agents, and many other issues are all factors that contribute to the moisture susceptibility of a mix. All these issues should be taken into consideration and well controlled in order that a test provides 100 percent reliable results in different situations.

The most recent effective tests that are used to quantify the stripping of mix and materials is given by [41] Buchanan and Moore (2005) as follows:

- Boiling Test (ASTM D-3625), (ASTM 2003)

- Texas Boiling Water Test (TBWT), (Kennedy et al. 1984)

- Static Immersion Test (AASHTO T-182-84 or ASTM D-1664), (AASHTO 2005)

- Resistance of Compacted Bituminous Mixture to Moisture-Induced Damage (ASTM D 4867and AASHTO T-283-03), (AASHTO 2005)

o Lottman Test

o Modified Lottman Test

o Root-Tunnicliff Test

- Immersion-Compression Test (AASHTO T-165-02 or ASTM D1075), (AASHTO 2005)

- Hamburg Wheel Tracking Device (HWTD), (Aschenbrener 1995)

- Purdue Wheel (PURWheel) Testing Device, (Pan and White 1999)

- Environmental Conditioning System (ECS), (Tandon et al. 1997)

Highway agencies based on their own policy or other subjective discretions have preferred either of these test alternatives to predict and control stripping during the past 
20 years. However, there seems to be a change in the policy after the launch of Strategic Highway Research Program (SHRP-a five year applied research initiative) in 1997. Table 2-3 shows the tests used before and after SHRP.

Table 2-3 Comparison of stripping tests and their popularity in states DOTs before and after SHRP (Kiggundu and Roberts 1988, Hicks 1991, and Aschenbrenner 2002).

\begin{tabular}{|c|c|c|c|c|}
\hline & $\begin{array}{l}\text { Number of } \\
\text { Agencies used } \\
\text { the test after } \\
\text { SHRP (1997)- }\end{array}$ & $\begin{array}{l}\text { Number of } \\
\text { Agencies used the } \\
\text { test before SHRP } \\
\text { (1997)- }\end{array}$ & $\begin{array}{l}\text { Minimum Test } \\
\text { Index }^{*} \text { Criteria }\end{array}$ & $\begin{array}{c}\%^{* *} \\
\text { Success }\end{array}$ \\
\hline & (Hicks 1991) & $\begin{array}{l}\text { (Aschenbrenner } \\
\text { 2002) }\end{array}$ & \multicolumn{2}{|c|}{$\begin{array}{c}\text { (Kiggundu and Roberts } \\
1988 \text { ) }\end{array}$} \\
\hline $\begin{array}{c}\text { Boiling Water } \\
\text { Test }\end{array}$ & 0 & 9 & $\mathrm{RC}=85 \% \sim 90 \%$ & $58 \%$ \\
\hline $\begin{array}{c}\text { Static } \\
\text { Immersion }\end{array}$ & 0 & 3 & - & - \\
\hline $\begin{array}{c}\text { Immersion } \\
\text { Compression }\end{array}$ & - & - & $\mathrm{SR}=75 \%$ & $47 \%$ \\
\hline $\begin{array}{l}\text { Original } \\
\text { Lottman }\end{array}$ & 3 & 3 & 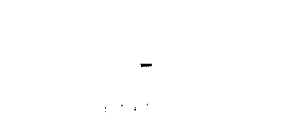 & - \\
\hline $\begin{array}{l}\text { Modified } \\
\text { Lottman }\end{array}$ & 30 & 9 & $\begin{array}{l}\mathrm{TSR}=70 \% \\
\mathrm{TSR}=80 \%\end{array}$ & $\begin{array}{l}67 \% \\
76 \%\end{array}$ \\
\hline Tunnicliff-Root & 6 & 9 & $\begin{array}{c}\mathrm{TSR}=70 \% \\
\mathrm{TSR}=80 \% \\
\mathrm{TSR}=70 \% \sim 80 \%\end{array}$ & $\begin{array}{l}60 \% \\
67 \% \\
67 \% \\
\end{array}$ \\
\hline $\begin{array}{l}\text { Immersion } \\
\text { Compression }\end{array}$ & 5 & 11 & $\mathrm{SR}=75 \%$ & $47 \%$ \\
\hline Wheel Tracking & 2 & - & & \\
\hline
\end{tabular}

* Test index represents the established value by which performance of HMA mixtures have been judged. $\mathrm{TSR}=$ Tensile Strength Ratio, $\mathrm{SR}=$ Strength Ratio, $\mathrm{RC}=$ Retained Coating.

** Percentage of projects in which the Test Protocol successfully represented the stripping propensity in the field performance.

Among the above tests, the first three tests, i.e. Boiling Test (ASTM D-3625), Texas Boiling Water Test (TBWT), and Static Immersion Test are applied onto loose mix. These tests are very similar in concept. They basically simulate the accelerated 
detachment mechanism of asphalt film from the surface of aggregates in super exaggerated moisture and temperature conditions. These tests are performed on loose mix and evaluation is made after the samples are immersed in warm (or boiling) distilled water for some period of time. Resistance / susceptibility to stripping is evaluated and rated by visual inspection. The temperature of distilled water, duration of immersion, and rating criteria are different among these tests. The biggest advantages of these tests are their simplicity (in lab equipment and procedure), quick response, low cost, and applicability. Their accuracy and reliability have received a wide acceptance among researchers, yet they are considered to be suitable for the initial screening and comparing the effectiveness of anti-stripping additives. The drawback of these tests is the subjective observance, however, this may not be the case when the purpose of the test is to compare a number of samples in the similar conditions, or the same observer is rating the samples, yet the lack of correlation with real world may still be the issue.

Boiling Test (ASTM D-3625), was developed based on Texas Boiling Water Test (Kenedy et al. 1984) which itself was the result of a research work done in the Center for Transportation Research, University of Texas, Austin. The summarized procedure for this test is as follows: 100 grams of coated aggregates (250grams if total fine and coarse mixture) are placed in boiling distilled water and maintain the boiling for ten minutes. Water is then decanted and conditioned mix is cooled to room temperature and visually rated for the coating retained. No passing/failing criteria is recommended by ASTM, however for Texas Boiling Water Test a rating board and passing/failing criteria was developed and recommended by Kenedy et al. (1984). Setting a rating board and its applicability has been also reported by Tarrer (1986), Parker (1987) and Kiggundu and 
Roberts (1988). The boiling water test has been used for a long time and reported to be effective by many researchers including Kennedy et al. (1984), Lee and Al-Jarallah (1986), Parker and Wilson (1986), Schilling and Schreuders (1988), Yoon and Tarrer (1988), Tunnicliff (1997) and others. Based on findings from interstate surveys and a previous ASTM survey (D04.22) Kiggundu and Roberts (1988) reported that more than fifteen States DOT's have been using the 10-minute Texas Boiling Test both in laboratory and field scales.

Immersion static test (AASHTO T182-84 or ASTM D1664) is conducted on 100grams of coarse aggregates $(6.3 \sim 9.5 \mathrm{~mm})$ only. The procedure is that after the coarse aggregates are coated with binder, the samples are warmed for $60^{\circ} \mathrm{C}$ for two hours; then the sample will be immersed in a covered jar for about $16 \sim 18 \mathrm{hrs}$; after that the conditioned sample is visually inspected; the $95 \%$ retained coating is set for the passing threshold. Ministry of Transportation Ontario has another similar setting for this standard with slight changes to the size of aggregates and the asphalt content (Hassan and Abd E1 Halim 2000). 
Table 2-4 illustrates the alternative setting for static immersion test and water boiling test.

Table 2-4: Summary of qualitative test methods to evaluate stripping for loose mix of HMA (Hassan and Abd El Halim 2000).

\begin{tabular}{|c|c|c|}
\hline & Static Immersion Test (MTO LS-285) & $\begin{array}{llll}\text { Boiling } & \text { Water Test } \\
\text { D3625) } & & & \\
\end{array}$ \\
\hline Specimens & $\begin{array}{l}100 \text { gram of aggregates passing the } 13.2 \mathrm{~mm} \\
\text { sieve and retained in the } 4.75 \mathrm{~mm} \text { sieve } \\
\text { (HMA) and } 4.0 \pm 0.1 \text { gram asphalt content }\end{array}$ & $\begin{array}{l}\text { Field mixture representation at } \\
\text { design asphalt content }\end{array}$ \\
\hline Procedure & $\begin{array}{l}\text { - Place the coated aggregate in a } 600 \mathrm{ml} \\
\text { beaker and allow to cool at room temperature } \\
\text { - Add distilled water in the beaker to about } 3 / 4 \\
\text { mark } \\
\text { - Place the beaker and contents in a water } \\
\text { bath at } 49 \pm 0.5^{\circ} \mathrm{C} \text { for } 24 \text { hrs } \\
\text { - Remove from the water bath and estimate } \\
\text { the total visible area of the aggregates that } \\
\text { retained coating }\end{array}$ & $\begin{array}{l}\text { - Place about } 950 \mathrm{ml} \text { of } \\
\text { distilled water in } 1500-2000 \\
\text { ml beaker } \\
\text { - Heat to boil, then add } \\
\text { mixture } \\
\text { - Bring mix back to boil and } \\
\text { hold for } 1 \text { min } \\
\text { - Decant asphalt from vessel } \\
\text { and refill with cold water }\end{array}$ \\
\hline Analysis & Qualitative based on Visual Assessment & $\begin{array}{l}\text { Qualitative based on Visual } \\
\text { Assessment }\end{array}$ \\
\hline
\end{tabular}




\section{Chapter 3. Experimental Design and Testing Implementation}

This section is intended to achieve a set of objectives, and validate an experimental approach based on a set of laboratory tests on raw and treated aggregates. A test plan is designed to evaluate the effects of aggregates chemistry, and surface charge, on stripping and interaction of lime additives with these factors. A set of laboratory tests are tailored to investigate the following specific intents:

- Characterize the materials (physicochemical parameters of aggregates, bitumen, additives, and etc.),

- Measure the change in $\mathrm{pH}$ of aqueous materials for different scenarios

- Evaluate the change in propensity/resistance to stripping in alternative treatment setups,

- Quantify the variation of surface potential in aggregates for corresponding treatment conditions.

In order to minimize the biased observations and readings, a double-blind testing method was employed during the testing phases. Double-blind test is a suitable method for investigating the answers to typical questions as "Does Treatment $[\mathrm{A}]$ being affected in Condition $[\mathrm{B}]$ ?" The observer tries to avoid the visual illusion, which might be a result of guessing or expectation of the due effect when measuring or observing the process of effect on samples. To avoid biased readings in double-blind test, the performer would be just simply unaware of the expected results when doing the measurements. To simulate this in this study, the comparison of the results of all readings was done only after all samples were tested regardless of the effectiveness of intended treatment (curing) on the 
stripping susceptibility. This way the performer minimized the biased observations to expected test results among different conditions of treatments and curing settings. 


\subsection{Phasing of the Tests}

The test plan developed for this thesis investigates the role of aggregates chemistry and mineralogy in stripping, role of zeta potential in stripping, role of lime additives in stripping, and role of curing conditions in stripping when lime additives are applied.

The conceptual scheme of this experimental process is depicted in Figure 3-1.

a Phase (I) Material Selection and Characterization (untreated raw materials):

- Material Selection

- Material Characterization

- X-Ray Fluorescence (XRF)

- Petrographical analysis

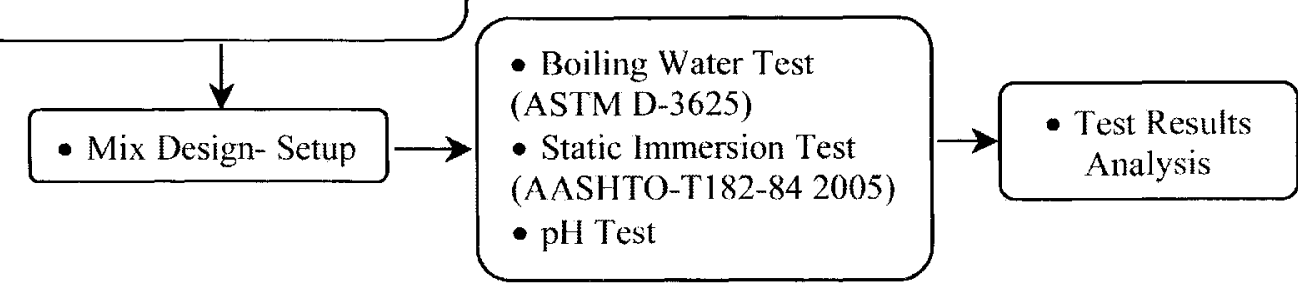

- Phase (II) Examining Lime Treated Materials (different lime treatment scenarios):

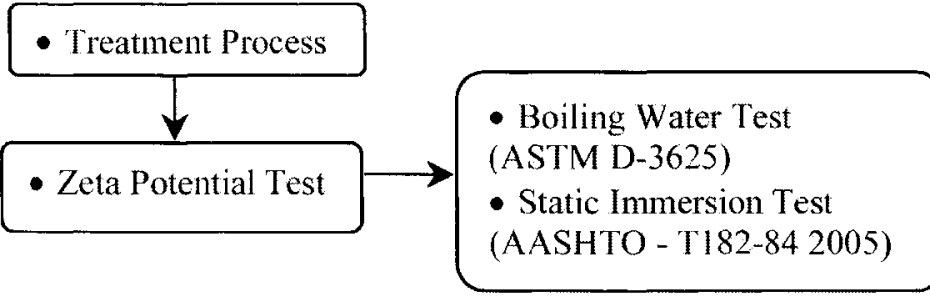

\section{- Test Results} Analysis

\ Phase (III) Examining Cured Limed Materials

(different controlling curing conditions):

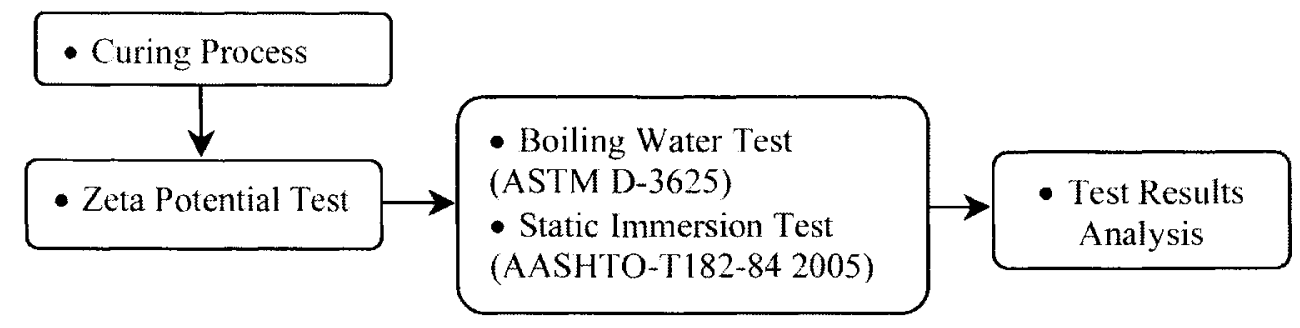

Figure 3-1: The procedural diagram of the staging and hierarchy of the tests. 


\subsection{PHASE (I): Material Selection and Characterization}

Raw materials incorporated in this research work were selected to represent typical materials of asphalt concrete mixtures in the province of Ontario, Canada. Materials used in this experimental study include three types of mineral aggregate, two types of lime additive, and one type of asphalt cement. Characteristics of these materials are discussed in the following sections.

\subsubsection{Selection of Stone Aggregates}

Three different sources of stone aggregates with different levels of susceptibility to stripping were considered for this experimental study. It was intended that aggregates with the known history of resistance or propensity to stripping be acquired for this experimental research. The reason for this was to have rational observations proportional with the field performance. The previous research shows that the qualitative stripping tests are generally applied onto loose mix of coarse aggregates (Kennedy et al. 1984). Accordingly, the selected stone materials were all course graded (Nominal Maximum Size $=13.2 \mathrm{~mm}$ ), crusher run product, and previously weathered in the site plant. The field performance and expectation of susceptibility to stripping of the materials were initially consulted with and acquired from the municipal and provincial authorities (City of Ottawa and Ministry of Transportation Ontario- Aggregate Section). 
The bulk samples (150kg of each source) were acquired from the following quarries:

I- "Dolimitic Sandstone" aggregates; fairly susceptible to stripping - From “R.W.TOMLINSON Ltd.“ Rideau Road Quarry, Source No. 05-67. (Recommended by MTO, and Supplied by the City of Ottawa),

II- "Limestone" aggregates; Not susceptible to stripping- "DECHAN Quarry", Valley Drive Quarry, South West Airport (Supplied by the City of Ottawa) (This aggregate considered as witness sample),

III- "Granite" aggregates; highly susceptible to stripping- Supplied from a Quarry in Orillia, Ont. (Recommended by MTO).

The stripping propensity of aggregates was known from their history of field performance. These three aggregate types were selected for this study because of their different mineralogy, typical stripping propensity, and availability in the area. Specific gravity, water absorption ratio and gradation of these aggregates are based on the test results available form the supplier (appendix "B") and can be seen in Table 3-1 and Table 3-2 and Figure 3-2. As it can be seen in Figure 3-2, trend of gradation for all three aggregate types are very close to each other. This is in favour of the test criteria, since previous research proved that aggregate size and gradation have considerable effect on the boiling test results. Parker and Wilson (1986) observed that in boiling test stripping of uniform (and coarse) size aggregates is more pronounced than that of well-graded aggregates containing fine aggregates. For the purpose of further control on the gradation factor, all aggregates retained on sieve number 30 were washed to avoid fines and clay dust on the larger grains (Stroup-Gardiner and Epps 1987). Only aggregates retained on sieves number 4 and $3 / 8$ inch (i.e. grain size greater than $4.75 \mathrm{~mm}$ and smaller than 
$13.2 \mathrm{~mm}$ ) were incorporated in test to minimize the effect of gradation in stripping of grains (Kennedy et al. 1984, and Parker and Wilson 1986).

Table 3-1: The Physical characteristics of the Agg.\#1, Agg.\#2 \& Agg.\#3.

\begin{tabular}{|c|c|c|c|}
\hline $\begin{array}{c}\text { Stone } \\
\text { Aggregates }\end{array}$ & Agg. No. 1 & Agg. No 2 & Agg. No 3 \\
\hline Source & $\begin{array}{c}\text { TOMLINSON } \\
\text { Quarry- Rideau } \\
\text { River (source no. } \\
\text { 05-67) }\end{array}$ & $\begin{array}{c}\text { DECHAN Quarry } \\
\text { (Rideau Valley } \\
\text { Drive- South West } \\
\text { Airport) }\end{array}$ & Orillia Quarry, Ont. \\
\hline NMS (mm) & 13.2 & 13.2 & 13.2 \\
\hline $\begin{array}{c}\text { Water } \\
\text { Absorption }\end{array}$ & 0.836 & 0.56 & 1.15 \\
\hline $\begin{array}{c}\text { Specific } \\
\text { Gravity }\end{array}$ & 2.662 & 2.729 & 2.65 \\
\hline $\begin{array}{c}\text { F. \& E. } \\
\text { Particles (\%) }\end{array}$ & 15 & 13 & 19 \\
\hline
\end{tabular}

Table 3-2: The individual aggregate percentage passing gradations for Agg.\#1, Agg.\#2 \& Agg.\#3 is illustrated based on U.S. sieve \& opening size.

\begin{tabular}{|c|c|c|c|c|c|}
\hline \multirow{2}{*}{\multicolumn{2}{|c|}{ U.S. sieves }} & \multirow{2}{*}{$\begin{array}{c}\text { Sieve size } \\
\text { opening } \\
\text { (mm) }\end{array}$} & Agg. \#1 & Agg. \#2 & Agg. \#3 \\
\hline & & & $\%$ Passing & $\%$ Passing & $\%$ Passing \\
\hline inch & $3 / 4$ & 19 & $100 \%$ & $100 \%$ & $100 . \%$ \\
\hline inch & $5 / 8$ & 16 & $100 \%$ & $100 \%$ & $100 \%$ \\
\hline inch & - & 13.2 & $98.80 \%$ & $96.90 \%$ & $98.10 \%$ \\
\hline inch & $3 / 8$ & 9.5 & $59.30 \%$ & $59.50 \%$ & $58.10 \%$ \\
\hline no. & 4 & 4.75 & $6.10 \%$ & $6.60 \%$ & $6.47 \%$ \\
\hline no. & 8 & 2.36 & $2.10 \%$ & $2.90 \%$ & $3.27 \%$ \\
\hline no. & 16 & 1.18 & $1.60 \%$ & $2.50 \%$ & $2.81 \%$ \\
\hline no. & 30 & 0.6 & $1.40 \%$ & $2.20 \%$ & $2.60 \%$ \\
\hline no. & 50 & 0.3 & $1.20 \%$ & $1.80 \%$ & $2.38 \%$ \\
\hline no. & 100 & 0.15 & $1.00 \%$ & $1.50 \%$ & $2.20 \%$ \\
\hline no. & 200 & 0.075 & $0.80 \%$ & $1.00 \%$ & $1.97 \%$ \\
\hline & ion $\mathrm{g}$ & & Graph (Agg. 1) & Graph (Agg.2) & Graph (Agg.3) \\
\hline
\end{tabular}

Notes: Max nominal size of all three types of aggregate is $13.2 \mathrm{~mm}$. 


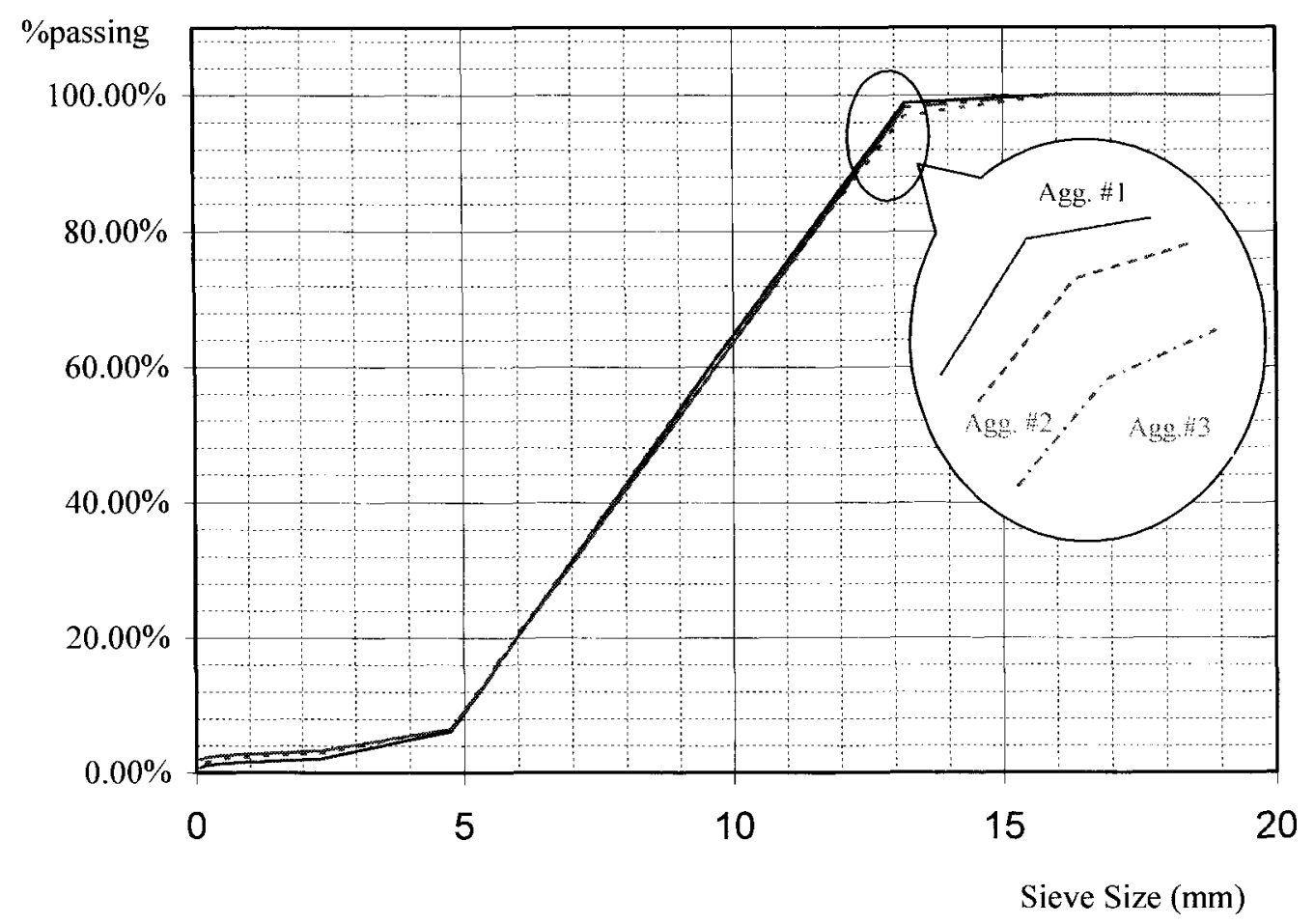

Figure 3-2: sieve analysis plot on a normal scaled graph for gradations of aggregates no. $1,2 \& 3$.

\subsubsection{Selection of Lime Products}

Two types of lime additives used in the tests were (Graymont-S(pecial) type) hydrated lime $\left(\mathrm{Ca}(\mathrm{OH})_{2}\right)$ and quick lime pulverized $(\mathrm{CaO})$ that were supplied by Smiths Construction and MERKLEY Ltd respectively. Hydrated lime and quick lime were in form of fine powder, and in white and gray color respectively. $100 \%$ of fines passed $20 \mathrm{~mm}$ sieve for both lime types. However only fines of passing sieve no. 200 were used for the purpose of test for uniformity of fine pebbles.

\subsubsection{Selection of Asphalt Bitumen}

Asphalt bitumen from only one source was applied in this experimental work, in order to minimize the interaction of change in asphalt functionalities and other qualitative factors 
with the effect of mineral composition and lime treatment. Virgin asphalt bitumen PG58-34 (not pre-mixed with any anti-striping agent) modified by block copolymers (Butadiene-Styrene) was supplied by "BITUMAR Inc.". The supplier also provided the lab with specifications for this source (Appendix No. A).

\subsubsection{X-Ray Fluorescence (or Whole Rock Analysis)}

A popular technique called X-Ray Fluorescence or XRF was considered to investigate the constituent elements and mineral composition of stone materials used in this study. XRF which is an elemental analysis technique with outstanding capabilities such as: (1) determining the major elements of an unknown substance and (2) an extensive elemental survey of sample compositions without standards. XRF is widely used in archeology, geology and mineralogy for qualitative and quantitative analysis of soils, minerals, rocks, and etc. Parts of the reasons XRF is used for investigating the elements of aggregates in this test were its availability, relative precision $(0.1 \%)$, multi-elemental, promptness, and cost effectiveness. XRF application in mineralogy is also called as "Whole Rock Analysis". Details of the test and its sophisticated procedures are out of the scope of this thesis and given elsewhere (Taggart et al. 1987).

This test was done in the laboratory of Department of Earth Science in University of Ottawa using wavelength-dispersive spectrometry XRF. Concentrations of major elements were measured and repeated for three samples of each aggregate type. Samples were selected from different batches to represent the rock types. Samples of 10gram powder of fines were required for this test. All samples were prepared in the laboratory of Department of Earth Science in Carleton University. Aggregate grains were first crushed 
to $2.4 \mathrm{~mm}$ (pass sieve no. 8 ) in a mechanical gyratory disk crusher (Bico Pulverizer Type UA), and then pulverized down to 45 micron (passing sieve number 325 ) using a shatterbox machine (SPEX 8510). Figure 3-3 shows the equipment used to prepare the pulverized materials for the Whole Rock Analysis test.

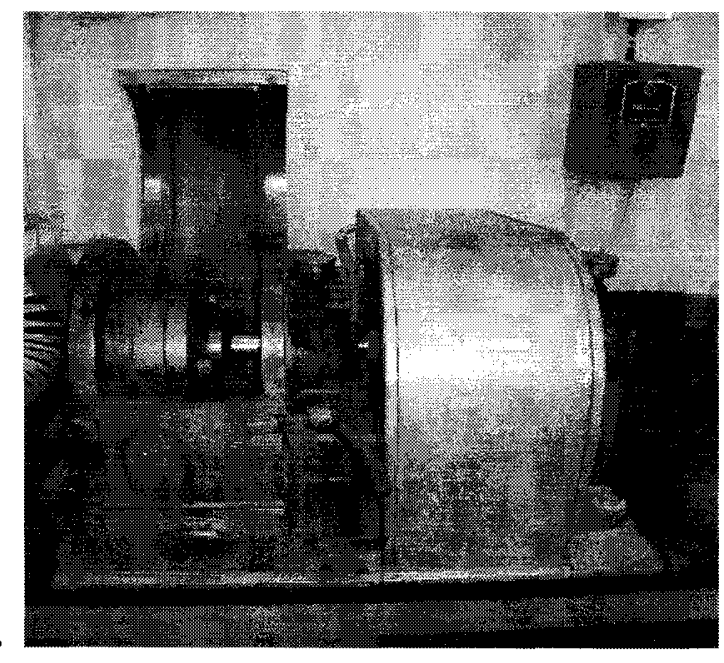

(a)

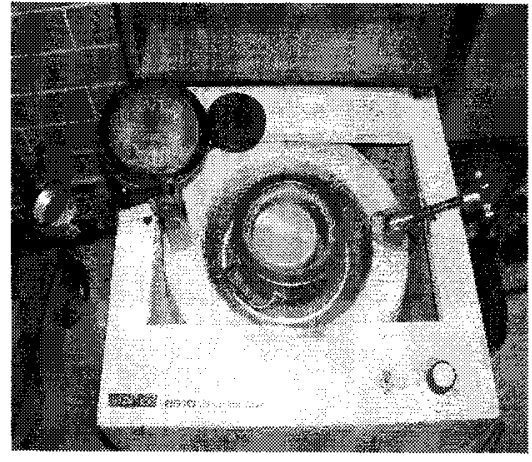

(b)

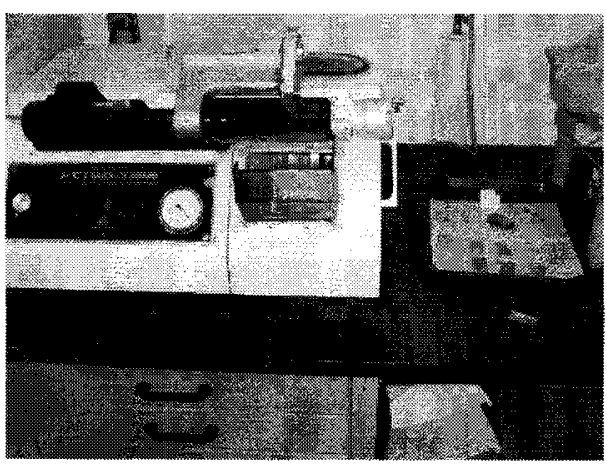

(c)

Figure 3-3: Devices used in the preparation of samples for the whole rock analysis and petrographical analysis: (a) heavy-duty mechanical disk crusher (Bico Pulverizer Type UA), (b) shatter-box machine (SPEX 8510), and (c) thin section system Petro-Thin Buehler model. 
Test results revealed the average major-element compositions for oxides of metals and other elements in weight percent of the whole rock type of each sample. Table 3-3 illustrates the range of measurements of the elements compositions.

Table 3-3: Test results of "whole rock analysis" or "X-ray fluorescence spectroscopy" (XRF).

\begin{tabular}{|c|c|c|c|c|}
\hline Rock Type Sample & & Agg. (1) & Agg. (2) & Agg. (3) \\
\hline Mineral composition & unit & & & \\
\hline Sio2 & $\%$ & $\underline{50.29}$ & 18.47 & 61.24 \\
\hline $\mathrm{Al} 2 \mathrm{O} 3$ & $\%$ & 1.91 & 1.55 & 13.92 \\
\hline $\mathrm{CaO}$ & $\%$ & 20.13 & 37.57 & 4.46 \\
\hline $\mathrm{K} 2 \mathrm{O}$ & $\%$ & 1.318 & 1.139 & 3.014 \\
\hline $\mathrm{MgO}$ & $\%$ & 9.68 & 11.79 & 2.94 \\
\hline $\mathrm{MnO}$ & $\%$ & 0.096 & 0.133 & 0.11 \\
\hline $\mathrm{Na} 2 \mathrm{O}$ & $\%$ & 0.1 & 0.02 & 3.68 \\
\hline $\mathrm{P} 2 \mathrm{O} 5$ & $\%$ & 0.07 & 0.11 & 0.21 \\
\hline $\mathrm{Fe} 2 \mathrm{O} 3(\mathrm{~T})$ & $\%$ & 2.702 & 1.327 & 8.301 \\
\hline $\mathrm{Zn}$ & $(\mathrm{ppm})$ & 44 & 9 & 84 \\
\hline $\mathrm{TiO} 2$ & $\%$ & 0.116 & 0.08 & 0.966 \\
\hline $\mathrm{Ba}$ & (ppm) & 174 & 110 & 507 \\
\hline $\mathrm{Ce}$ & (ppm) & 0 & 22 & 90 \\
\hline $\mathrm{Co}$ & $(\mathrm{ppm})$ & 4 & 1 & 24 \\
\hline $\mathrm{Cr}$ & $(\mathrm{ppm})$ & 185 & 96 & 143 \\
\hline $\mathrm{Ga}$ & (ppm) & 1 & 1 & 17 \\
\hline $\mathrm{La}$ & (ppm) & 38 & -25 & 58 \\
\hline $\mathrm{Nb}$ & $(\mathrm{ppm})$ & 2 & 2 & 12 \\
\hline $\mathrm{Nd}$ & (ppm) & 9 & -1 & 54 \\
\hline
\end{tabular}




\section{(Continuation of Table 3-3) Test results of "whole rock analysis" or "X-ray fluorescence spectroscopy" (XRF).}

\begin{tabular}{|c|c|c|c|c|}
\hline Rock Type Sample & & Agg. (1) & Agg. (2) & Agg. (3) \\
\hline Mineral composition & unit & & & \\
\hline $\mathrm{Ni}$ & $(\mathrm{ppm})$ & 100 & 25 & 71 \\
\hline $\mathrm{Pb}$ & $(\mathrm{ppm})$ & 38 & 4 & 14 \\
\hline $\mathrm{Rb}$ & $(\mathrm{ppm})$ & 23 & 17 & 74 \\
\hline $\mathrm{Sr}$ & $(\mathrm{ppm})$ & 73 & 107 & 319 \\
\hline $\mathrm{Th}$ & $(\mathrm{ppm})$ & 14 & 7 & 13 \\
\hline $\mathrm{U}$ & $(\mathrm{ppm})$ & 8 & 2 & 5 \\
\hline $\mathrm{V}$ & $(\mathrm{ppm})$ & 14 & 19 & 117 \\
\hline $\mathrm{Y}$ & $(\mathrm{ppm})$ & 7 & 12 & 56 \\
\hline $\mathrm{Zr}$ & $(\mathrm{ppm})$ & 267 & 111 & 354 \\
\hline Misc. $\mathrm{Residuals}$ & $\%$ & 13.502 & 27.763 & 0.956 \\
\hline
\end{tabular}

Test results revealed the following understanding about the aggregates:

- Aggregate (1) is a "Dolomitic Sandstone" with relatively high $\mathrm{CaO}$ and $\mathrm{MgO}$ $(30 \%)$, and $\mathrm{SiO}_{2}(50 \%)$; since the percentage of quartz is more than alkaline earth oxides, hence the aggregates are expected to exhibit stripping susceptible characteristics (graph of Figure 2-8). This prediction coincides with field performance reported for the aggregates.

- Aggregate (2) is known to be a "Limestone" with abundant amount of $\mathrm{CaCo}_{3}$ of which is depicted a high percentage of $\mathrm{CaO}$ content (37\%). It is also understood that due to presence of some quartz particles (only 18\%), aggregates might show some minor stripping prone features, which is not enough to make the aggregates 
to a stripper in normal conditions. (see graph of Figure 2-8 that for $\mathrm{CaO}+\mathrm{MgO}=$ $48 \%$, and $\mathrm{SiO}_{2}=18 \%$, aggregate is classified as a limestone)

- Aggregate (3) with a high amount of $\mathrm{SiO}_{2}(61 \%)$, versus considerably less amount of alkaline earth oxides (only 7\%), is categorized as a silica-rich granite (graph of Figure 2-8). This type of aggregates is expected to severely strip in normal site conditions. Again this was expected according to field experience.

\subsubsection{Petrographical analysis}

A petrographical analysis test was also performed in order to further examine the mineral composition of aggregates and to verify the findings in the Whole Rock Analysis test. This qualitative examination was performed in conjunction with the lab petrography experts in the laboratory of National Research Center. However, polished thin sections were prepared in Earth science laboratory in Carleton University (Figure 3-3). External surface of nine thin sections (three of each rock type) were examined using an optical microscope between crossed polarizers in a magnification of X25, X50 and X100. Results of observations and examinations of the minerals under optical microscope are given as follows.

- Aggregate (1) found to be Dolomitic Sandstone of sedimentary nature. This rock type contains $\mathrm{SiO}_{2}$ crystals with colorless dolomite bonds exhibiting light brown to red in general. Microscopic examination of crystals showed that these aggregates are calcareous sandstone. Their quartz sand grains vary is size from 10 to 900 micrometer. The interstitial material between the sand grains is calcite. This aggregate consists of between $45 \%$ to $50 \%$ quarts in average. Figure $3-4$ shows the examined thin sections under different magnifications. 
- Aggregate (2) was also a rock of sedimentary nature but found to be a mixture of sandy limestone and sandy dolostone. Observations showed a very few amount of $\mathrm{SiO}_{2}$ crystals (less than 15\%) and abundant mass of colorful calcite. Quartz grains were relatively smaller only between 40 and 150 micrometers. Figure 3-5 shows the details about observation.

- Aggregate (3) as expected exhibited full characteristics of Silica-rich granite with igneous nature. According to the observations under optical microscope, this rock type is a hornblende granite with abundant and large $\mathrm{SiO}_{2}$ crystals (mainly quartz/feldspar crystals- little calcite). It presents a colourful pattern due to quartz crystals of dark green to black. It contains between $15 \%$ to $20 \%$ hornblende and biotite mica, with $15 \%$ feldspar and above $60 \%$ quartz. Again this corresponds with the $\mathrm{SiO}_{2} \%$ of aggregate (3) as given in Table 3-3. Figure 3-6 shows the magnifications.

Figure 3-4 shows the summary of findings of examination of aggregate (1) under optical microscope that are as follows: slide (a) exhibits the examined thin section in X25 magnification, and also shows a Dolostone with few quartz crystals. The dolomite grains shown are typically between 10 and 100 micrometer in crystal size; thin section was examined between crossed polarizers showing Dolomite Rhombs " $D$ " and a quartz grain "Q". Slides (b) and (c) are the photos showing a X25 and X100 magnification of calcareous sandstone respectively with quartz grains "Q" and small amount of feldspar (F) in a matrix of calcite (Calcium). Slide (d) shows another thin section viewed between crossed polarizers showing calcite matrix with embedded quartz grains $(40 \% \sim 50 \%$ as a representative) (white grains) in a X50 magnification. 


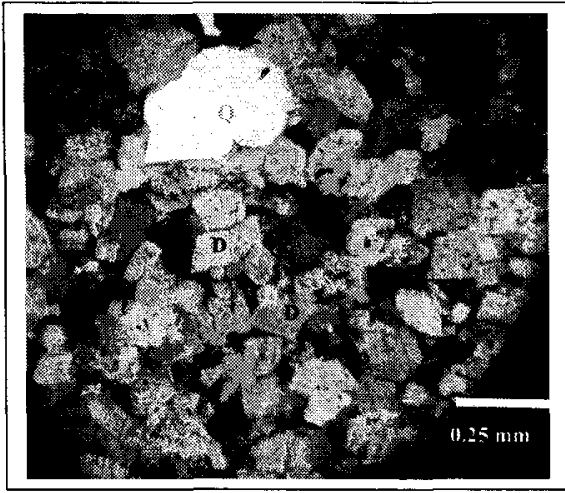

(a)

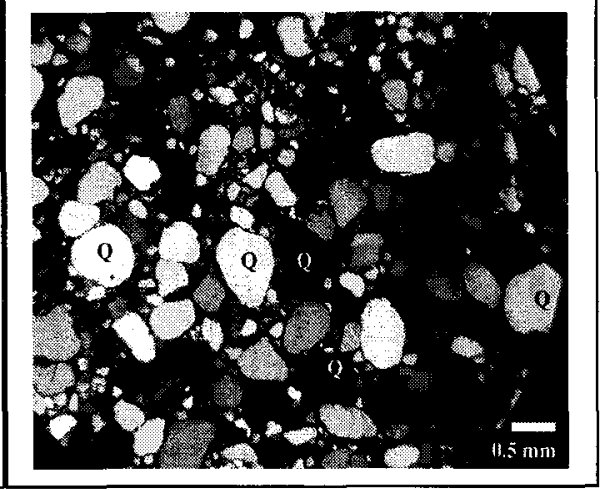

(b)

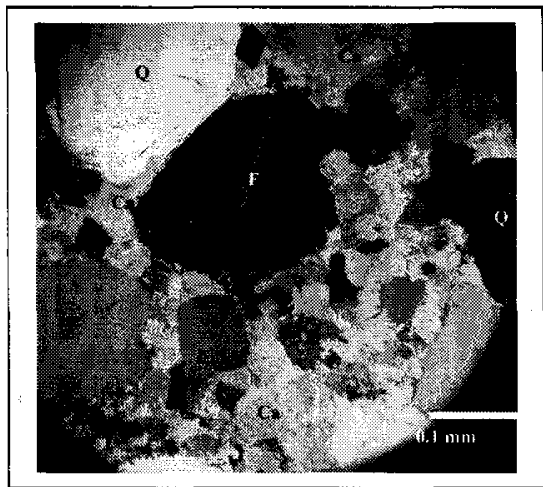

(c)

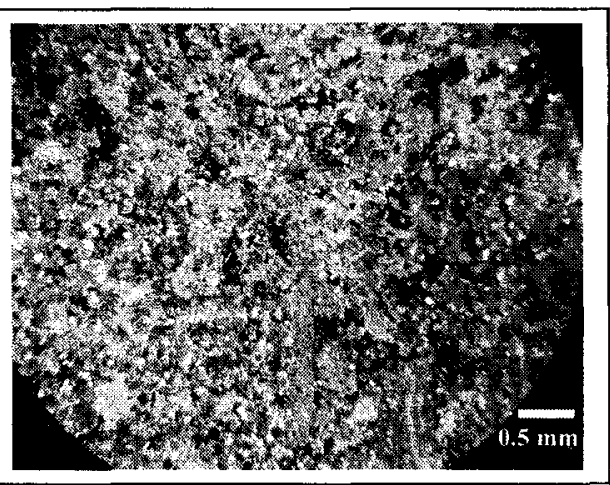

(d)

Figure 3-4: The details of observations made in the examination of the thin sections of aggregate (1) under the optical microscope.

Figure 3-5 exhibits three slides taken from the thin sections of aggregate (2) under optical microscope. Slide (a) is the photo of a thin section examined in X25 magnification and shows a mixture of limestone and dolostone with few quartz crystals (less than $15 \%$ ). The dolomite grains shown are typically between 10 and 100 micrometer in crystal size; thin section viewed between crossed polarizers showing Dolomite Rhombs " $\mathrm{D}$ " and a quartz grain "Q". Slide (b) is the photo of anther this section showing coarse calcite crystals ( sparite) $(\mathrm{Ca})$ in a matrix of finer calcite containing small quartz grains, less than 
$10 \%$. Slide (c) is a photo representing dolomite rhombs of the this section with marked rims, indicated by arrows. The dolostone is unusual in that the dolomite rhombs have marked rims. In general, rock type consists of a mixture of coarse-grained sparite limestone with less than $15 \%$ quartz grains and sandy dolostone.

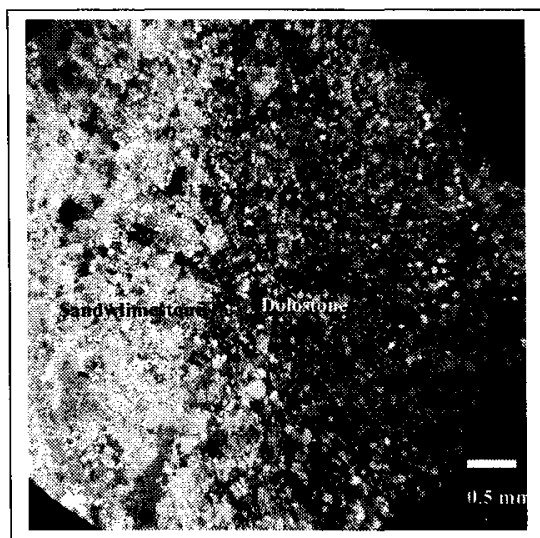

(a)

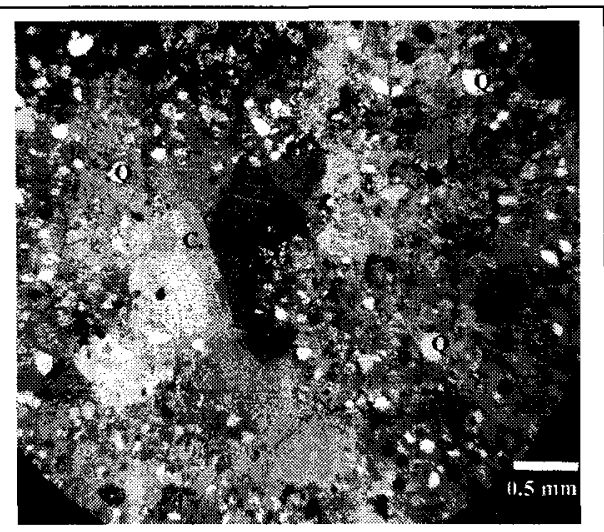

(b)

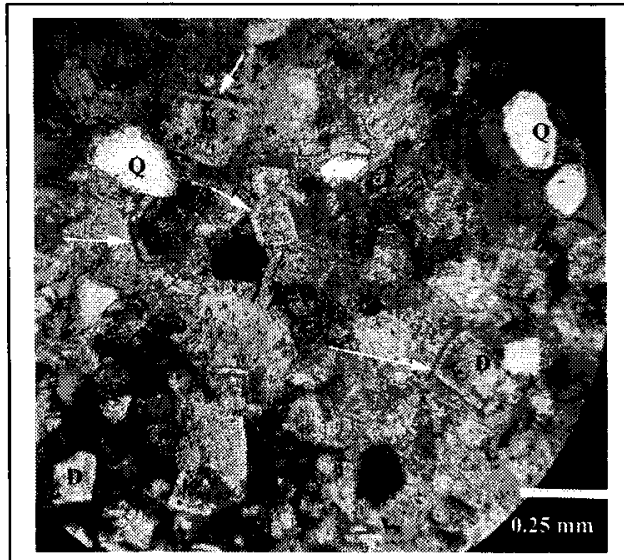

(c)

Figure 3-5: The details of observations made in the examination of the thin sections of aggregate (2) under the optical microscope.

Figure 3-6 displays the slides of photos taken from thin sections of aggregate (3). Slide (a) is the exhibit of a thin section showing that aggregate (3) is a hornblende granite with 
a crystal size of between 100 and 300 micrometer. It contains $15-20 \%$ hornblende and biotite mica, with $15 \%$ feldspar and between $60 \%$ to $65 \%$ quartz; coarse grained granite consisting of quartz "Q", hornblende " $\mathrm{H}$ ", biotite "B" and feldspar "F". Slide (b) is another thin section showing finer grained granite consisting mainly of quartz above $60 \%$ and feldspar about $35 \%$ with about $2 \%$ opaque minerals; the quartz crystals typically have a size of $0.6 \mathrm{~mm}$ but some are up to $1.5 \mathrm{~mm}$ across.

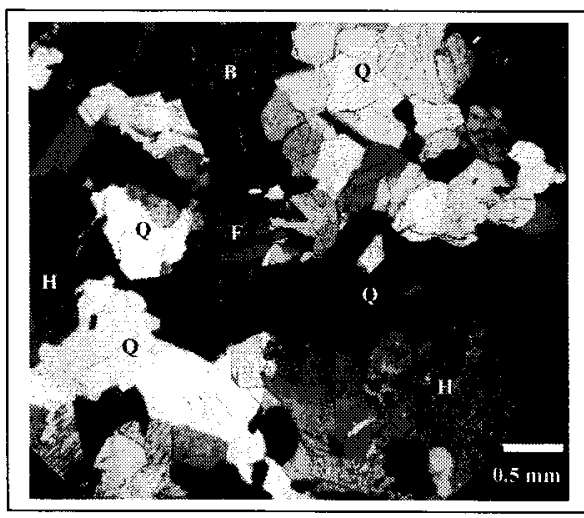

(a)

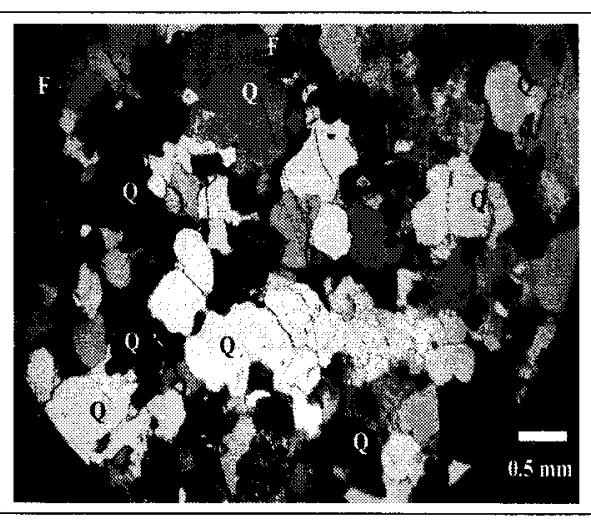

(b)

Figure 3-6: The details of observations made in the examination of the thin sections of aggregate (1) under the optical microscope. 


\subsubsection{Mix Design and Test Settings}

Asphalt content: The suitable asphalt content was determined through a trial process for both boiling water test and immersion test. Previous research revealed that stripping of susceptible aggregates has no significant correlation with the asphalt content of the mix. It is also understood that the percentage of asphalt content is related to the surface area of equivalent sphere and for the same size (gradation) aggregates this is known to be a constant value (Parker and Wilson 1988). Considering the above postulation, different scenarios were developed to obtain the minimum asphalt content for having complete asphalt coating on aggregates. This trial and error procedure of visually evaluation of the coating of aggregates by certain asphalt content is also recommended in previous research (Kennedy et al. 1984). Asphalt content of $1.5 \%$ found to be the minimum rate at which a thoroughly coating could be achieved. Figure 3-7 illustrates a comparison among the different scenarios of asphalt contents developed for the three types of aggregates. However, it was observed that above a specific rate, adding to asphalt content has limited effect on coating retained on aggregates after boiling test.

The suitable (optimum) percent of asphalt content in this study was defined to be the minimum amount of asphalt bitumen that firstly provide full coating for the aggregates, and secondly above which no significant coating retained is achieved for the samples tested in boiling test. According to the above criteria and observation the minimum desirable asphalt content was set to be the bending point of curves in Figure 3-7, after which the rate of coating retained is almost constant. This value for all three types of 
aggregate set to be $1.75 \%$ (a little above the minimum value for full coating) as a common criterion of asphalt content in all asphalt-aggregate mixtures in this study.

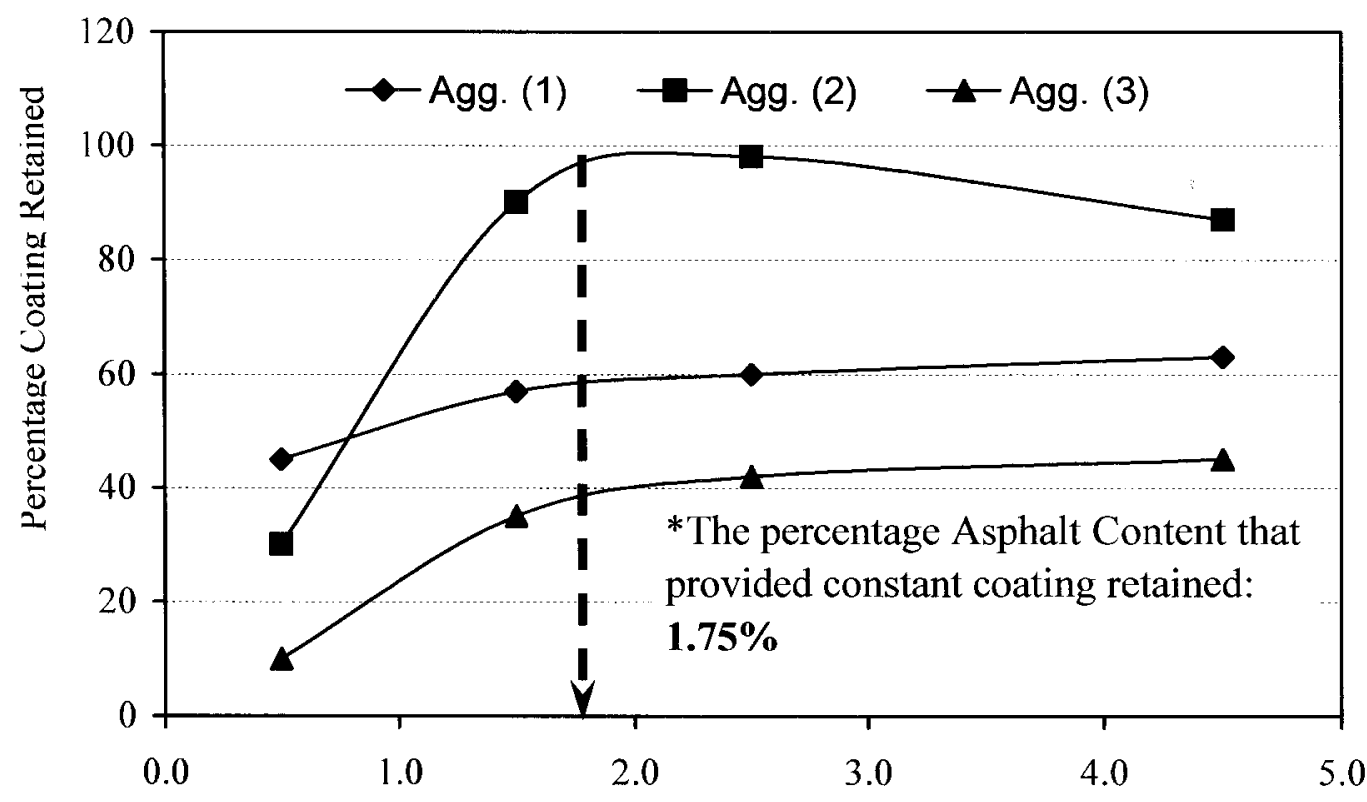

Percentage Asphalt Content in Trial Mix

Figure 3-7: The effect of different asphalt contents on the percentage coating retained on the asphalt asphalt-aggregate mixture.

\subsubsection{Boiling Water Test on Raw Materials}

Testing Procedure: The original test protocol given by Kennedy et al. (1983) differs in some details from what given in ASTM D3625. The process followed in this thesis is adopted from a combination of both sources with some minor changes, so that the original concepts of the sources are maintained. A concept of imposing some modifications to the test was to further pronounce the rate of stripping and getting a wider spectrum of coating retained. Previous research shows that increasing the severity of 
conditioning and duration of boiling enhances the effectiveness of Boiling Test. (Hefer, and Little 2005). The variables altered were boiling time, and the intervals of stirring the boiling mix and skimming off the floating bitumen. The panel of observers were also limited to only one person, and the percentage of coating retained was considered to be the ratio of number of pebbles that received full coating to the number of pebbles with one or more stripped face(s) after conditioning. Furthermore the asphalt bitumen was preheated to $163 \pm 2.5 \mathrm{C}$ before mixing with aggregates. Aggregates also were washed (to remove their surface dust and fines) and preheated to $163 \pm 2.5 \mathrm{C}$ for two hours. After blending the hot aggregates and introduced bitumen at desired asphalt content, the mix was allowed to cool at room temperature for one hour. A $1000 \mathrm{ml}$ beaker containing distilled water was brought to boiling temperature using an electrical laboratory hot plate. The mixture was then placed into the beaker. It was controlled that the distilled water maintained the boiling status before and after the mixture was placed into the beaker. A glass rod was used to stir the submerged mixture every one minute. Skimming the floating asphalt bitumen off the boiling water was also repeated in one-minute intervals to avoid any possible recoating. This process continued for 10 minutes for the first trial. Further trials with different boiling periods were performed which is discussed in the following section. The water was decanted after the submerged mixture was cooled to room temperature. The stripped mixture, if any, was rated based on counting the pebbles that had lost coating on more than one face. A percentage scoring system was developed as the test progressed that was used as a control method for checking the evaluation of percent coating of mixture after conditioning. The general accuracy of evaluation of percent coating retained was about $\pm 5 \%$. 
Setting the Boiling Duration: In order to calibrate the boiling water test process with the aggregates and bitumen conditions, the effect of duration of boiling process was also examined. In order to adjust the optimum boiling period for these mixtures, a series of boiling test repeated for $5,10,15,20$, and 30 minutes. It was observed that after a certain boiling duration, rate of coating retained did not change dramatically. These rates for on untreated mixtures of aggregates (1) and (3) were 18 and 15 minutes corresponding to $35 \%$ and $63 \%$ coating retained respectively. However, the effect of boiling duration was not meaningful for the aggregate (2) for which the normal 10-minute boiling duration was set to be as recommended in the ASTM D3625 standard that corresponds to $90 \%$ coating retained. It was also observed that all three aggregates might reach a dramatically lower level of stripping in a very severe environmental condition (boiling more than 40 minuts or so).

The results of calibration process are given in Figure 3-8. 


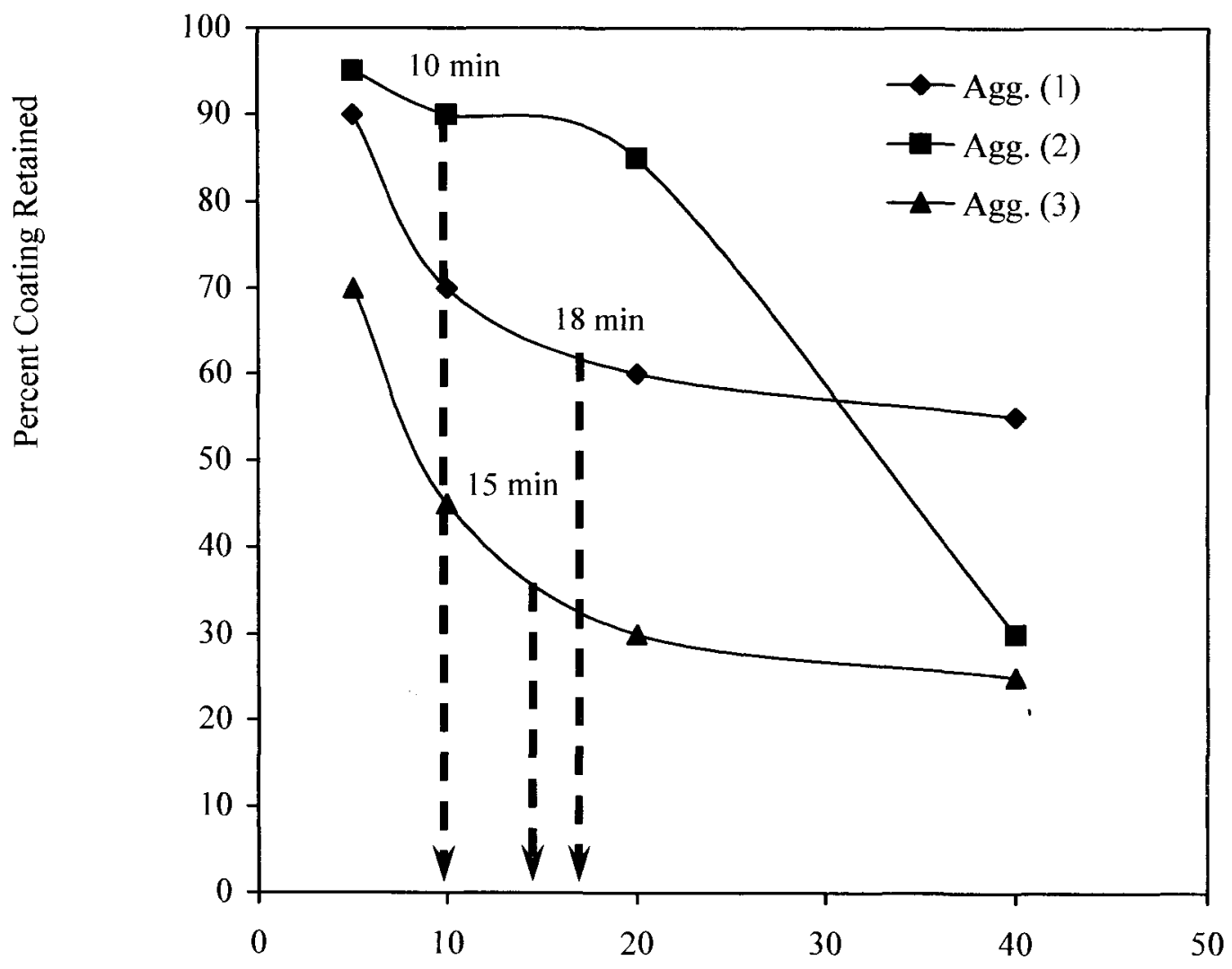

Duration of Boiling (minutes)

Figure 3-8: The effect of boiling duration on the percent coating retained on asphalt-aggregate mixtures. 


\subsubsection{Static Immersion Test on Raw Materials}

Testing Procedure:

Static immersion test was also conducted as a control test on the observations of Boiling Water Test. The procedure of AASHTO-T182-845 (2005) was followed. However, similar to the boiling water test, some minor changes were considered to make the test more compatible with the conditions of this study. For mixing purpose 100grams of aggregates retained on sieve number 4 and $3 / 8$ inch (size between $4.75 \mathrm{~mm}$ and $13.2 \mathrm{~mm}$ ) were mixed with bitumen corresponding to the optimum asphalt content $(1.75 \%)$ and cured at $60 \mathrm{C}$ for 2 hours. The mixture after cooling down to the room temperature was placed in a $600 \mathrm{ml}$ beaker containing distilled water at $25 \mathrm{C}$. After 18 hours the floating bitumen was cleared off the surface of distilled water and the conditioned loose mix was inspected under illumination while still submerged. Percentage of mixture stripped was evaluated. Mixtures received less than 95\% coating retained considered stripped and failing, and mixtures of $95 \%$ or more coating retained considered passing (not-stripped).

\section{Test results of static immersion test}

Figure 3-9 shows the results of static immersion test for three aggregates at optimum asphalt content. The results were consistent with the boiling water test, showing fail (susceptible to stripping) score for aggregates (1) and (3), and pass score for aggregate (2). 


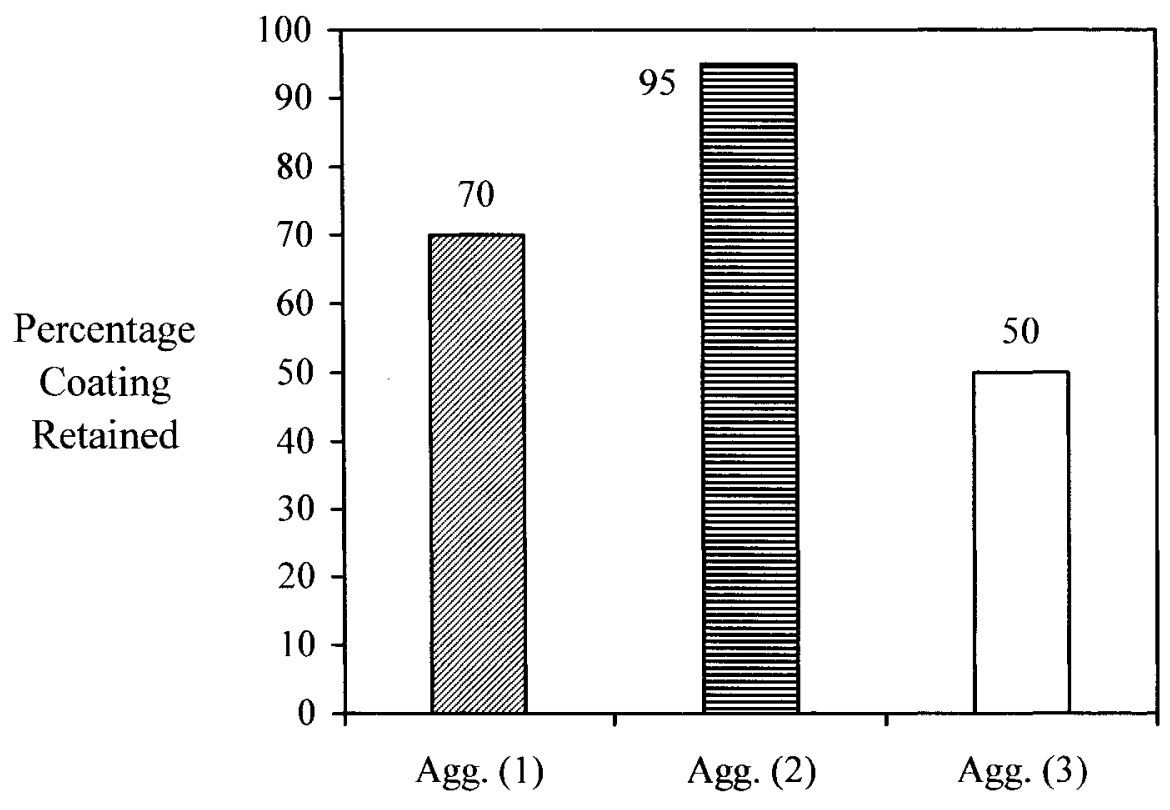

Figure 3-9: Results of the static immersion test on three types of aggregates.

\subsection{9 pH Test}

It is recalled from the literature review that $\mathrm{pH}$ of contact water can significantly influence the electrophoretic characteristics of aggregates in their aqueous interface. In order to evaluate the applicability of this hypothesis in this study a series of $\mathrm{pH}$ measurements were performed on all three types of aggregate powders in the following procedure. 
Process of $\mathrm{pH}$ measurement was as following. $\mathrm{pH}$ of distilled water in a $100 \mathrm{ml}$ beaker was read using a pH-meter available in the environmental lab of Carleton university (Figure 3-10).

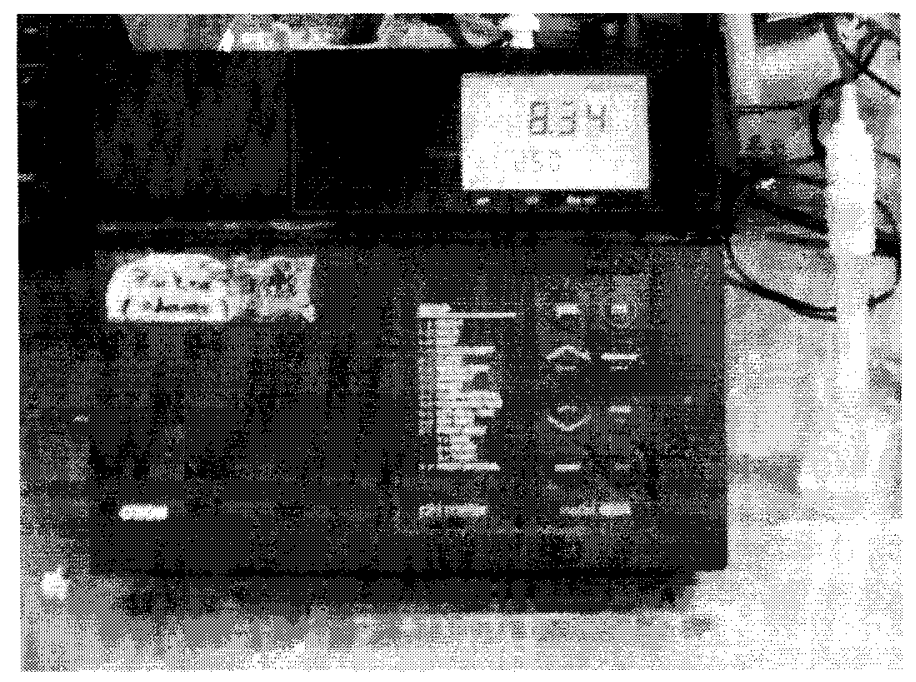

Figure 3-10: The pH meter instrument.

Forty gram of powdered aggregates of each type (passed sieve 325) was mixed with $40 \mathrm{ml}$ distilled water in a 1:1 ratio, resulting in a relatively thick suspension. The aqueous mix was stirred for 30 seconds every three minutes for five stirring/waiting intervals until the soil and water were thoroughly mixed. Then the mix was allowed to settle until a supernatant formed. The $\mathrm{pH}$ was then recorded using the $\mathrm{pH}$ meter every three minutes. The results are shown in Figure 3-11. 


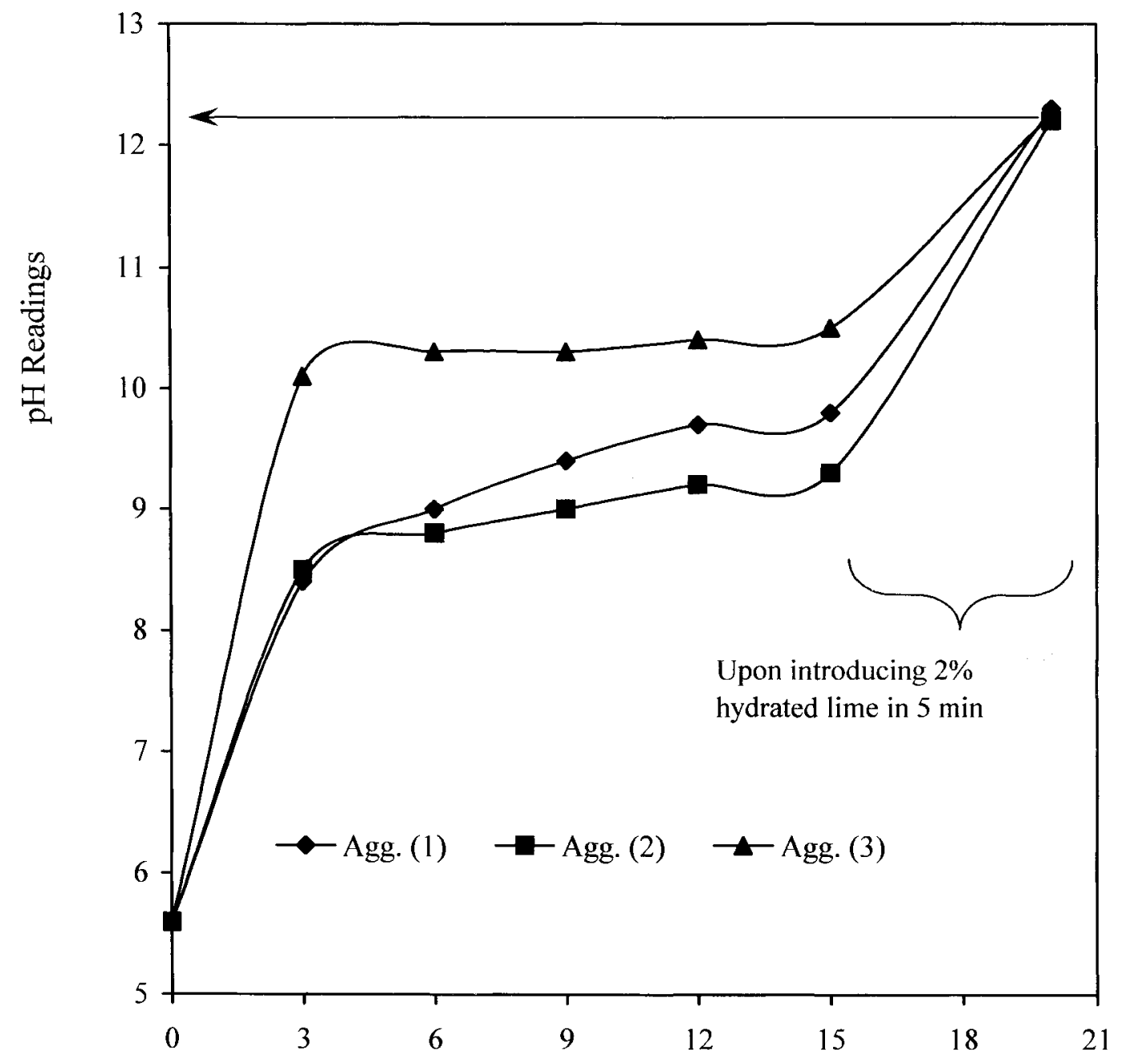

Stirring Time (minutes)

Figure 3-11: Record of pH meter for diluted powdered aggregates in three minutes interval readings. 


\subsubsection{Test Results Analysis}

Phase one was basically designed to give an assessment of the materials acquired for this study and to evaluate their compatibility and suitability with the requirements of intended tests. During the first phase of this experimental study, materials were selected, characterized, and their physicochemical properties were determined as well. Aggregate test methods and settings were also calibrated to meet the comparative requirements of the study and a corresponding mix design was devised accordingly. The highlights of findings in this phase can be summarized as follows:

- Given the fact that each type of materials, in overall, exhibited a relatively different mineral composition and propensity to stripping, material acquisition from the three sources has been successful; this has worked toward a relatively wider spectrum for comparing the change in propensity/resistance to stripping of each type of aggregates.

- Aggregates (1), (2), and (3), exhibited close physical properties especially in terms of grading, which is in favour of this study. This minimizes the factor of surface area that can be an issue when comparing rates of stripping for different sources of materials; The only pronounced difference among the aggregates is their water absorption rate.

- Results of XRF and petrographical examination were both in agreement with each other, giving similar picture of mineral composition of each group of aggregates. These test results showed that amount of silica and alkaline oxides in the mineral composition of stone materials have a critical role in their performance upon 
moisture damage. Aggregate (1) having moderate amount of silica $\left(\mathrm{SiO}_{2}\right)$ and $(\mathrm{CaO}+\mathrm{MgO})$, revealed to be a dolomitic sandstone being known also as a fairly susceptible to stripping aggregate according to field experience. Aggregate (2) having high amount of alkaline earth oxide, and much less amount of silica was a non- susceptible to stripping limestone and was used as a control aggregate in this study; Aggregate (3), an igneous granite, with abundant amount of silica and little alkaline oxides also known to be a highly susceptible aggregate according to the field experience.

- The rate of asphalt content in the asphalt-aggregate mixtures was set to be $1.75 \%$ for all three aggregate types; this criterion found to be consistent and rationally working for the rest of test trials.

- Duration of boiling water test calibrated and was set to be $18 \mathrm{~min}, 10$, min and 15 min for aggregates (1), (2), and (3) respectively; it was observed that at this duration aggregates exhibited their approximate resisting capacity of stripping.

- Results of boiling water and immersion tests were in agreement. Both tests showed that aggregate (2) is not a stripper, while aggregate (1) and (2) strip when exposed to severe conditions; boiling water test revealed that propensity to stripping of aggregate (3)- being a silica-rich granite- is higher that of aggregate (1) having less silica and more alkaline oxides in its minerals.

- Results of $\mathrm{pH}$ test revealed that all three types of aggregates tend to increase the $\mathrm{pH}$ when exposed to water; the rate of $\mathrm{pH}$ reaches its maximum in the first 10 minutes of contact with water; alkaline nature of aggregates (2), being a limestone, seems to be logical due to its alkaline and electropositive nature; while, 
high $\mathrm{pH}$ of aggregate (2) and especially aggregate (1) can be explained with regards to their earth alkaline oxides and sodium oxides components (Table 3-3); according to the literature review (2) these oxides also yield in high $\mathrm{pH}$ regardless of the initial nature of the aggregates.

- Adding lime to the aqueous powder of all three types of aggregates increases the $\mathrm{pH}$ rapidly to a higher value; this value is interestingly unique for all aggregates; an indication can be that above a specific alkaline saturation rate, the electronegative silica components or other impurities are totally defused and inactive, upon receipt of more calcium cations $\left(\mathrm{Ca}^{++}\right)$the aqueous powdered aggregates will be stabilized in a higher, but almost equal $\mathrm{pH}$ rate. 


\subsection{PHASE (II) Examining Lime Treated Materials}

Phase two of this study is designed to investigate the effects of treatment of aggregates surface on their surface potential and stripping resistance. Lime-based additives considered in this study include "Hydrated Lime" and "Quick Lime". A mix design was devised to obtain the optimum rate of application of additive to the mixture. Change in the rate of stripping (coating retained) was investigated through boiling water test and checked with static immersion test for the most promising method of treatment. Zeta potential of raw materials and lime treated aggregates were also determined at the most promising rate of application of lime additive(s).

\subsubsection{Lime Treatment Scenarios and Mix Design}

In order to find the optimum treatment ratio, slurry hydrated lime and quick lime were added to the aggregates in different rates of $0.5 \%, 1 \%, 2 \%, 3 \%$, and $4 \%(\mathrm{w} / \mathrm{w})$ by weight of aggregates. Hydrated lime was applied in slurry form. Slurry lime was made by combining distilled water to white powder of hydrated lime in a $4: 1$ ratio (weight percentage) as recommended in previous research (Kennedy et al. 1986, Stroup-Gardiner and Epps 1987, and others). Since granite aggregate (aggregate (3)) had exhibited the most pronounced rate of stripping in this test, this trial treatment was only conducted on granite aggregates. Slurry hydrated lime was added to washed and dried aggregates, while quick lime was added to newly washed and wet aggregates. It was noticed that slurry hydrated lime thoroughly coated the aggregates pebbles, while quick lime did not provide an equal coating for all aggregates surfaces (specially in lower rates of application). While adding the quick lime to wet aggregates, quick lime excessively 
reacted with the moisture in the aggregates surface, producing heat. Test results of coating retained after water boiling test are discussed in the next section. Similar details were reported in the other studies (Stroup-Gardiner and Epps 1987).

\subsubsection{Boiling Water Test}

The optimum rates of application of lime for hydrated lime and quicklime were defined as the rates of adding lime above which aggregates would receive no significant improvement in the boiling water test. In other words, above this rate additional lime has no improving effect on stripping propensity of aggregates. The trial for determining the optimum rate of lime was applied for aggregate (3). Limed aggregates remained 24 hours in the room temperature and then were heated to $163 \pm 2.5 \mathrm{C}$ for two hours. Heated limed aggregates were then mixed with bitumen (also already preheated to $163 \pm 2.5 \mathrm{C}$ ) in due optimum asphalt content rate of $1.75 \%$ and were cooled to the corresponding rates of coating retained were recorded for different lime additives in the above-said dosage using boiling water test. Figure 3-12 shows the results. The optimum rates of application of lime for hydrated lime and quicklime were found to be $2 \%$ and $1 \%$ respectively. Since it was observed that above these rates no significant improvement is observed for percent coating retained. Aggregates (1) and (2) were also treated at the above-said most promising dosages (i.e. $2 \%$ and $1 \%$ for hydrated lime and quick lime respectively). The results are given in Figure 3-13. It was observed that similar to the case of aggregate (3), hydrated lime caused more coating retained on aggregates (1) than did quick lime. Effects of adding hydrated lime and quick lime to aggregate (2) were almost equal and not as dramatic as aggregates (1) and (3). 


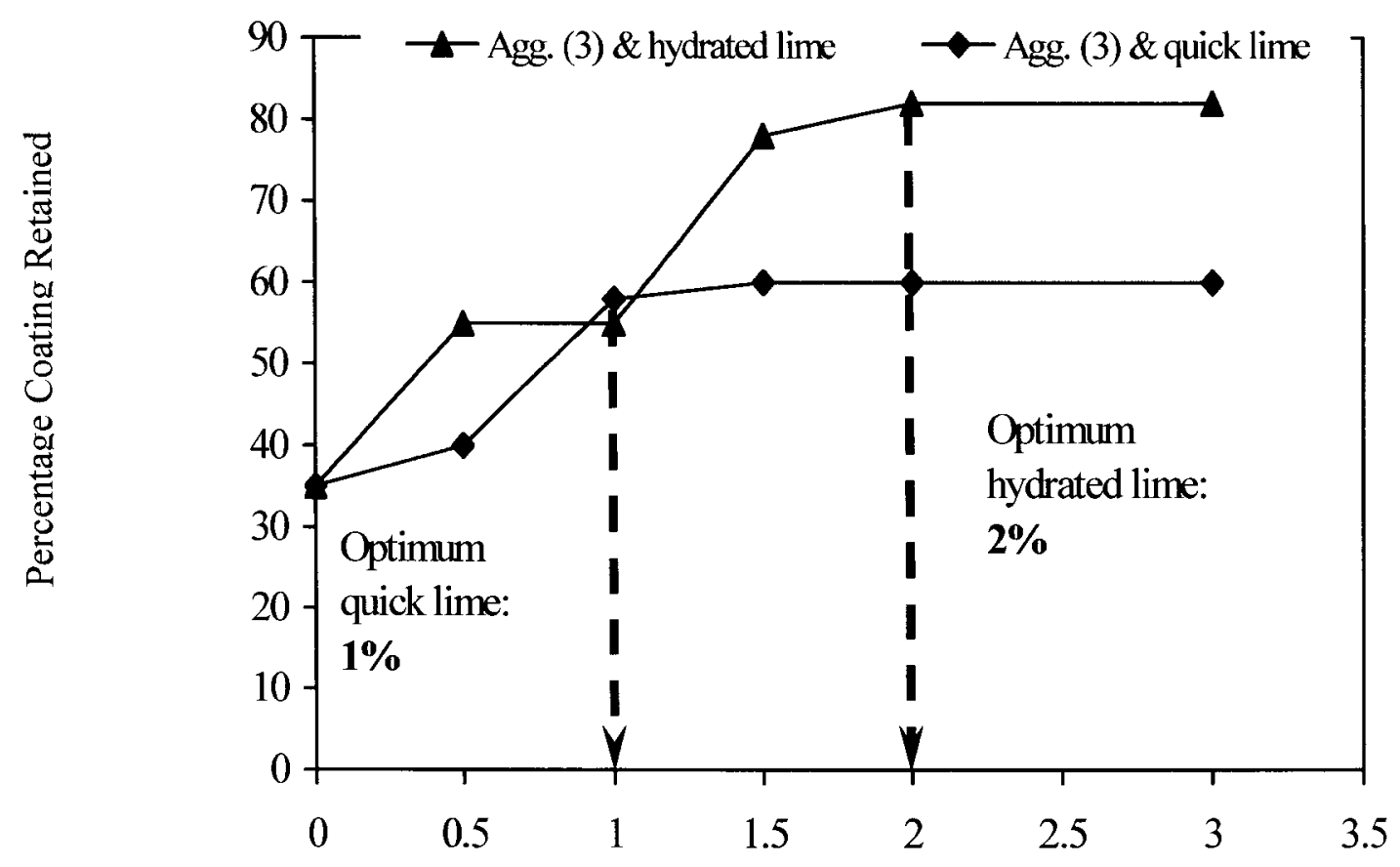

Percentage Lime Added to the Trial Mix

Figure 3-12: The effect of different percentage of lime-based additives on the percentage coating retained on aggregate (1) in the boiling water test. 


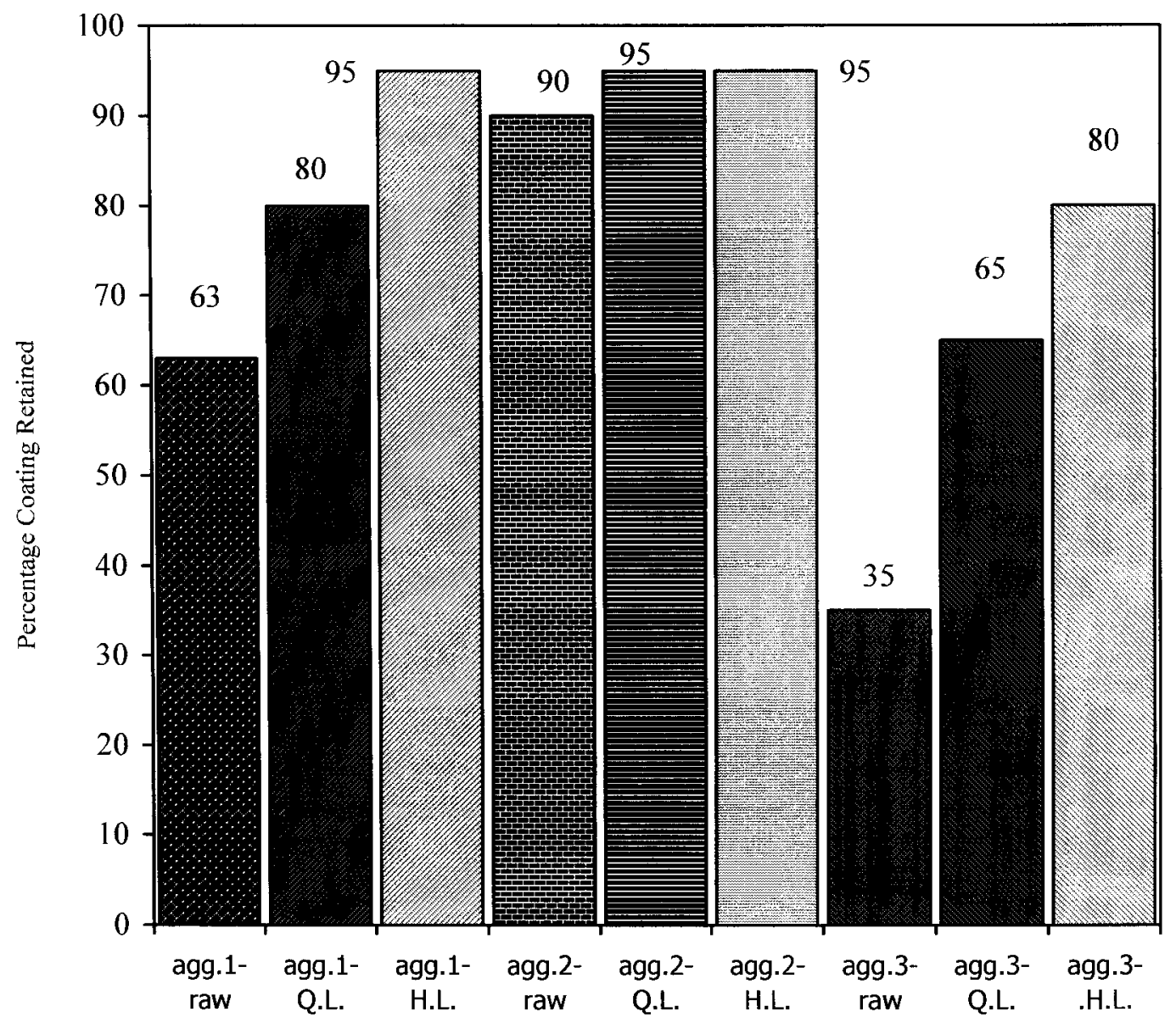

RAW: Untreated mateials; H.L.: Hydrated Limed; Q.L.: Quick limed

Figure 3-13: The effect of adding hydrated lime and quick lime on the percentage coating retained on aggregates (1), (2) and (3) in the boiling water test. 


\subsubsection{Static Immersion Test}

Only aggregates (1) and (3) were tested for the purpose of static immersion test. Samples were treated according to the process outlined in this phase (section 3.3.1 and 3.3.2). Treated aggregates were then prepared for static immersion test similar to the procedure of phase I (section 3.2.8) and tested similar to boiling water test as explained in the above. Quick lime and hydrated lime treated loose samples were then scored based on percent coating retained of below or above $95 \%$. A comparison of passing and/or filing treated and untreated samples is given in Figure 3-14. 




RAW: Untreated materials; H.L.: Hydrated Limed; Q.L.: Quick limed

Figure 3-14: Graphical comparison of treated and untreated samples in static immersion test.

\subsubsection{Zeta potential Measurements}

Zeta potential of the powdered aggregates of all three types were also measured before and after lime treatment. Zeta potential measurements were conducted using a ZetaPlus zeta potential Analyzer (BROOKHAVEN MODEL, available in the Department of Chemistry of McGill University, Montreal). Figure 3-15 shows the instrument used to measure the zeta potential readings in this study. The software attached to the system was able to calculate and convert the measured electrophoretic mobility (or conductance, Siemens) to zeta potential (volt) for suspension colloids. 


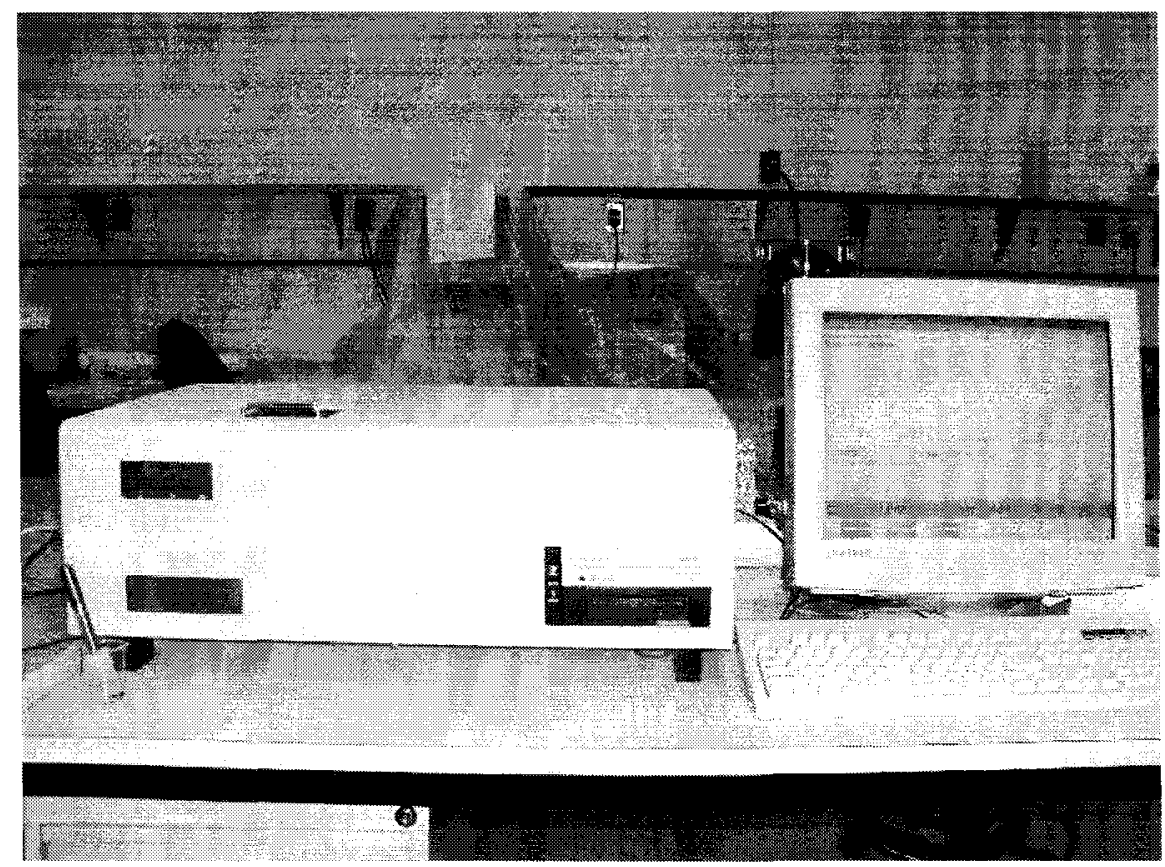

Figure 3-15 Zetaplus zeta potential analyzer (Brookhaven Model).

\section{Sample Preparations:}

In this case aggregates were pulverized down to 45 micron (passing sieve 325 ) and mixed in distilled water as the base solvent liquid for colloidal suspension. Three sets of powdered aggregates were tested, untreated powdered aggregate, quick lime treated powdered aggregates, and hydrated lime treated powders. Quick lime and hydrated lime were both introduced in form of dry powder to aggregates powder in the optimum rate of 
mix design ( $2 \%$ and $1 \%$ for hydrated lime and quick lime respectively). According to the literature review presence of water is required for the occurrence of pozzolanic reactions and cationic exchange between rock siliceous elements and calcium cations. To simulate the role of water, the blends of limed powders were cured in a small steam bath. The ambient temperature was controlled and kept down to room temperature (about 25C) with placing ice cubes adjacent to the bath container. This was done for both quick lime treated and hydrated lime treated samples.

\section{Zeta Readings:}

Zeta potentials of untreated raw materials of each type were first quantified; this was followed with measurements for treated blends. Zeta potential readings were repeated for three batches of each aggregate type. In each batch ten runs were performed, and for each run almost three cycles of trial and error were reported. For each reading of zeta potential due to a specific treatment average of 60 to 90 readings were processed to ensure the reliability of the measurements. Samples of calculations and reading data sheets together with the basic statistical assessment are given in the Appendix "A". Relatively small standard errors of measurements show a good precision and high reliability of zeta potential readings.

Zeta Potential Results for Treated Rock Powders:

Average zeta potential readings for untreated powdered aggregates together with the lime treated aggregates are shown in the Table 3-4. The summary of results is also depicted in Figure 3-16. The results interestingly illustrate that Agg. (1) being a fairly stripper aggregate, exhibits relatively moderate negative zeta potential $(-11.6 \mathrm{mV})$, while 
aggregates (2) being a non-stripper and (3) being a stripper, on the two extreme, show $+15.3 \mathrm{mV}$ and $-30.5 \mathrm{mV}$ zeta potentials respectively. This is well coincides with previous expectations from the electrostatic nature of these rocks in the literature review.

Table 3-4: Average of weighted means and standard errors of zeta potential readings for untreated and lime treated powdered aggregates.

\begin{tabular}{|c|c|c|}
\hline \multicolumn{1}{|c|}{ Zeta Potential } & $\begin{array}{c}\text { Average of } \\
\text { Weighted Means } \\
(\mathrm{mV})\end{array}$ & Standard Errors (mV) \\
\hline Agg. (1)- Untreated & -11.65 & 1.25 \\
\hline Agg. (2)- Untreated & 15.30 & 2.16 \\
\hline Agg. (3)- Untreated & -30.49 & 4.17 \\
\hline Agg. (1)- Quick Limed & -10.10 & 0.76 \\
\hline Agg. (2)- Quick Limed & 18.55 & 0.87 \\
\hline Agg. (3)- Quick Limed & -24.35 & 3.25 \\
\hline Agg. (1)- Hydrated Limed & -9.20 & 0.87 \\
\hline Agg. (2)- Hydrated Limed & 18.86 & 0.49 \\
\hline Agg. (3)- Hydrated Limed & -23.77 & 2.95 \\
\hline
\end{tabular}




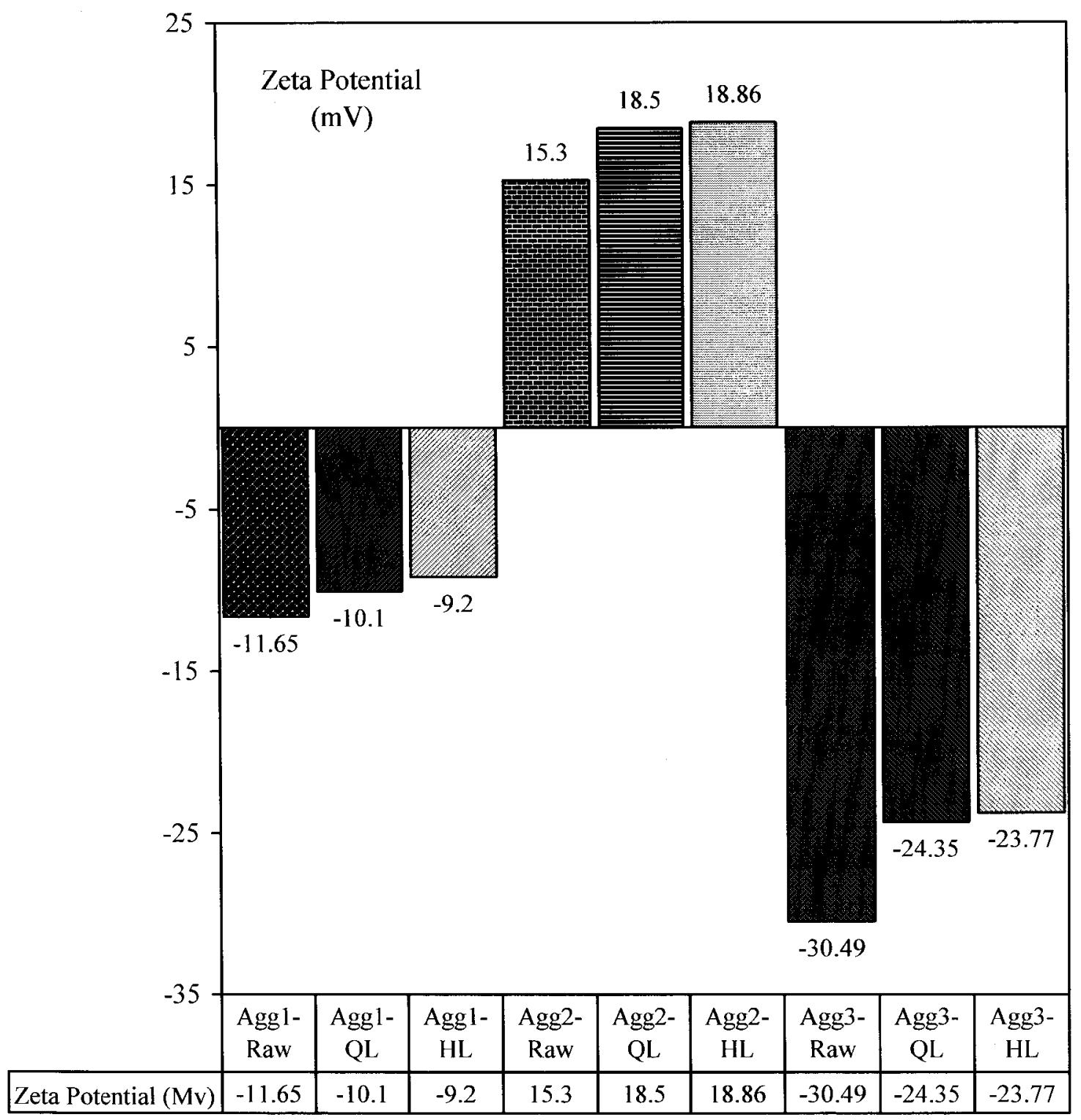

Raw: Untreated materials; Q.L.: Quick Limed; H.L.: Hydrated limed.

Figure 3-16: The effect of hydrated lime and quick lime on Zeta potential of

pulverized aggregates. 
Aggregate (3) was also tested for another setting to investigate the effect of different rates of application of hydrated lime on the powdered aggregates. It was observed that as the rate of application of hydrated lime increased, the negative zeta potential of rock powder decreased and at high rates of application it appeared as positive zeta potential apparently changing the nature of aggregates from siliceous to calcareous. Results are shown in the graph of Figure 3-17.

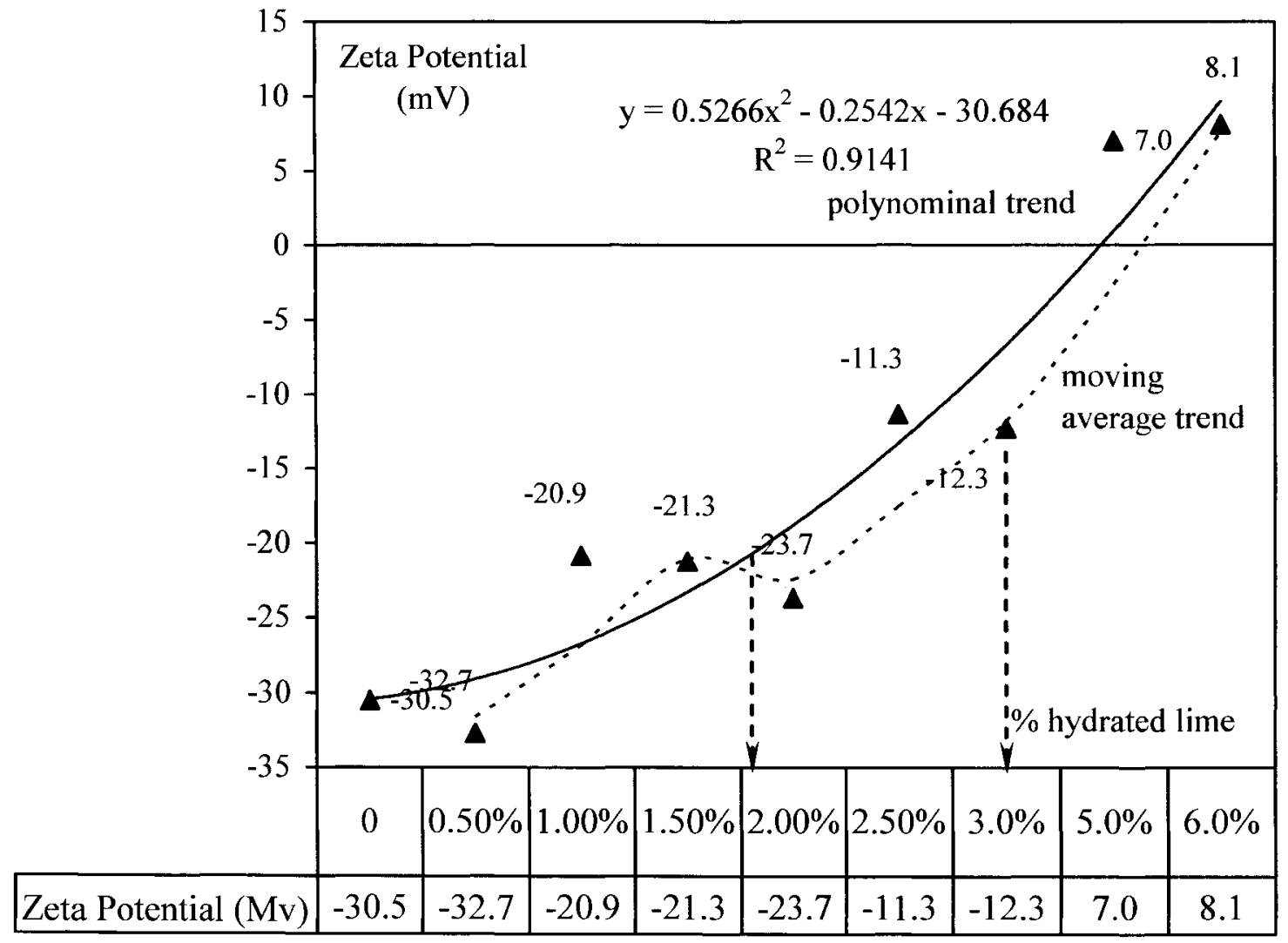

Figure 3-17: The effect of different dosages of hydrated lime on Zeta potential of powdered aggregate (3). 


\subsubsection{Test Results Analysis}

The purpose of this phase has been to implement the different settings of lime treatment and evaluate the effect of treatment and rate of response to lime-based additives by each type of aggregates. At the first step, different treatment scenarios were developed for both quicklime treatment and hydrated-lime treatment. Level of effectiveness of treatment for samples were evaluated with boiling water test, and checked with immersion tests. Powdered aggregates were also assessed before and after similar treatment in terms of change in their zeta potential value as a characteristic representing their propensity to stripping. The summary of findings and discussions on the above sets of tests is given as follows:

- It was observed during the setup for optimum percent of lime that however improvement of coating retained was observed for all samples, no significant improvement in coating retained was achieved for above $2.0 \%$ application of hydrated lime. This rate for quick lime was about $1.0 \%$. One indication of this observation is that higher rates of lime do not necessarily benefit the HMA, and that the optimum rate of application is surface area specific.

- Another observation was that except for one treatment settings (i.e. at $1 \%$ lime added), slurry hydrated lime caused higher coating retained than did quick lime, while for the rest of lime percentages, hydrated lime resulted in more coating retained. The latter is in agreement with the findings of previous research (Taylor and Khosla 1983, Kennedy et al. 1984, Lee and -Jarallah 1096, Stroup-Gardiner and Epps 1987, and Parker and Wilson 1986). 
- Results of boiling water test revealed that lime treatment definitely improve the resistant to moisture damage of aggregates regardless of their chemical composition; however the rate of improvements is more pronounced for the aggregates containing more $\mathrm{SiO}_{2} \%$. Aggregates (1), (2), and (3) that were have been rated as fair, good, highly stripper based on their percentage coating before lime treatment all received a better rate of coating retained; this improvement, however, in some cases (especially when treated with quick lime) was not significant enough to improve them to a better level of resistance to stripping as described in the boiling water test.

- Results of static immersion test however in agreement with the result of water boiling test for aggregate (1) but still showed a failing score for aggregate (3) even after being treated for either types of lime treatments. This test was incapable of evaluation of effectiveness of different treatment methods; all treated samples were failed according to its passing/failing single criterion.

- The results of zeta reading were consistent with the general expectation of the nature of these aggregate (3) (which is of granite type) and due to their field performance.

- However, the level of zeta readings for the granite raw was (about $-5 \mathrm{mv}$ ) less than that available from zeta readings in other studies (Yoon and Tarrer 1988, and Hefer and Little 2005); this probably is directly related to the different percentage of $\mathrm{SiO} 2$ or other involving impurities in the mineral composition of those granite aggregates than the one tested in this study. The zeta reading for raw limestone was positive in this study while small negative or zero zeta potential values were 
reported by the same previous sources as above. The general trend of zeta readings is in compliance with other findings though. The mentioned difference is due to the wide variation in elemental composition of each rock types sampled from different sources.

- Lime improvements either in quicklime or hydrated lime treatment alleviated the negative surface potential of all samples. This indicates that lime treatment modifies the aggregates through defusing their negative surface potential.

- Rate of reduction in negative surface charge (or increase in positive charge in case of aggregate (2)) was more pronounced when hydrated lime was used, which is in agreement with the results of water boiling test.

- Another significant postulation exists for treatment of aggregate (3) when different rates of hydrated lime is applied (figure 3-17). It was observed that upon adding $5.5 \%$ more hydrated lime to the powdered aggregate (3), its zeta potential decreased about $40 \mathrm{mv}$ (from -30 to +10 ). This observation is discussed as followes. It is recalled from the literature review that if concentration of calcium cations $\left(\mathrm{CA}^{++}\right.$becomes dominant in the $\mathrm{CSH}$ interface, positively charged calcium cations control the electrophoresis character of the CSH. A similar postulation can be adopted when high amount of hydrated lime (above the optimum rate of $2 \%$ as given in mix design e.g. $2 \% \sim 3 \%$ ) is introduced to the powdered aggregate (3). Active calcium cations react with negatively charge $\mathrm{SiO}^{-}$ anions. When the negative charges in the interface are (almost) totally neutralized and upon advent of more $\mathrm{Ca}(\mathrm{OH})_{2}$ to the solution, concentration of calcium cations increases in the CSH system. This normally yields in the over saturation 
of quartz particles by alkaline particles. As a result of this occurrence, positive potential charges defuse the majority of initial negative charges on the silica gel surface, and the extra $\mathrm{Ca}^{++}$change the zeta potential to positive values. further progression is upon the availability of cations. Accordingly, in such a condition, $\mathrm{pH}$ is also expected to increase in the aqueous interface. 


\subsection{PHASE (III) Examining Cured Lime Treated Materials}

It is recalled from the literature review that the rate of hydration of lime particles in soil stabilization is enhanced in hot and moisturized conditions. Both conventional and advanced research on the technology of curing autoclaved aerated concrete blocks or autoclaved calcium silicate bricks reveal that curing is a substantial stage in improving the characteristics of $\mathrm{CSH}$ products. The main purpose of this phase was to investigate the applicability of the same concept to the process of treatment of siliceous aggregates. A series of experimental trials were considered to evaluate the effect of temperature and pressure on the process of lime treatment on aggregates. These curing scenarios are explained in the following section.

\subsubsection{Curing Scenarios}

Effect of curing process was only investigated on aggregate (3) (granite), having the highest percentage of silicate content. Curing including increasing the temperature and pressure was considered in a matrix setting. Temperature was considered to be elevated in $50 \mathrm{C}$ intervals, ranging from $25 \mathrm{C}$ to $275 \mathrm{C}$, and pressure was control in only three different settings, being normal pressure ( $0 \mathrm{psi})$, low pressure (100psi), and high pressure (300 psi). Further trials in other pressure intervals were not practical due to the technical difficulties with adjusting the industrial autoclave used in this study. Samples cured for six hours in controlled pressure and temperature conditions. Curing trials in setting of normal pressure were done in conventional dry oven with externally induced steam to the system (simulating the steam autoclaving in zero pressure). Curing trials in 100psi and 300psi were conducted in an industrial autoclaved in National Research Council Canada 
- Institute for Research in Construction (NRC-IRC). The equipment is shown in Figure $3-18$.

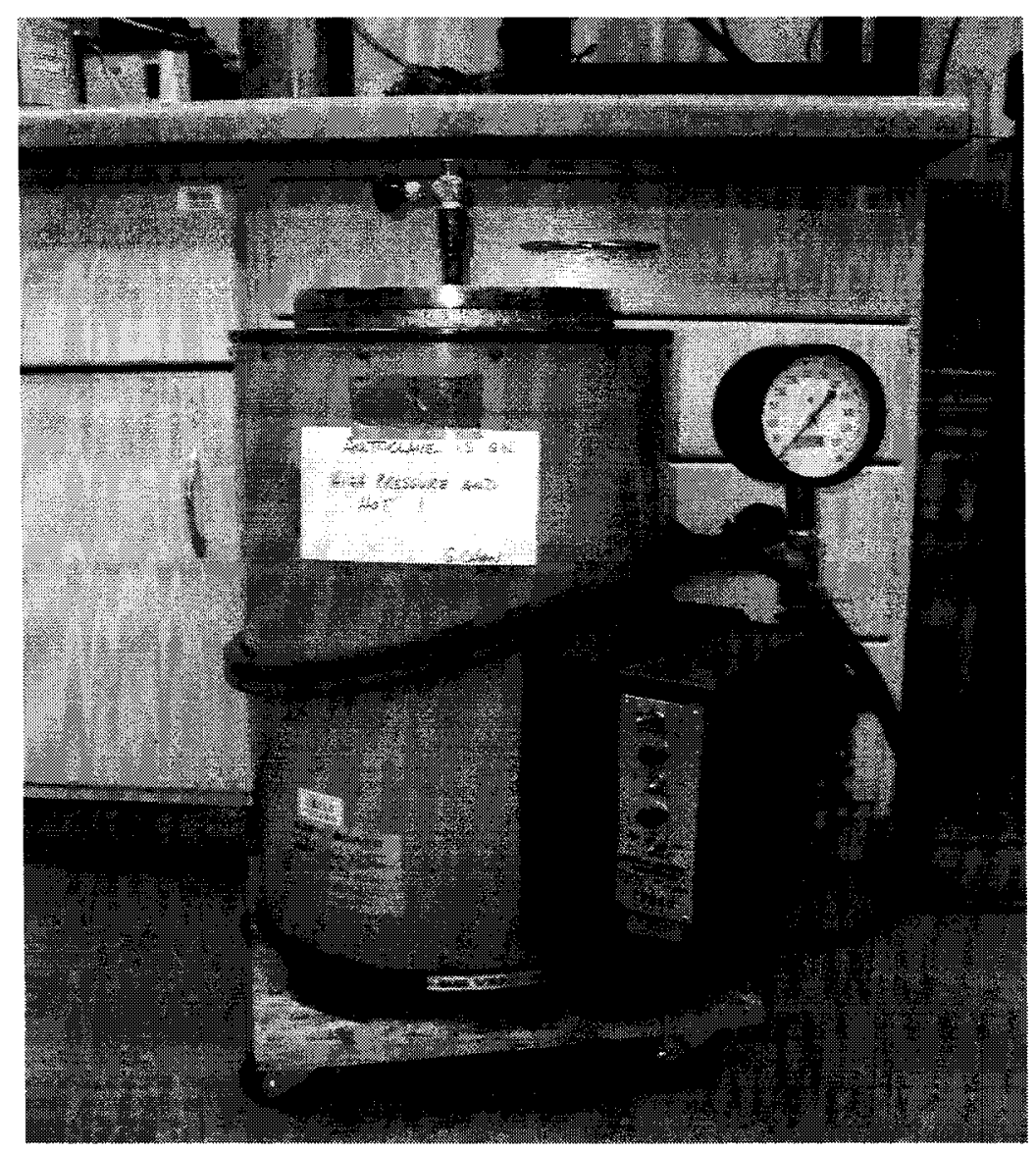

Figure 3-18: Steam autoclave with variable temperature and pressure settings.

In order to investigate the effectiveness of microwave curing as reported by previous research (Al-Ohaly and Terrel 1988), another experimental trial was performed. Zeta potential of untreated powder of aggregates (treated with hydrated lime at $2 \%$ ) was assessed after microwave-curing in two different setting of long (15 minutes) and short period (5 minutes) in saturated conditions. Curing was performed using a conventional 
microwave, and steam produced with a cup of water in the microwave container. Curing temperature was measured to be about $125 \mathrm{C}$ after the curing time elapsed.

\subsubsection{Results of Water Boiling Test for Cured Limed Materials}

Samples of aggregate (3) were prepared and treated according to the procedure described in phase I (section 3.2.8), phase II (section 3.3.2) of this study. The real pebbles of granite aggregates were then cured according to the curing process as outlined above in phase III (section 3.4.1). Percent coating retained of the limed aggregates was determined after curing. The results are graphically compared against each other in Figure 3-19.

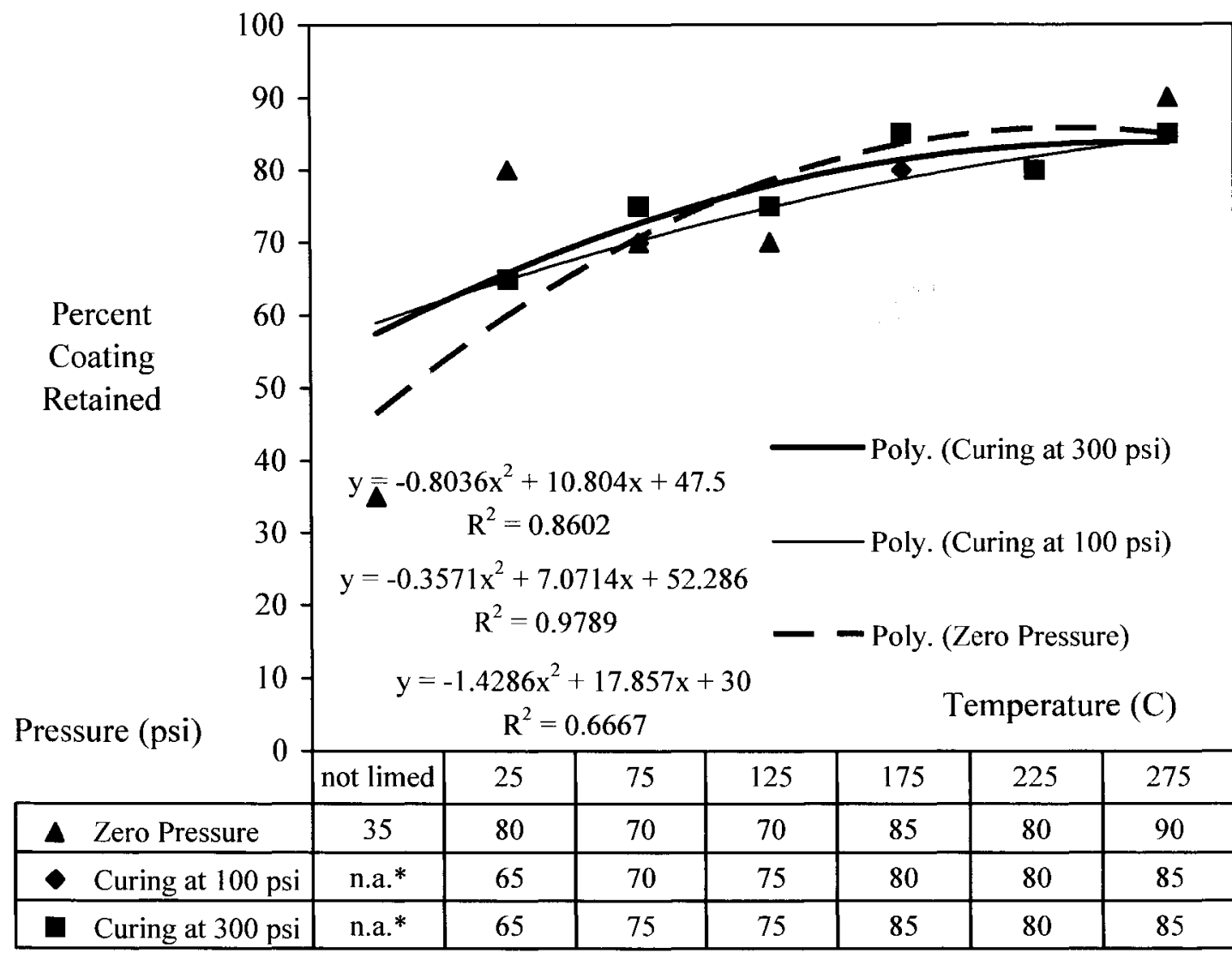

* n.a. Data Not available.

Curing Matrix

Figure 3-19: The effect of temperature and pressure on the percent coating retained on aggregate (3) treated by hydrated lime in different temperature. 


\subsubsection{Static Immersion Test}

The static immersion test was performed on aggregate (3) and for four settings of temperature and pressure only (temperature of $75 \mathrm{C}$ and $175 \mathrm{C}$, and pressure of 0 and 300 psi). Aggregate samples were treated, and cured similar to the procedure described in phase II (section 3.3.2), and phase III (section 3.4.1), and prepared for immersion test according to the process outlined in section 10-2 of this study. Only hydrated lime treated aggregates were cured according to the process described in phase I (section 3.2.8). The loose aggregate samples were then scored based on the percent coating retained of below or above $95 \%$ single criterion. A comparison of passing and/or failing criterion for treated and untreated samples is given in Figure3-20.

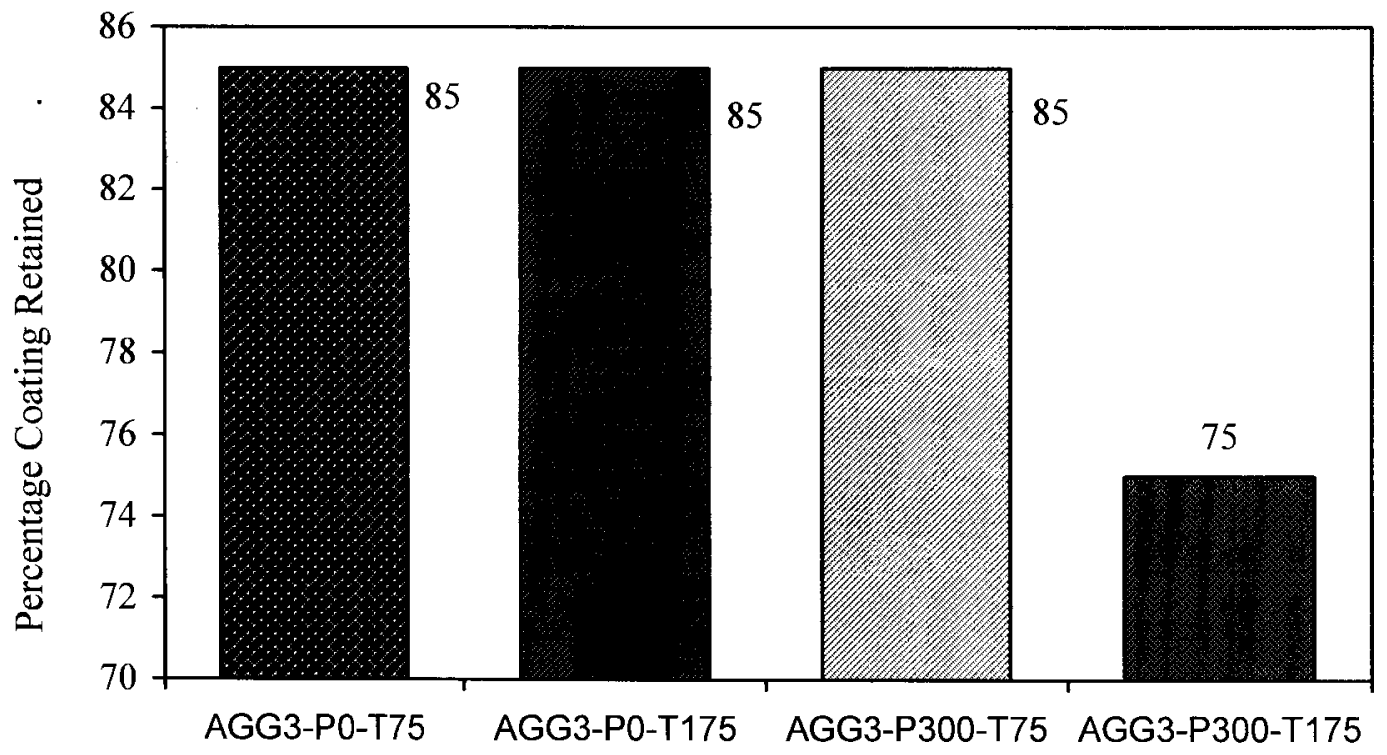

P: Pressure - psi and T: Temperature- Celsius

Figure 3-20: The effect of curing in different pressure and temperature settings on percent coating retained in the static immersion test for Aggregate (3) treated with hydrated lime. 
The results of immersion test did not show any meaningful relationship between the effects of curing and improvement in resistance to stripping for aggregate (3). None of the samples could even pass the threshold of acceptability ( $95 \%$ coating retained)even in the most severe curing conditions.

\subsubsection{Zeta Potential Measurements (on cured lime treated aggregate powder)}

Powdered aggregate samples were treated with hydrated lime according to the process described in section 3.3.2 of this phase. Different settings of curing were carried out on hydrated lime-treated powder of aggregates (all limed with $2 \%$ hydrated lime only), and zeta potential was measured on the cured limed powder accordingly. Table 3-5 illustrates the zeta potential readings in different curing settings applied in this phase.

Table 3-5: Zeta potential readings for different curing settings performed on hydrated lime treated samples of aggregate (3).

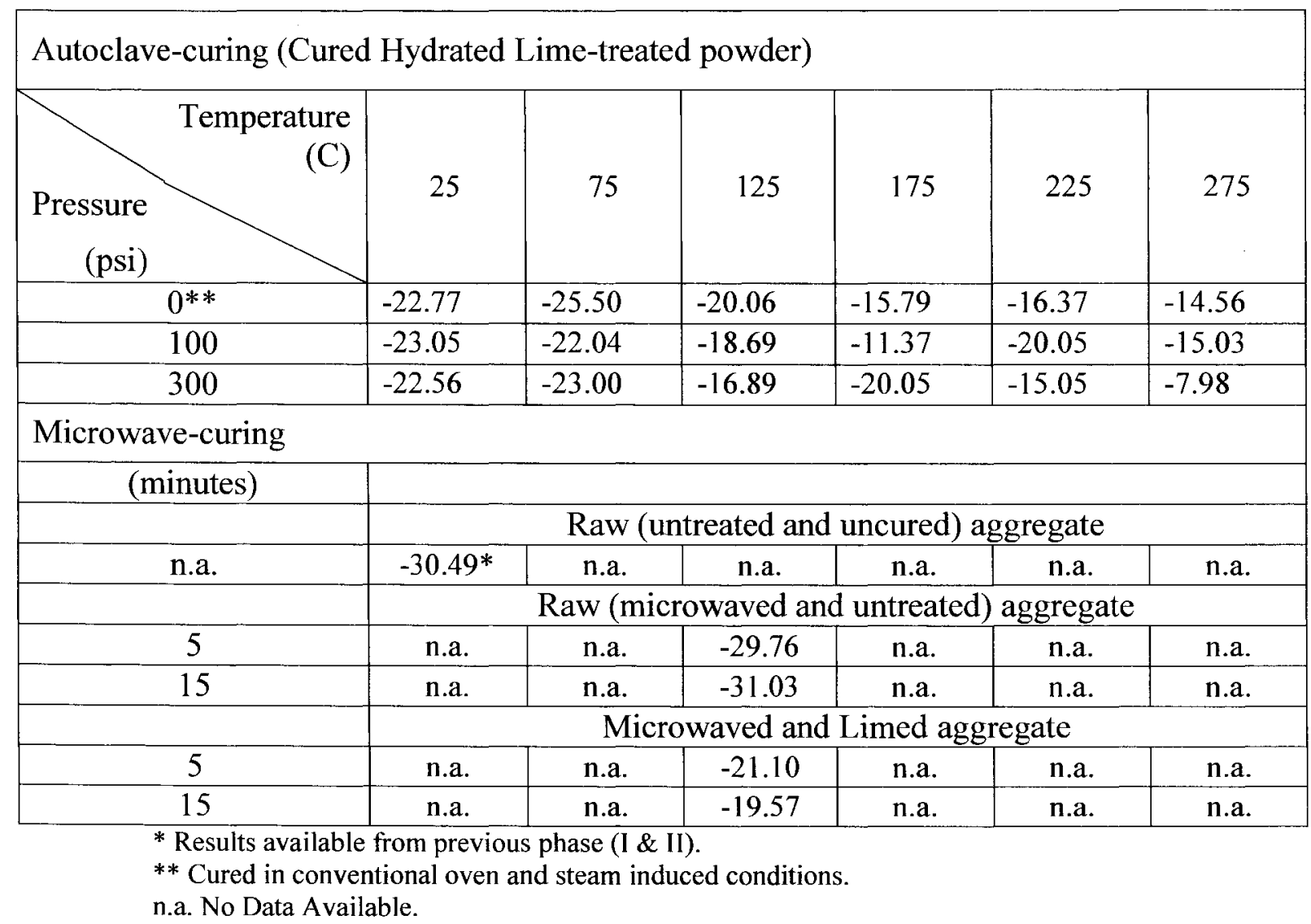


A comparison among the uncured and cured samples is displayed in Figure 3-21, and Figure 3-22.

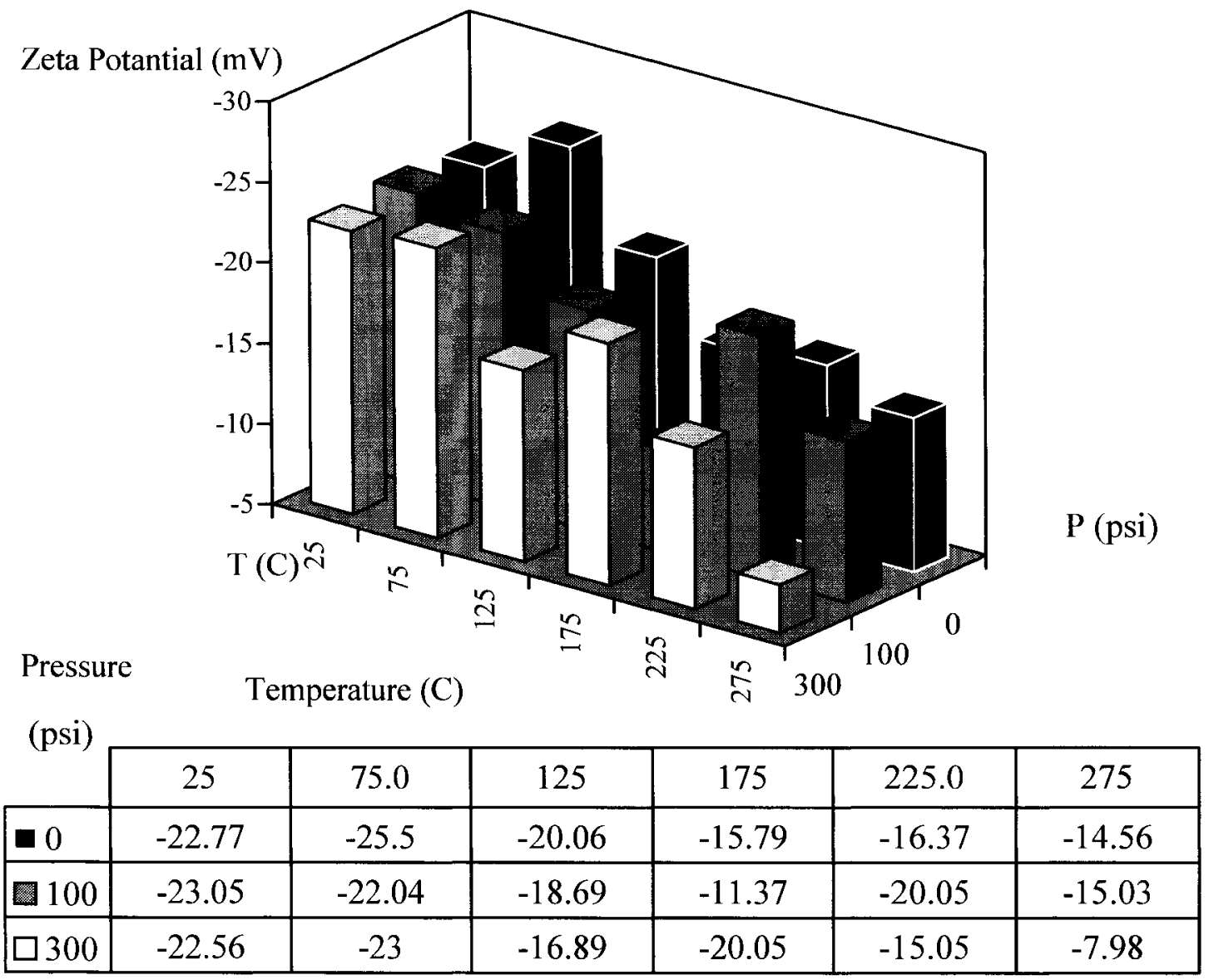

Figure 3-21: Comparison of the effectiveness of different curing settings on Zeta potential values for hydrated lime treated samples of aggregate (3). 


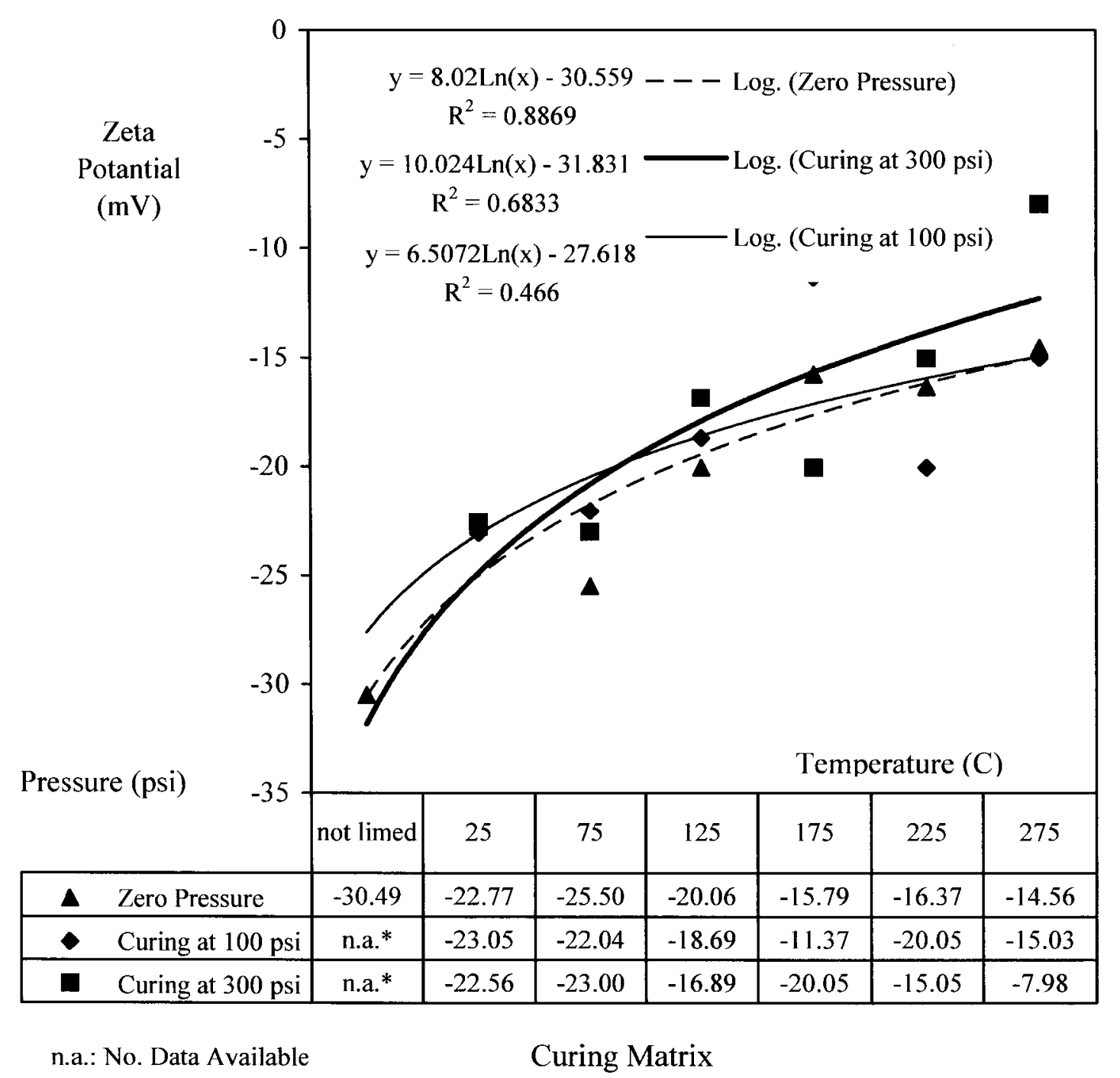

Figure 3-22: Effect of adding hydrated lime in different temperature, and pressure settings in Zeta potential of hydrated-lime treated aggregate (3). 


\subsubsection{Test Results Analysis}

The purpose of this phase was to evaluate the effects of curing the lime treated samples in different temperature and pressure conditions. Findings of this phase are listed and discussed follows.

- The pattern of improvement in coating retained on treated aggregate as a function of increase in curing temperature was evidenced (Figure 3-13). It was observed that all samples cured in higher temperatures (except one case) received better coating retained; however the rates of these improvements were not significant.

- Similar to curing with high temperature a general trend of increase in resistance to stripping was observed; however this was limited to the lower temperature bellow 125 for which improvements achieved in 300psi was greater than that of 100 psi. Similar results observed for sampled cured at 100psi and standard pressure. For the pressures above $125 \mathrm{C}$, decrease in percent coating was observed instead of increase. This can be related to the equipment error associated with the pressure stabilizer regulator of the autoclave.

- Zeta readings are also in general agreement with the results of boiling water test in terms of increase in curing temperature; the general trend of change in zeta potentials was decreasing as a result of increase in curing temperature (except some sporadic exceptions).

- Zeta potential values measured in $100 \mathrm{psi}$ and $300 \mathrm{psi}$ were above those measured at normal pressure, while zeta readings of 300psi pressure were higher than that of $100 \mathrm{psi}$ only for the temperature settings of above $125 \mathrm{C}$. The irregularity and 
unexpected loss in the alleviation of zeta potentials for above $125 \mathrm{C}$ again could be related to equipment error, which could not be easily stabilized in the desired pressure setting(s).

- The comparison of changes in Zeta potential readings for raw materials, microwaved and limed-treated aggregates, and microwaved untreated aggregates revealed that microwaving the raw aggregates has no effect on their zeta potential. If the same aggregates are limed and cured in microwave for some time their zeta potanntial is considerably mitigates to almost one third of the original value. This observation supports the findings of Al-Ohaly and Terrel (1988) that indicated microwaving modifies the surface charge of the HMA on the binder layer (not on the aggregate surface). Improve in zeta potential of lime treated powder when microwaved in hot steam conditions can be related to the beneficial effect of temperature (similar to autoclaving) that could have dispersed the microwave energy and cured the rock powder with hot steam resulting in alleviation of its Zeta potentials.

- General analysis of the effect of curing on Zeta potential, with regard to the discussions made in the literature review, is as follows. It is understood from previous research that autoclaving the calcium silicate hydrate system results in more crystallized silica gel products (Weiker and Stade 1965). Tylor (1965) denoted that the hydrothermal process initiates at normal conditions, however, the typically crystallized CSH products are formed in the intermediate phase of autoclaving the CSH system above 100C. According to Tylor's observations the process typically occurs between $170 \mathrm{C}$ and $200 \mathrm{C}$, under steam pressure (wet 
autoclaving) of between $100 \mathrm{psi}$ and $200 \mathrm{psi}$, while at temperature above $250 \mathrm{C}$ compressive strength of sand-lime bricks was diminished. Results of recent research done by Dietz and Bohnemann (2000) are in general agreement with the above findings. They also indicated that pozzolanic reactions between silica components and alkali agents are accelerated in elevated temperature and pressure conditions, which indicates the possibility of a similar occurrence in the curing process of samples in this study. 


\section{Chapter 4. Conclusion, Recommendations and Application}

\subsection{Conclusion}

Based on the obtained test results and observations made in this study, the following conclusions have been drawn:

- It was observed that the percentage of silica ( $\mathrm{SiO} 2)$ and Calcium Oxide (CaO) in stone aggregates has a strong relationship with the aggregates propensity to stripping. The more the silica content, and the less the alkali content, the more susceptible aggregates. This criterion could be directly used to predict the general behavior of aggregates in terms of resistance or propensity to stripping after their mineral composition is understood in lab.

- A relationship between the contents of silica $\left(\mathrm{SiO}_{2}\right)$ and Calcium Oxide $(\mathrm{CaO})$ and "negative surface charge" (or Zeta potential) was identified. High concentrations of quartz crystals on one hand, and low content of Calcium Oxide on the other hand in the surface of aggregates (1), (2), and (3) were identified as the main contributing factors to the negative surface potential charge of the sampled aggregates.

- A correlation was observed between the negative surface charge and propensity to stripping of sampled aggregates in this study. However, a hypothetic model was not investigated, which would be pending to evaluate the samples using quantitative testing techniques in future research. 
- It was observed that the negative surface charge of silica rich aggregates could be modified (even reversed to positive zeta charge) by addition of lime. This was observed to have significant effect on improvement of the stripping resistance of tested aggregates as well. Advent and accumulation of defused molecules of hydrated lime $\left(\mathrm{Ca}^{++}\right)$in $\mathrm{CSH}$ explained to be responsible for this phenomenon.

- A postulation was developed to explain the role of lime in improving the surface of siliceous aggregates based on the hydrothermal reactions of lime and silica gel.

- It was investigated that the healing effect of lime in improving the aggregates surface is enhanced when the limed aggregates are cured at elevated temperature and pressure conditions (autoclaving process). The effect of the temperature on stripping was more pronounced regardless of the source aggregates.

- Microwaving the bare aggregates (not mixed with asphalt cement) was found to be ineffective at improving the stone materials. However, it was observed that when bare aggregates are limed in steam conditions, microwave energy can efficiently heat the limed aggregates and facilitate their pozzolanic reactions under hot steam conditions.

- Results of XRF and petrographical analysis in terms of mineral compositions of aggregates were in compliance with each other and with the known field performance of aggregates samples in regards to moisture damage. However, it is recommended that XRF, and optical petrographical survey techniques both are required to obtain an objective understanding about the constituent minerals of rock samples. 
- Boiling water test was successful in reflecting the effectiveness of lime-based additives and different curing conditions especially for susceptible mixtures. The Static Immersion test, however, showed the general trend of lime improvement but was not as effective as the boiling water test. It is understood that boiling water and static immersion tests should be properly calibrated to suit the test conditions. This provision especially found to be necessary for testing the samples that exhibit close resistance or propensity to stripping.

In general, findings and observations of this study concur with the hypothesis of occurrence of pozzolanic reactions between silica and lime components in a CSH system. However, the theoretical concepts and justifications that relate to surface chemistry and mineralogy of aggregates need more comprehensive research. 


\subsection{Recommendations For Future Research}

As both stripping tests applied in this study were of "qualitative" type and applied to loose mix only. A series of supplementary "quantitative" stripping tests can be devised to verify the correlation of the results of this study with full-scale field performance. Further investigation can be planned to test the hypothesis for treating the stone aggregates applied in real Hot Mix Asphalt. Long-term performance, and durability of HMA with pre-treated aggregates can be investigated accordingly. A typical mix design is required to be prepared, based on which Lottman durability (AASHTO T-283) and stiffness properties tests (resilient modulus- ASTM 4123) will be conducted onto HMA mixes with differently cured and treated aggregates. Effectiveness of the proposed treatment and curing technique can be compared against the effectiveness of chemical anti-stripping agents. 


\subsection{Application in the Asphalt Industry}

The test results and analysis of the investigation performed in this thesis relate the concepts of "pozzolanic reactions in CSH systems", "change in zeta potential" and "lime treatment and curing of stone aggregates". These concepts can be used in developing rating boards for a wider range of aggregates in a regional basis. Such a dataset ultimately would be used to predict the striping propensity of new quarry aggregates with unknown field performance. The results of this research are also expected to optimize and advance the use of lime-based additives in a more effective approach in competition with other chemical-based anti-stripping agents in asphalt and pavement construction industries. 


\section{REFERENCES}

AASHTO. "Coating and Stripping of Bitumen-Aggregate Mixtures.", T182-84-2002, Washington, D.C. 2005.

AASHTO. "Resistance of Compacted Bituminous Mixture to Moisture- Induced Damage.", T283-03, Washington, D.C. 2005.

AASHTO. "Standard Test Method for Effect of Water on Compressive Strength of Compacted Bituminous Mixtures.”, T165-02, Washington, D.C. 2005.

Al-Ohaly, A. A. and Terrel, R. L. Effect of Microwave Heating and Moisture Damage of Asphalt Mixtures. In Transportation Research Record: Journal of the Transportation Research Board, No 1171, TRB, National Research Council, Washington, D.C., 1988 , pp. 27-36.

Aschenbrener, T. Evaluation of Hamburg Wheel-Tracking Device to Predict Moisture Damage in Hot-Mix Asphalt. In Transportation Research Record: Journal of the Transportation Research Board, No 1492, TRB, National Research Council, Washington, D.C., 1995, pp. 193-201.

Aschenbrener, T. Results of Survey on Moisture Damage of Hot Mix Asphalt Pavements. Colorado Department of Transportation, Denver, USA. 2002

ASTM. (2003). "Practice for Effect of Water on Bituminous-Coated Aggregate Using Boiling Water.”, D3625, West Conshohocken, Pennsylvania.

Boynton, R. S. Chemistry and Technology of Lime and Limestone. $2^{\text {nd }}$ Edition John Wiley \& Sons, Inc. USA. 1980. 
Buchanan, S., and V. M. Moore Laboratory Accelerated Stripping Simulator for Hot Mix Asphalt. Report No. FHWA/MS-DOT-RD-04-167, Prepared for Mississippi Transportation Research Centre, by Mississippi State University, Department of Civil Engineering, Construction Materials Research Centre, 2005.

Buttlar, W. G., D. Bozkurt., G. G. Al-Kateeb., and A. S. Waldhoff. Understanding Asphalt Mastic Behavior through Micromechanics. Paper Presented at the Annual Meeting of the Transportation Research Board, Washington, D.C. 1999.

Cheng, D., D. N. Little, R. L. Lytton, and J. C. Holste. Use of Surface Free Energy Properties of the Asphalt-Aggregate System to Predict Moisture Damage Potential Asphalt Paving Technology. Workshop Session- Proceedings Association of Asphalt Technologists, Vol. 71, 2002, pp. 59-88.

Collins, R. Status Report on the Use of Hydrated Lime in Asphaltic Concrete Mixtures in Georgia. Materials and Research, Georgia DOT . 1988.

Curtis, C. W. A Literature Review of Liquid Anti-stripping And Tests for Measuring Stripping. SHRP - A/UIR - 90-016 National Research Council;, Auburn University, Alabama. 1990.

Dietz, T., and K. Bohnemann. Calcium Silicate Hydrate in Fiber Cement Sheets and Autoclaved Aerated Concrete (AAC). $7^{\text {th }}$ International Inorganic-Bonded Wood \& Fiber Composite Materials Conference, University of Idaho, Sun Valley, USA, 2000. Epps, J. A., P. E. Sebaaly, J. Penaranda, M. R. Maher, M. B. Mccann, and A. J. Hand. Compatibility of a Test for Moisture-Induced Damage with Superpave Volumetric Mix Design. NCHRP REPORT 444, Transportation Research Board, National Research Council, National Academy Press, Washington, D.C., 2000. 
Epps, J., E. Berger, and J. N. Anagnos. Moisture Sensitivity of Asphalt Pavements- Topic 4: Treatments. In Transportation Research Board of the National Academies- A National Seminar, San Diego, California, 2003, pp. 117-132.

Fromm, H. J. The Mechanisms of Asphalt Stripping from Aggregate Surfaces." Asphalt Paving Technology- Proceedings of Association of Asphalt Paving Technologists, Vol. 43, 1974, pp. 191-223.

Hassan, Y., and A.O.A. Halim. Evaluation of Laboratory Testing of Moisture Susceptible of Asphalt Concrete Mixes. Final report submitted to Airport Engineering Division public Works and Governmental services, Ottawa, Ontario, Canada. 2000.

Hefer, A., D. N. Little. Adhesion in Bitumen-Aggregate Systems and Quantification of the Effects of Water on the Adhesive Bond." Research Report Number ICRA505-1, Prepared for International Centre for Aggregate Research, by Texas Transportation Institute - Texas A\&M University, 2005.

Hicks, R. G. Moisture Damage in Asphalt Concrete" National Cooperative Highway Reseach POGRAM, NCHRP, Synthesis of Highway Practice Report 175, Transportation Research Board, National Research Council, Washington, D.C. 1991.

Hubbard, P. Adhesion of Asphalt to Aggregate in the Presence of Water. Proceedings, Highway Research Board, Vol. 8, Part 1.1938.

Jimenez, R. A. Testing for Debonding of Asphalt from Aggregates. Transportation Research Record 515, 1974, pp. 1-17.

Kandhal, P., and I. Rickards. Premature Failure of Asphalt Overlays from Stripping Case Histories. Asphalt Paving Technology- Proceedings Association of Asphalt Technologists, Vol. 70, 2001, pp. 301-351. 
Kanitpong, K., and H. U. Bahia. Role of Adhesion and Thin Film Tackiness of Asphalt Binders in Moisture Damage of HMA. Asphalt Paving Technology-Proceedings Association of Asphalt Technologists, Vol. 72, 2003, pp. 502-528.

Kennedy, T. W., F. L Roberts, and K. W. Lee. Evaluating Moisture Susceptibility of Asphalt Mixtures Using the Texas Boiling Test. In Transportation Research Record: Journal of the Transportation Research Board, No. 968, TRB, National Research Council, Washington, D.C., 1984, pp. 45-54.

Kiggundu, B. M., and F. L. Roberts. Stripping in HMA Mixtures: State-Of-the-Art and Critical Review of Test Methods. NCAT Report No. 88-2, 1988.

Kim, Y., D. N. Little, and I. Song. Effect of Mineral Fillers on Fatigue Resistance and Fundamental Material Characteristics, Mechanistic Evaluation. In Transportation Research Record: Journal of the Transportation Research Board, No 03-3454, TRB, National Research Council, Washington, D.C., 2003, pp. 1-8.

Lee, K. W., Al-Jarallah, M. I. (1986). "Utilization of Texas Boiling Test to Evaluate Effectiveness of Anti-stripping Additives in Saudi Arabia. In Transportation Research Record: Journal of the Transportation Research Board, No. 1096, TRB, National Research Council, Washington, D.C., 1986, pp. 81-89.

Little D. N., and J. A. Epps. The Benefits of Hydrated Lime in Hot Mix Asphalt. Report for National Lime Association, Virginia, 2001.

Little, D. N., and D. R. Jones IV. Moisture Sensitivity of Asphalt Pavements- Topic 2: Chemical and Mechanical Processes of Moisture Damage in Hot-Mix Asphalt Pavements.In Transportation Research Board of the National Academies-A National Seminar, San Diego, California, 2003, PP. 37-74. 
Little, D. N., J. W. Button, and C. Estakhri. Handbook for Stabilization of Bases and Subbases with Lime. Kendall-Hunt Publishing Co., New York. 1995

Mertens, E. W., J. J. Borgfeldt. Cationic Asphalt Emulsions; Bituminous Materials: Asphalts, Tars, and Pitches, Edited by Hoiberg." Vol. 2, Part1, Interscience Publishers, John Wiely \& Sons. N.Y., 1965.

Mohamed, E. H. Stripping of Asphalt Pavements. Ph.D. Thesis-Department of Civil and Environmental Engineering, Carleton University, Ottawa, ON. 1991.

Mostafa, A. The Stripping Susceptibility of Airfield Asphalt Mixes: The Development of Guidelines for a Laboratory Test Method. Ph.D. Thesis- Department of Civil and Environmental Engineering, Carleton University, Ottawa, ON. 2005.

Nehdi, M., and K. Welker. Investigation of Premature Failure of Dense Friction Course Asphalt Highways in Ontario. Journal of Materials in Civil Engineering, ASCE, Vol. 14, No. 3, 2002pp. 210-216.

Nguyen, T., E. W. Byrd., D. Bentz, and J. Martin. In-Situ Spectroscopic Study of Water at the Asphalt/Siliceous Substrate Interface and its Implication in Stripping. The Journal of Adhesion, Vol. 81, No. 1, 2005, pp. 1-28.

Pan, C., White, T. Conditions for Stripping Using Accelerated Testing. Report FHWA/IN/JTRP-97/13, Joint Transportation Research Program, Purdue University, West Lafayette, Indiana, Rep. 1999.

Parker Jr., F., and F. A. Gharaybeh. Evaluation of Tests to Assess Stripping Potential of Asphalt Concrete Mixtures. In Transportation Research Record: Journal of the Transportation Research Board, No 1171 , TRB, National Research Council, Washington, D.C., 1988, pp. 18-20. 
Parker, F. Jr., and M. S. Wilson. Evaluation of Boiling and stress Pedestal Tests for Assessing Stripping Potential of Alabama Asphalt Concrete Mixtures. In Transportation Research Record: Journal of the Transportation Research Board, No. 1096, TRB, National Research Council, Washington, D.C., 1986, pp. 90-100.

Parker, F., Jr., Stripping of Asphalt Concrete-Physical Testing. Final Report number 930111, Alabama Highway Department, USA. 1987.

Perry, L. M., and C. W. Curtis. Effect of Aggregate Chemistry and Modification on Moisture Sensitivity. In Transportation Research Record: Journal of the Transportation Research Board, No1386, TRB, National Research Council, Washington, D.C., 1993, pp. 38-48.

Petersen, J.C. Quantitative Functional Group Analysis of Asphalt Using Differential Infrared Spectrometry and Selective Chemical Reactions-Theory and Application. In Transportation Research Record: Journal of the Transportation Research Board, No. 1096, TRB, National Research Council, Washington, D.C., 1986, pp. 1-11.

Petersen, J.C., H. Plancher, and P.M. Harnsberger, Lime Treatment of Asphalt to Reduce Age Hardening and Improve Flow Properties. Asphalt Paving TechnologyProceedings of Association of Asphalt Paving Technologists, Vol. 56, 1987.

Roberts, F. L., P. S. Kandhal, E. R. Brown, L. Dah-Yinn, T. W. Kennedy. Hot Mix Asphalt Materials, Mixture Design, and Construction, $2^{\text {nd }}$ Ed., NAPA Education Foundation, Lanham, Maryland, 1996.

Schilling, P. and H. G. Shreuders. Improved Quick-Set Slurry Seal Emulsifier With Tall Oil Derivatives." In Transportation Research Record: Journal of the Transportation 
Research Board, No. 1177, TRB, National Research Council, Washington, D.C., 1988, pp. 98-105.

Shah, B. D. Evaluation Of Moisture Damage Within Asphalt Concrete Mixes. MSc. Thesis- Department of Civil Engineering, Texas A\&M University, Texas, USA. 2003.

Stroup-Gardiner, M. and J. Epps. Four Variables that Affect the Performance of Lime in Asphalt-Aggregate Mixture. In Transportation Research Record: Journal of the Transportation Research Board, No. 1115, TRB, National Research Council, Washington, D.C., 1987, pp. 12-22.

Taggart, J.E. Jr., J.R. Lindsay, B.A. Scott, D.V. Vivit, A.J. Bartel, and K.C. Stewart Analysis of geological materials by wavelength-dispersive X-ray fluorescence spectrometry. In: Baedecker, P. H. (ed.) Methods for Geochemical Analysis. U.S. Geological Survey Bulletin, Vol. 1170, E1-E19, 1987.

Tandon, V., Vemuri, N., Nazarian, S., Tahmoressi, M. A Comprehensive Evaluation of Environmental Conditioning System. Proceedings of the Association of Asphalt Paving Technologists, Vol. 66, 1997, pp. 187-210.

Tarrer, A. R., and V. Wagh. The Effect of the Physical and Chemical Characteristics of the Aggregate on Bonding. Strategic Highway Research Program, National Research Council, Washington, D.C. 1991.

Tarrer, R. Use of Hydrated Lime to Reduce Hardening and Stripping in Asphalt Mixes. 4th Annual ICAR Symposium, Atlanta, Georgia. 1996.

Tarrer, R.A., 1 Stripping of Asphalt Concrete: Chemical Testing. Report number 2, Project \#930-111, Alabama Highway Department, USA. 1986. 
Taylor, M. A. and N. P. Khosla. Stripping of Asphalt Pavements: State of the Art. In Transportation Research Record: Journal of the Transportation Research Board, No. 911, TRB, National Research Council, Washington, D.C., 1983, pp. 150-138.

Tunnicliff, D. G. Performance of Anti-stripping Additives. Asphalt Paving TechnologyProceedings Association of Asphalt Technologists, Vol. 66, 1997, pp. 344-378.

Viallis-Terris, H., A. Nonat, and J. Petit. Zeta-Potential Study of Calcium Silicate Hydrates Interacting with Alkaline Cations." Journal of Colloid and Interface Science, Vol. 244, No. 1, 2001,pp. 58-65.

Yoon, H. H., A. R. Tarrer. Effect of Aggregate Properties on Stripping. In Transportation Research Record: Journal of the Transportation Research Board, No. 1096, TRB, National Research Council, Washington, D.C., 1988, pp. 81-89. 


\section{APPENDIX A: Samples of Zeta Potential Reading Datasheet(s)}


Table A-1: Test results of "ZETA POTENTIAL MEASUREMENTS" for untreated raw samples of aggregate 1

\begin{tabular}{|c|c|c|c|c|c|c|}
\hline & \multicolumn{2}{|c|}{ AGGREGATE 1- Batch 1} & \multicolumn{2}{|c|}{ AGGREGATE 1- Batch 2} & \multicolumn{2}{|c|}{ AGGREGATE 1- Batch 3} \\
\hline $\begin{array}{l}\text { Conductance } \\
\text { (mic- }\end{array}$ & \multicolumn{2}{|c|}{96} & \multicolumn{2}{|c|}{102} & \multicolumn{2}{|c|}{126} \\
\hline $\begin{array}{l}\text { Zeta potential } \\
\text { value (mVolt) }\end{array}$ & $\begin{array}{c}\text { average of } \\
\text { three reads } \\
\text { (mVolt) }\end{array}$ & width (mVolt) & $\begin{array}{l}\text { average of } \\
\text { ten reads } \\
\text { (mVolt) }\end{array}$ & width (mVolt) & $\begin{array}{c}\text { average of } \\
\text { ten reads } \\
\text { (mVolt) }\end{array}$ & width (mVolt) \\
\hline Runl & -5.12 & 2.76 & -18.21 & 3.1 & -5.85 & 3.34 \\
\hline Run2 & -2.02 & 4 & -15.66 & 2.41 & -4.82 & 3.56 \\
\hline Run3 & -8.06 & 2.53 & -15.84 & 3.14 & -11.87 & 3.64 \\
\hline Run4 & -12.19 & 3.32 & -18.56 & 2.99 & -6.69 & 3.5 \\
\hline Run5 & -7.3 & 5.09 & -18.84 & 2.77 & -4.03 & 3.49 \\
\hline Run6 & -15.06 & 4.6 & -15.8 & 3.46 & -2.17 & 4.13 \\
\hline Run7 & -10.71 & 2.39 & -11.96 & 2.54 & -16.93 & 5.29 \\
\hline Run8 & -10.7 & 2.48 & -14.75 & 3.06 & -12.94 & 3.1 \\
\hline Run9 & -22.46 & 2.97 & -13.6 & 2.99 & -8.28 & 3.48 \\
\hline Run10 & -20.62 & 4.6 & -14.91 & 2.59 & -2.03 & 3.64 \\
\hline MEAN & -11.42 & 3.47 & -15.81 & 2.91 & -7.56 & 3.72 \\
\hline VARIANCE & 41.97 & 1.03 & 4.91 & 0.10 & 24.35 & 0.37 \\
\hline $\begin{array}{l}\text { STANDARD } \\
\text { DEVIATION }\end{array}$ & 6.48 & 1.01 & 2.22 & 0.32 & 4.93 & 0.61 \\
\hline $\begin{array}{l}\text { STANDARD } \\
\text { ERROR OF } \\
\text { THE MEAN }\end{array}$ & 2.05 & 0.32 & 0.70 & 0.10 & 1.56 & 0.19 \\
\hline
\end{tabular}

\begin{tabular}{|c|c|c|c|}
\hline $\begin{array}{c}\text { Affecting } \\
\text { confidence } \\
\text { coefficient } \\
\text { value: }\end{array}$ & reading in one cycles- 10run & reading in three cycles- 10run & reading in three cycles- 10run \\
\cline { 2 - 4 } & $13 \%$ & $43.5 \%$ & $43.5 \%$ \\
\hline
\end{tabular}

ZETA POTENTIAL OF AGGREGATE (1)

\begin{tabular}{|c|cc|}
\hline $\begin{array}{c}\text { AVERAGE OF WIGHTED } \\
\text { MEANS }\end{array}$ & -11.65 & (mVolt) \\
\hline $\begin{array}{c}\text { AVERAGE OF WIGHTED } \\
\text { S.E.'s }\end{array}$ & 1.25 & (mVolt) \\
\hline
\end{tabular}


Table A-2 Test results of "ZETA POTENTIAL MEASUREMENTS" for untreated raw samples of aggregate 2

\begin{tabular}{|c|c|c|c|c|c|c|}
\cline { 2 - 7 } \multicolumn{1}{c|}{} & \multicolumn{2}{c|}{ Aggregate 2- Batch 1 } & \multicolumn{2}{c|}{ Aggregate 2- Batch 2 } & \multicolumn{2}{c|}{ Aggregate 2- Batch 3 } \\
\hline $\begin{array}{c}\text { Conductance } \\
\text { (mic- } \\
\text { siemence): }\end{array}$ & \multicolumn{2}{|c|}{129} & \multicolumn{2}{c|}{118} \\
\hline $\begin{array}{c}\text { Zeta potential } \\
\text { value (mVolt) }\end{array}$ & $\begin{array}{c}\text { average of } \\
\text { three reads } \\
\text { (mVolt) }\end{array}$ & width (mVolt) & $\begin{array}{c}\text { average of } \\
\text { three reads } \\
\text { (mVolt) }\end{array}$ & width (mVolt) & $\begin{array}{c}\text { average of } \\
\text { three reads } \\
\text { (mVolt) }\end{array}$ & width (mVolt) \\
\hline Run1 & 18 & 2.74 & 12.67 & 2.85 & 16.15 & 3.49 \\
\hline Run2 & 13.93 & 2.72 & 11.42 & 2.89 & 16.74 & 3.94 \\
\hline Run3 & 20.76 & 3.96 & 14.32 & 3.36 & 18 & 3.42 \\
\hline Run4 & 26.37 & 2.43 & 15.29 & 3.06 & 14.92 & 3.15 \\
\hline Run5 & 15.89 & 2.35 & 12.83 & 3.45 & 14.65 & 4 \\
\hline Run6 & 8.81 & 4.54 & 11.85 & 4.11 & 19.82 & 3.69 \\
\hline Run7 & 14.45 & 3.84 & 13.32 & 3.63 & 19.92 & 5.04 \\
\hline Run8 & 20.85 & $\mathbf{6 . 2 9}$ & 13.32 & 4.32 & 19.09 & 3.97 \\
\hline Run9 & 10.84 & 2.53 & 13.82 & 2.81 & 14.3 & 4.44 \\
\hline Run10 & 12.97 & 2.62 & 11.85 & 3.5 & 18.8 & 3.81 \\
\hline & & & & & & \\
\hline MEAN & $\mathbf{1 6 . 2 9}$ & 3.40 & $\mathbf{1 3 . 0 7}$ & 3.40 & $\mathbf{1 7 . 2 4}$ & 3.90 \\
\hline VARIANCE & 27.90 & 1.61 & 1.46 & 0.27 & 4.72 & 0.29 \\
\hline $\begin{array}{l}\text { STANDARD } \\
\text { DEVIATION }\end{array}$ & 5.28 & 1.27 & 1.21 & 0.52 & 2.17 & 0.54 \\
\hline $\begin{array}{l}\text { STANDARD } \\
\text { ERROR OF } \\
\text { THE MEAN }\end{array}$ & $\mathbf{1 . 6 7}$ & 0.40 & $\mathbf{0 . 3 8}$ & 0.16 & $\mathbf{0 . 6 9}$ & 0.17 \\
\hline
\end{tabular}

\begin{tabular}{|c|c|c|c|}
\hline $\begin{array}{c}\text { Affecting } \\
\text { confidence } \\
\text { coefficient } \\
\text { value: }\end{array}$ & reading in one cycle- 10run & reading in three cycles- 10run & reading in three cycles- 10run \\
\cline { 2 - 4 } & $13 \%$ & $43.5 \%$ & $43.5 \%$ \\
\hline
\end{tabular}

ZETA POTENTIAL OF AGGREGATE (2)

\begin{tabular}{|c|cc|}
\hline $\begin{array}{c}\text { AVERAGE OF WIGHTED } \\
\text { MEANS }\end{array}$ & 15.30 & (mVolt) \\
\hline $\begin{array}{c}\text { AVERAGE OF WIGHTED } \\
\text { S.E.'s }\end{array}$ & 2.16 & (mVolt) \\
\hline
\end{tabular}


Table A-3 Test results of "ZETA POTENTIAL MEASUREMENTS" for untreated raw samples of aggregate 3

\begin{tabular}{|c|c|c|c|c|c|c|}
\hline \multirow{2}{*}{$\begin{array}{c}\text { Conductance } \\
\text { (mic- } \\
\text { siemence): }\end{array}$} & \multicolumn{2}{|c|}{ Aggregate 3- Batch 1} & \multicolumn{2}{|c|}{ Aggregate 3- Batch 2} & \multicolumn{2}{|c|}{ Aggregate 3- Batch 3} \\
\hline & \multicolumn{2}{|c|}{80} & \multicolumn{2}{|c|}{79} & \multicolumn{2}{|c|}{72} \\
\hline $\begin{array}{l}\text { Zeta potential } \\
\text { value (mVolt) }\end{array}$ & $\begin{array}{c}\text { average of } \\
\text { three reads } \\
\text { (mVolt) }\end{array}$ & width (mVolt) & $\begin{array}{c}\text { average of } \\
\text { three reads } \\
(\mathrm{mVolt})\end{array}$ & width (mVolt) & $\begin{array}{c}\text { average of } \\
\text { three reads } \\
\text { (mVolt) }\end{array}$ & width (mVolt) \\
\hline Run1 & -31.95 & 2.5 & -26.55 & 2.98 & -33.06 & 4.05 \\
\hline Run2 & -26.95 & 2.48 & -24.38 & 3.39 & -32.49 & 3.46 \\
\hline Run3 & -32.95 & 2.82 & -36.35 & 3.1 & -33.44 & 3.87 \\
\hline Run4 & -34.31 & 2.54 & -36.16 & 3.67 & -20.9 & 3.38 \\
\hline Run5 & -32.23 & 2.46 & -28.06 & 2.75 & -36.93 & 4.76 \\
\hline Run6 & -34.38 & 2.42 & -31.72 & 3.15 & -29.9 & 3.93 \\
\hline Run7 & -31.51 & 2.33 & -29.54 & 3.05 & -32.15 & 3.46 \\
\hline Run8 & -20.98 & 2.91 & -31.94 & 3.63 & -30.09 & 5.45 \\
\hline Run9 & -30.24 & 2.3 & -31.66 & 3.13 & -26.95 & 5.57 \\
\hline Run10 & -34.23 & 2.97 & -29.6 & 3.54 & -26.6 & 5.36 \\
\hline MEAN & -30.97 & 2.57 & -30.60 & 3.24 & -30.25 & 4.33 \\
\hline VARIANCE & 17.41 & 0.06 & 14.65 & 0.09 & 20.35 & 0.77 \\
\hline $\begin{array}{l}\text { STANDARD } \\
\text { DEVIATION } \\
\end{array}$ & 4.17 & 0.24 & 3.83 & 0.30 & 4.51 & 0.88 \\
\hline $\begin{array}{l}\text { STANDARD } \\
\text { ERROR OF } \\
\text { THE MEAN }\end{array}$ & 1.32 & 0.08 & 1.21 & 0.10 & 1.43 & 0.28 \\
\hline
\end{tabular}

\begin{tabular}{|c|c|c|c|}
\hline $\begin{array}{c}\text { Affecting } \\
\text { confidence } \\
\text { coefficient } \\
\text { value: }\end{array}$ & reading in one cycle- 10run & reading in three cycles- 10run & reading in three cycles- 10run \\
\cline { 2 - 4 } & $13 \%$ & $43.5 \%$ & $43.5 \%$ \\
\hline
\end{tabular}

ZETA POTENTIAL OF AGGREGATE (3)

\begin{tabular}{|c|cc|}
\hline $\begin{array}{c}\text { AVERAGE OF WIGHTED } \\
\text { MEANS }\end{array}$ & -30.49 & (mVolt) \\
\hline $\begin{array}{c}\text { AVERAGE OF WIGHTED } \\
\text { S.E.'s }\end{array}$ & 4.17 & (mVolt) \\
\hline
\end{tabular}


APPENDIX B: Test Results of Sampled Aggregates 
Jacques Whittord

2781 Lancaster koad, Sulte 200

Ottaina, ON KIB 1AT

In: (613) 738-07as fix. (613) 738-072t
DPSS 1150 HL-3 PG 58-34

ERUHAWOUS MDX DESIGN REPORT
TESTING LAB CONTRACT No. PROJECTNO. LAB MIXNo CONTRAC LOCATION \begin{tabular}{l} 
Joogues, Whitford and Assocales LAd. HOT MIX TYPE \\
ITEM\# \\
\hline ONO22946 \\
\hline DATE SAMPIES RECDD
\end{tabular} SC-200401 DATF COMPLETED

\begin{tabular}{|c|}
\hline OPSS 1150 HL-3 PG 58-34 \\
\hline MeV 18, 2006 \\
\hline June 8, 2005 \\
\hline
\end{tabular}

JOB MDX FORMULA -GRADATION PERCENT PASSIHG

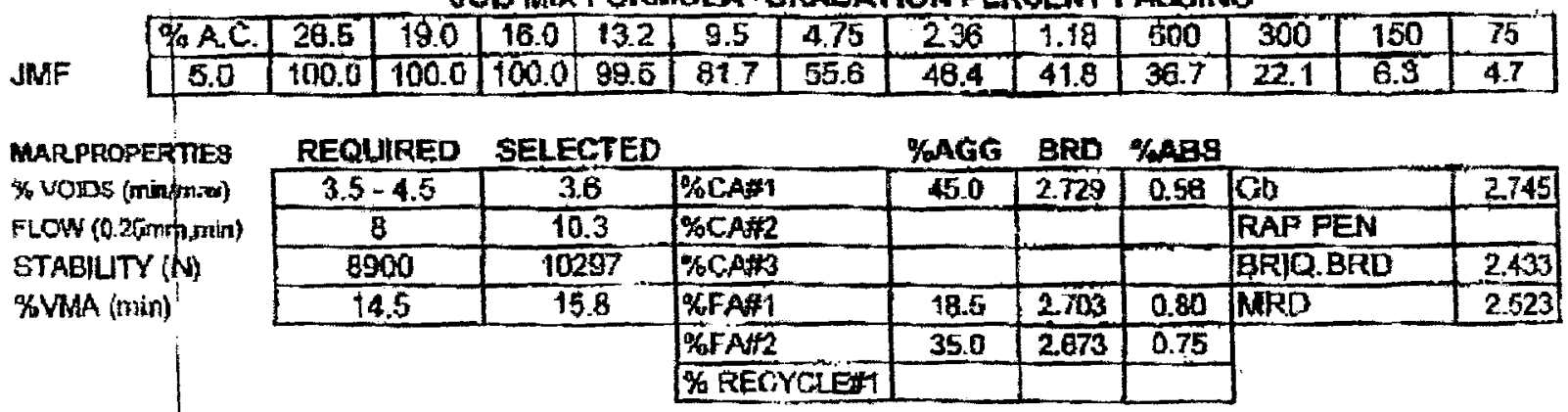

\begin{tabular}{|c|c|c|c|c|}
\hline \multicolumn{2}{|c|}{ ASPHALT CEMENT } & \multicolumn{3}{|c|}{ ADOTIVE } \\
\hline SUPPUIFR & PGAC & SUPPLIER & TYPE & AS \% Agg. \\
\hline McAspltait & PG 58-34 & Gmymont & Lime & 1.5 \\
\hline
\end{tabular}

\begin{tabular}{|c|c|c|c|}
\hline AGO TYPE & TYPEISOURCE & AGOTYPE & TYPESSOURCE \\
\hline$\%$ & $13.2 \mathrm{~mm}$ HL-3 Slone. Dechan Quarry & FFFA\#2 & Natural Sand, Charfie Mogre South Gower Pit \\
\hline$\% C A \cap 2$ & & BofAN3 & \\
\hline QFFAN1 & Screenings, Dechan Quamy & 16 RECYCLEH & \\
\hline
\end{tabular}

AGGREGATE GRADATION - PERCEMT PASSING

\begin{tabular}{|c|c|c|c|c|c|c|c|c|c|c|c|c|c|}
\hline & & & & & & & & & & & & & \\
\hline AGG TYPE & & 26.5 & 19.0 & 16.0 & 93.2 & 9.5 & 4.75 & 2.38 & 7.18 & 600 & 300 & 150 & 75 \\
\hline $6 \mathrm{CA} 1$ & & 100 & 100 & 100 & 98.8 & 59.3 & 6.1 & 2.1 & 1.6 & 1.4 & 1.2 & 1.0 & 0.6 \\
\hline$\% C A=2$ & & & & & & & & & & & & & \\
\hline$\% \mathrm{CA}+3$ & & & & & & & & & & & & & \\
\hline GFA & & 100 & 100 & 100 & 100 & 100 & 90.0 & 54.0 & 37.0 & 28.8 & 21.2 & 16.1 & 11.5 \\
\hline$\%$ FAA2 & & 100 & 100 & 100 & 100 & 100 & 99.7 & 97.0 & 83.5 & 83.5 & 40.0 & 3.8 & 20 \\
\hline$\%$ RECYCL & & & & & & & & & & & & & \\
\hline
\end{tabular}

Remarks: Aggregate gredations based on contracturs process control. Compacted at 75 Blows 1 Side $140 \mathrm{C}$, Marshall Compllance $\mathrm{T}=140 \mathrm{C}$

Typical briquele teight to achieve $63.5+1-2.5 \mathrm{~mm}=1244$ arams Mbxture is to be monitored for compliance to $\mathrm{J}$ b M Mix Fomula during production. JMF adjusted for Lime addex to the mixture. Any adjugtments to materials to be verified.

DATA CERTIFIED BY:

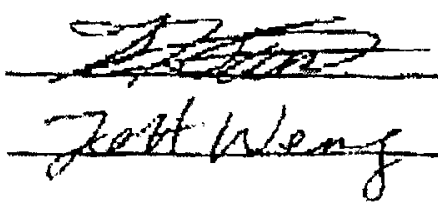
Frank Gainer, Lab Supervisor

DATA VERIFIED BY Jeft K. Weng, M. Eng., M.Sc., P.Eng 


\section{R.W. TOMLINSON LIMITED RIDEAU ROAD QUARRY \\ 05R15}

SPECIFICATION:

DESIGN TYPE:

$\frac{\text { OPSS } 1150^{\circ}}{F-3104}$

MIX TYPE:

HL-1 MOD

MARSHALL 5 POINT

ANTI-STRIPPING
DESIGN AVC CONTENT, $\%$ :

5.00

AC SUPPLIER:

BITUMAR

MIX PROPERTIES

Marshall Stability (N@60 $\mathrm{C}$ )

Flow Value (@3.5\% air voids)

Air Voids in Mixture, \%

Voids in Mineral Aggregate, \%

Combined Aggregate Specific Gravity

Bulk Relative Density $\left(\mathrm{Mg} / \mathrm{m}^{3}\right)$

Maximum Relative Density $\left(\mathbf{M g} / \mathrm{m}^{3}\right.$ )

Retained Stability. \%

16,600
9.8
4.1
15.1
2.696
2.408
2.512
73

SPECIFICATION

$14,000(\mathrm{~min}$ )

$8.0(\mathrm{~min}$.

$4.0+1-0.5$

14.5 ( $\mathrm{min}$.)

70 (min.)

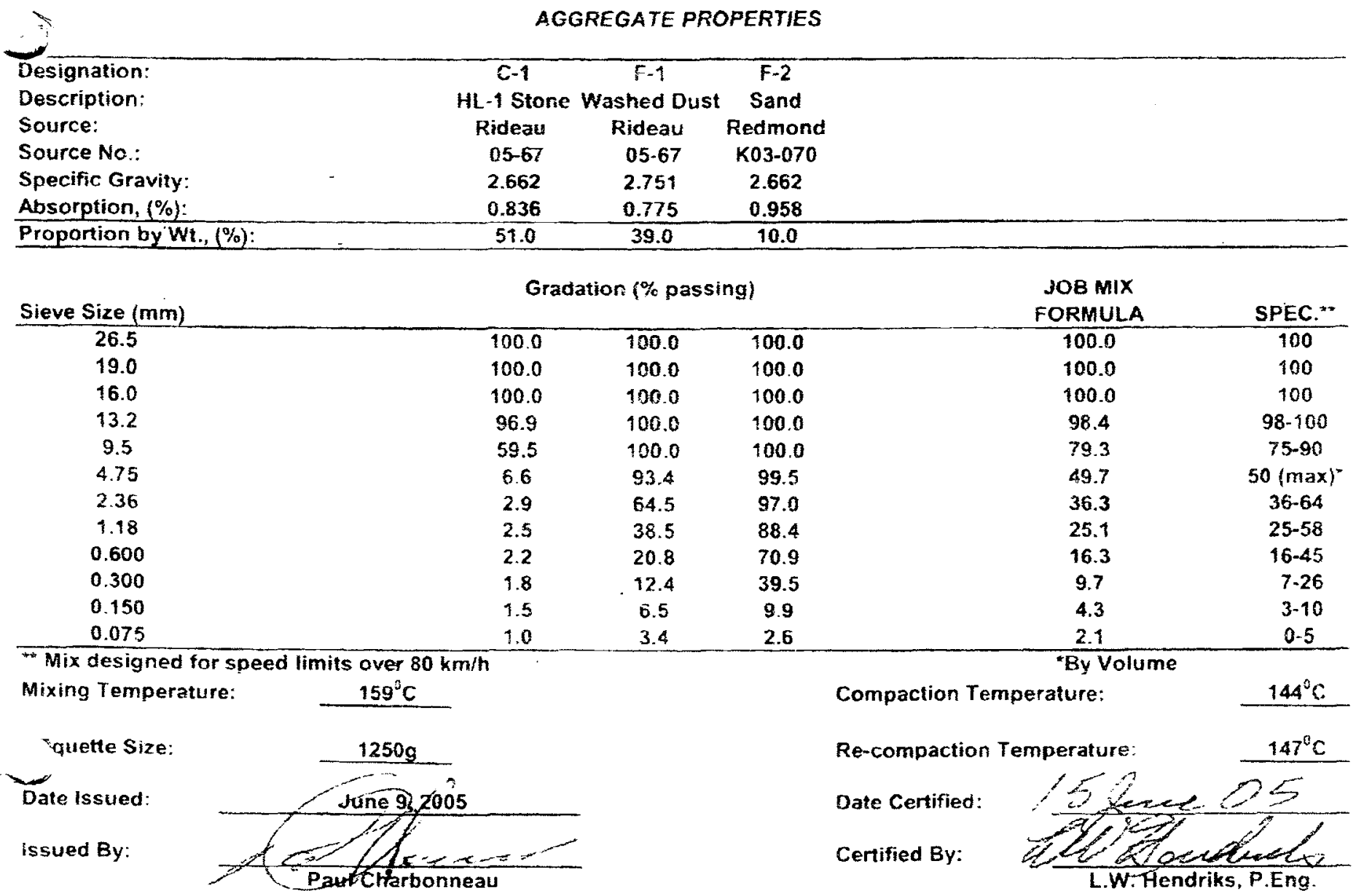


Certificate of Analysis

Supplier Name Bitumar Inc

$\begin{array}{ll}\text { Address: } & 11650 \text { Metropolitain Blvd. } E \\ & \text { Montreal, QC H1B 1A5 }\end{array}$

Phone: $514-645-4561$

Fax: $\quad 514-645-6978$

BITUMAR

\begin{tabular}{lllc}
\hline Grade & $58-34$ & Lot number & 055834-19 \\
Production Code & BIMT-T-78-L-19- & & \\
Date Sampled & $2005 / 10 / 03$ & Specification & AASHTO M320 \\
Unit of Production & $264,550.0 \quad$ gal @ $60^{\circ} \mathrm{F}$ & Binder Type & Modified
\end{tabular}

Standard Report YES

Terminal: $\quad$ Main Terminal, Montreal

Supplier Lab: Central Lab, Montreal -

\begin{tabular}{|c|c|c|c|c|c|}
\hline TEST & & METHOD & $\begin{array}{l}\text { TEST } \\
\text { LAB }\end{array}$ & $\begin{array}{l}\text { SPECIFICATION } \\
\text { REQUIREMENTS }\end{array}$ & $\begin{array}{c}\text { TEST } \\
\text { RESULTS }\end{array}$ \\
\hline \multicolumn{6}{|l|}{ Unaged Binder } \\
\hline Sp. Gravity@15.6º $@ \mathrm{gm} / \mathrm{cm}$ & & AASHTO T 228 & & $-N A-$ & \\
\hline Sp. Gravity@25.0 $@$ C, gm $/ \mathrm{cm}$ & & AASHTO T 228 & & $-N A-$ & 1.007 \\
\hline Flash Point, ${ }^{\circ} \mathrm{C}$ & & AASHTO T 48 & & $>230^{\circ} \mathrm{C}$ & 282 \\
\hline Viscosity@135 $\mathrm{C}, \mathrm{Pa}-\mathrm{s}$ & & AASHTO T316 & & $<3.0 \mathrm{~Pa}-\mathrm{s}$ & 0.407 \\
\hline 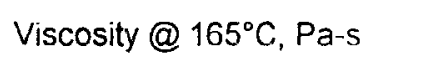 & & AASHTO T316 & & & 0.141 \\
\hline Lab Mixing Temp, ${ }^{\circ} \mathrm{C}$ & & & & Min: 156 & Max: 163 \\
\hline Lab Compaction Temp ${ }^{\circ} \mathrm{C}$ & & & & Min: 142 & Max: 148 \\
\hline$G^{*} / \sin ($ delta) $(k P a)$ & $58^{\circ} \mathrm{C}$ & AASHTO T 315 & BICL & $>1.00 \mathrm{kPa}$ & 1.08 \\
\hline \multicolumn{6}{|l|}{ RTFOT } \\
\hline $\mathrm{G}^{*} / \sin ($ delta $)(\mathrm{kPa})$ & $58^{\circ} \mathrm{C}$ & AASHTO T 315 & $\mathrm{BICL}$ & $>2.20 \mathrm{kPa}$ & 3.38 \\
\hline RTFOT Mass Change (\%) & & AASHTO T 240 & $B I C L$ & $<1.00 \%$ & 0.24 \\
\hline \multicolumn{6}{|l|}{ PAV } \\
\hline $\mathrm{G}^{*} \sin ($ delta) $(\mathrm{kPa})$ & $16^{\circ} \mathrm{C}$ & AASHTO T 315 & $\mathrm{BICL}$ & $<5,000 \mathrm{kPa}$ & 3096 \\
\hline Stiffness (MPa)@60s & $-24^{\circ} \mathrm{C}$ & AASHTO T 313 & $\mathrm{BICl}$ & $<300 \mathrm{MPa}$ & 207 \\
\hline m-value @60s & & AASHTO.T 313 & $\mathrm{BICl}$ & $>0.300$ & 0.314 \\
\hline \multicolumn{6}{|l|}{ Direct Tension } \\
\hline Critical cracking temp ${ }^{\circ} \mathrm{C}$ & & & & & \\
\hline
\end{tabular}

Remarks: Elastic recovery: 59\%. Modifier: block (SB and/or SBS) copolymers.

This material conforms to the specification set forth in AASHTO M320 and is a Modified binder.

Testing Laboratory:

Bitumar Inc.

Central Lab, Montreal -
Responsible Technician: Hua Qin Liu (NETTCP 130)
Person responsible for certification: Hua Qin Liu 2005/10/04

Signature:

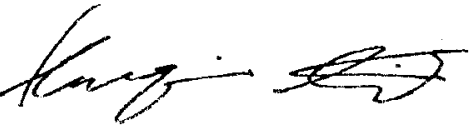

FPSQ-10.12 R0 (RÉF ALLLSH2) 


\begin{tabular}{|c|c|c|}
\hline $\begin{array}{l}\text { Date: } \\
01 / 28 / 2005\end{array}$ & $\begin{array}{l}\text { Reference \# : } \\
5834 A\end{array}$ & $\begin{array}{r}\text { Page: } \\
1 \text { of } 3\end{array}$ \\
\hline
\end{tabular}

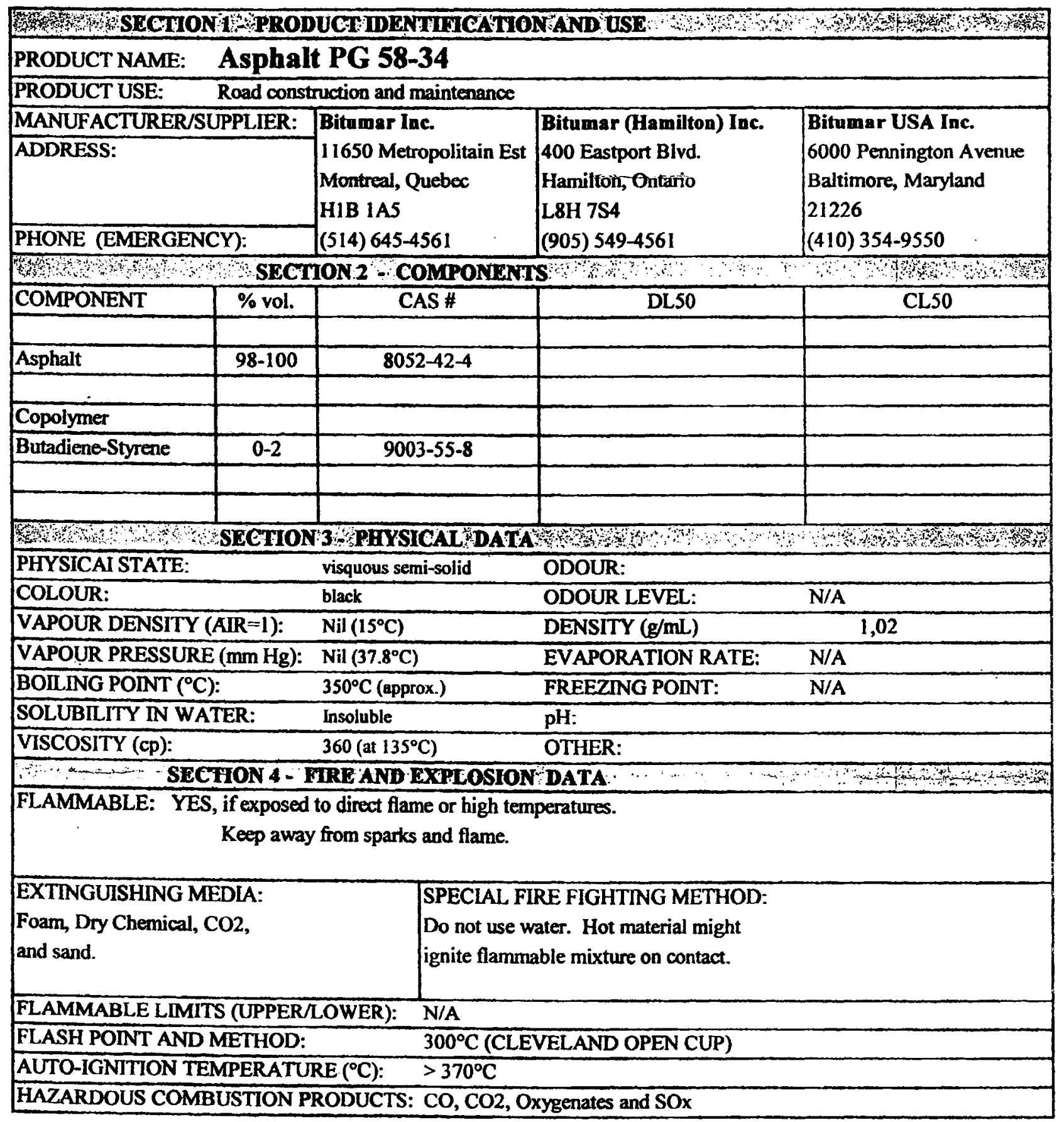

